\title{
Methadone and buprenorphine effects on driving abilities
}

Citation for published version (APA):

Strand, M. C. (2020). Methadone and buprenorphine effects on driving abilities. [Doctoral Thesis, University of Oslo, Maastricht University]. University of Oslo. https://doi.org/10.26481/dis.20200622ms

Document status and date:

Published: 01/01/2020

DOI:

10.26481/dis.20200622ms

Document Version:

Publisher's PDF, also known as Version of record

\section{Please check the document version of this publication:}

- A submitted manuscript is the version of the article upon submission and before peer-review. There can be important differences between the submitted version and the official published version of record.

People interested in the research are advised to contact the author for the final version of the publication, or visit the DOI to the publisher's website.

- The final author version and the galley proof are versions of the publication after peer review.

- The final published version features the final layout of the paper including the volume, issue and page numbers.

Link to publication

\footnotetext{
General rights rights.

- You may freely distribute the URL identifying the publication in the public portal. please follow below link for the End User Agreement:

www.umlib.nl/taverne-license

Take down policy

If you believe that this document breaches copyright please contact us at:

repository@maastrichtuniversity.nl

providing details and we will investigate your claim.
}

Copyright and moral rights for the publications made accessible in the public portal are retained by the authors and/or other copyright owners and it is a condition of accessing publications that users recognise and abide by the legal requirements associated with these

- Users may download and print one copy of any publication from the public portal for the purpose of private study or research.

- You may not further distribute the material or use it for any profit-making activity or commercial gain

If the publication is distributed under the terms of Article $25 \mathrm{fa}$ of the Dutch Copyright Act, indicated by the "Taverne" license above, 


\section{Methadone and buprenorphine effects on driving abilities}

Dissertation to obtain a joint doctorate at the University of Oslo, Norway, and at the Maastricht University, the Netherlands

Maren Cecilie Strand, MD

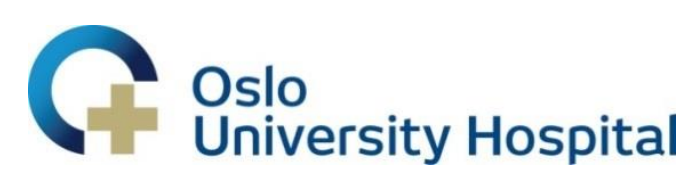

Division of Laboratory Medicine, Department of Forensic Sciences

\section{Maastricht University}

Faculty of Psychology and Neuroscience

Department of Neuropsychology and Psychopharmacology

\section{$\mathrm{UiO}:$ University of Oslo}

Faculty of Medicine, Institute of Clinical Medicine

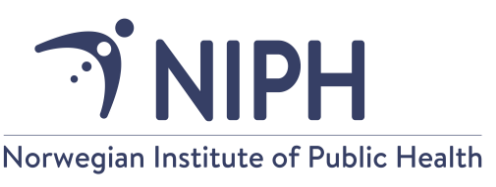

Division of Forensic Sciences 
(C) Maren Cecilie Strand, 2020

\section{Series of dissertations submitted to the} Faculty of Medicine, University of Oslo

\section{ISBN 978-82-8377-648-5}

All rights reserved. No part of this publication may be reproduced or transmitted, in any form or by any means, without permission.

Cover: Hanne Baadsgaard Utigard.

Print production: Reprosentralen, University of Oslo. 


\section{Contents}

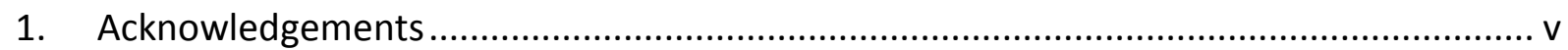

2. Abbreviations and definitions ....................................................................................

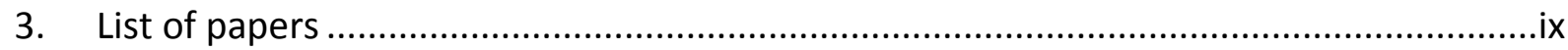

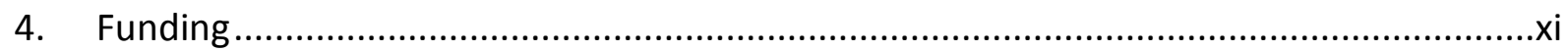

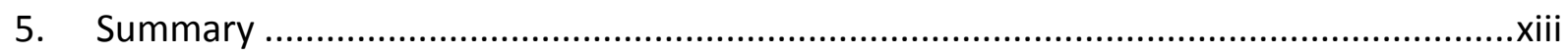

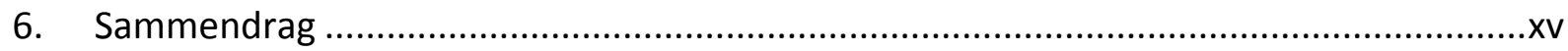

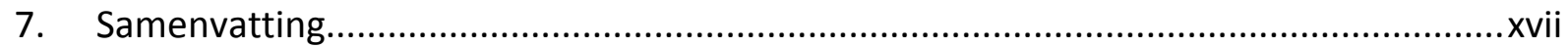

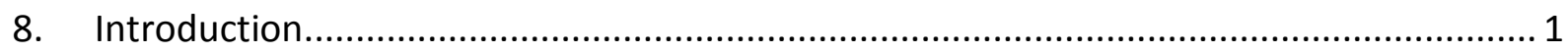

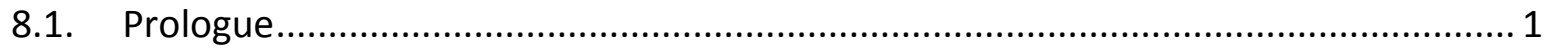

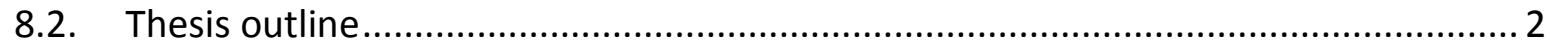

8.3. Driving under the influence (DUI) of alcohol or other drugs .................................... 3

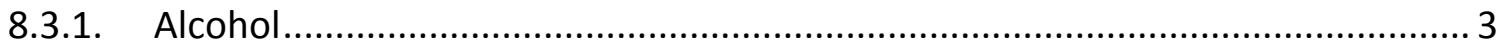

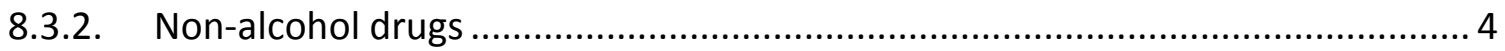

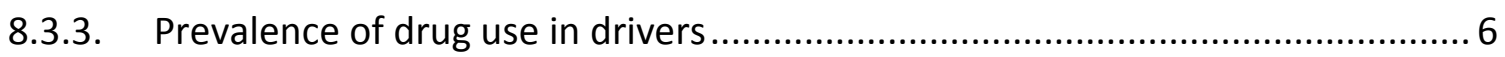

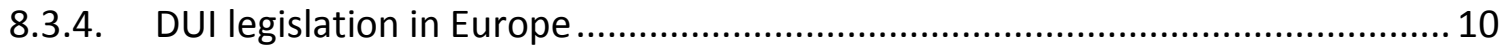

8.4. Research on impairing effects of drugs on driving ............................................. 11

8.4.1. Crash risk investigated by epidemiological studies........................................ 12

8.4.2. Measuring driving performance (experimental studies) ................................ 14

8.5. Opioids: use, pharmacodynamics and pharmacokinetics ..................................... 20

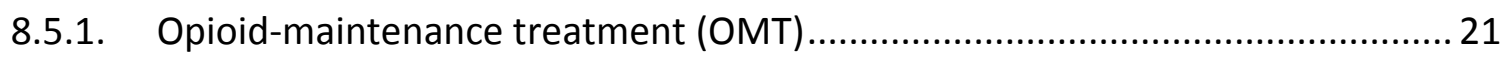

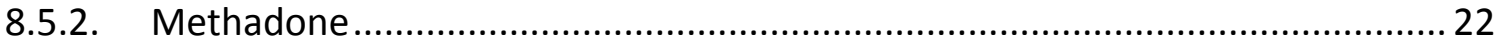

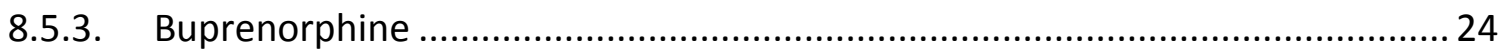

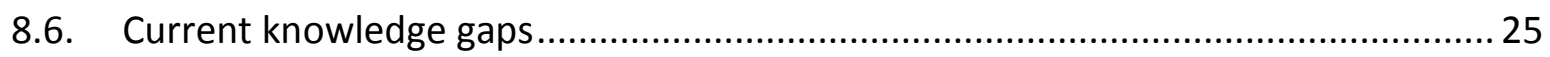

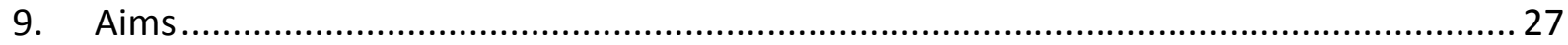

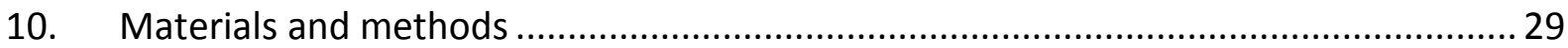

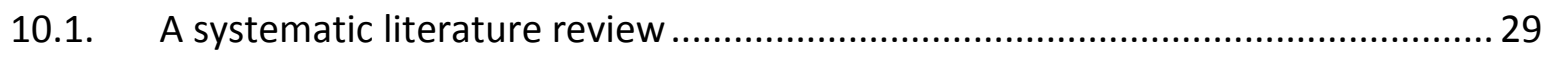

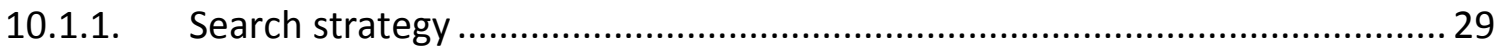

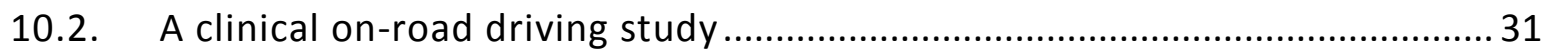




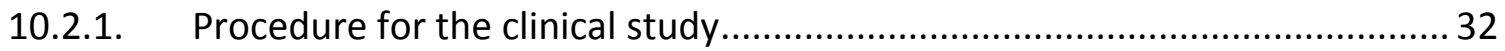

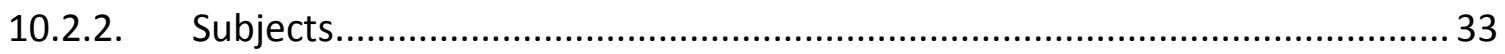

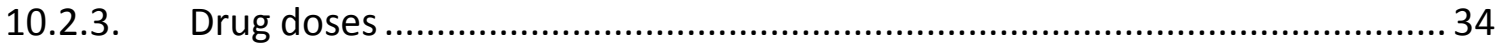

10.2.4. Actual Driving Performance (On-Road Highway Driving Test) ...................... 36

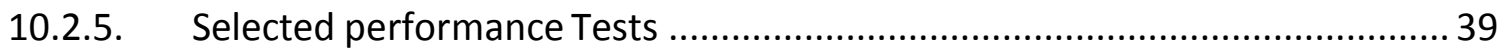

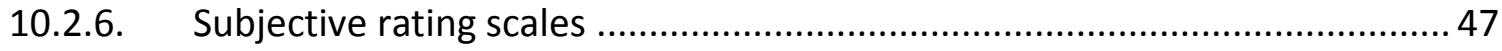

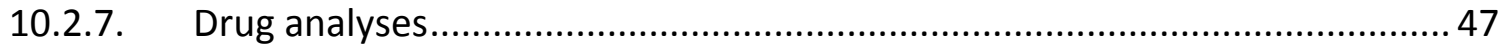

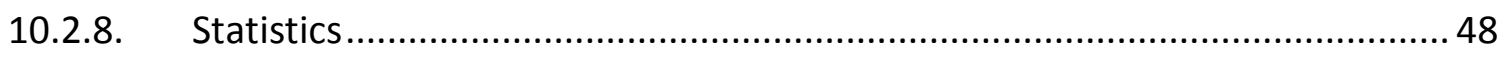

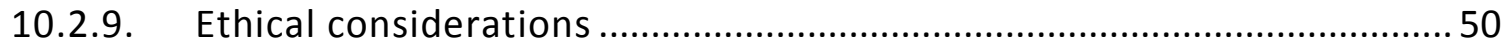

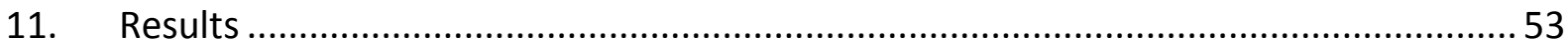

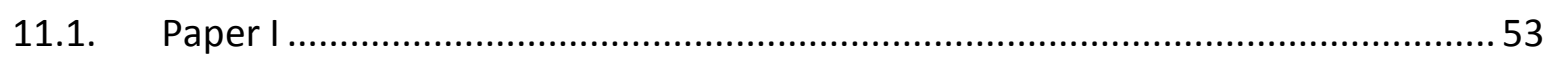

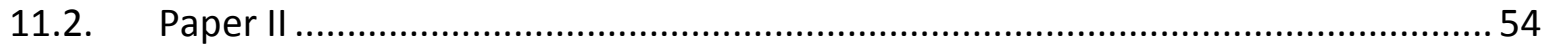

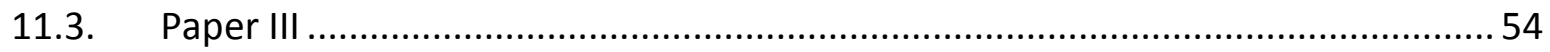

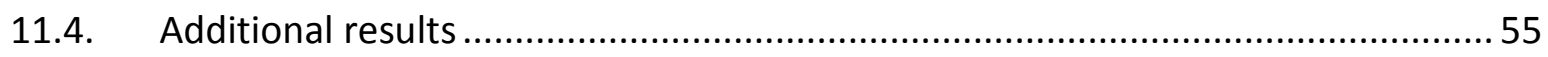

11.4.1. Summary of results from the clinical study .................................................. 55

11.4.2. Concentrations of methadone and buprenorphine in blood ......................... 58

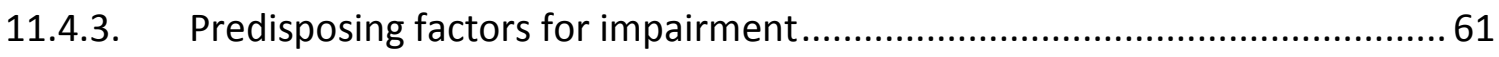

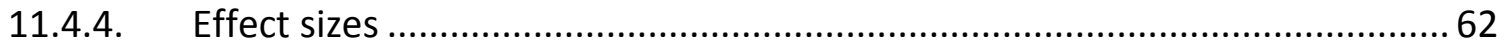

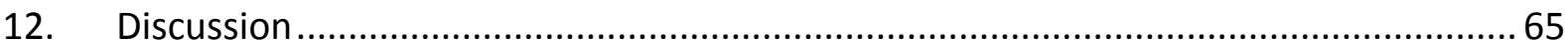

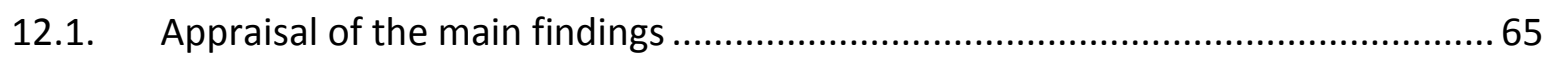

12.1.1. The current knowledge regarding crash risk and impairing effects on driving

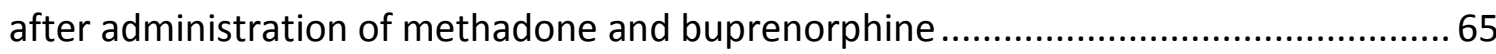

12.1.2. Do methadone and buprenorphine cause traffic relevant impairment and is there a dose- and/or concentration-effect relationship for methadone and

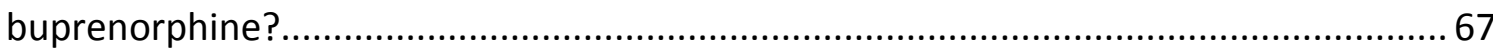

12.1.3. The pharmacokinetic properties of methadone and buprenorphine in blood

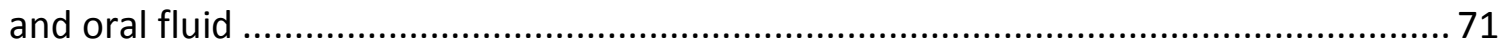

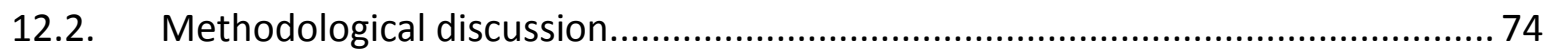

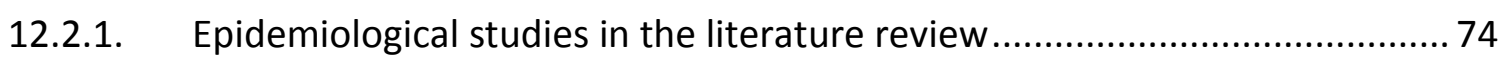

12.2.2. Experimental studies in the literature review ............................................. 75

12.2.3. Selection of tests used in the clinical study................................................. 76 
12.2.4. Sensitivity of the tests used in the clinical study ....................................... 77

12.2.5. Lack of benchmark substance in the clinical study ..................................... 78

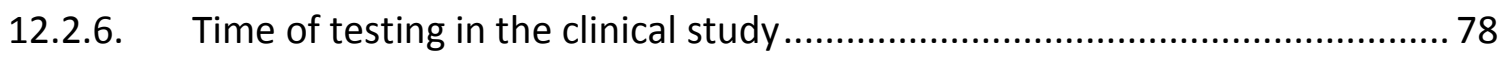

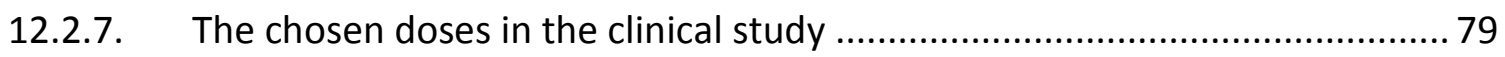

12.2.8. Predictive validity of the tests used in the clinical study ............................. 79

12.2.9. Measuring drug concentrations in blood in the clinical study ...................... 79

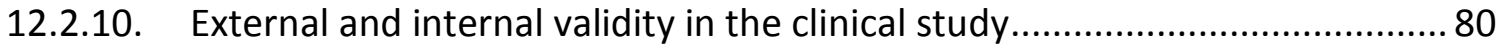

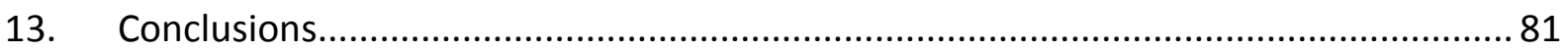

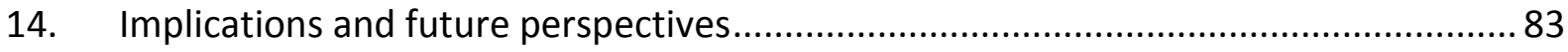

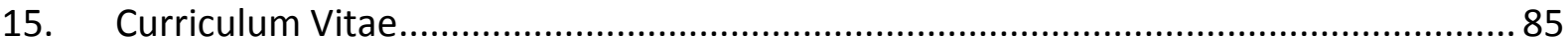

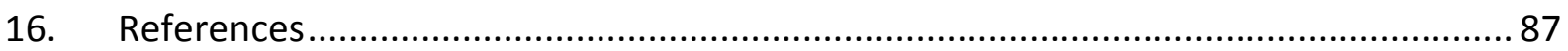

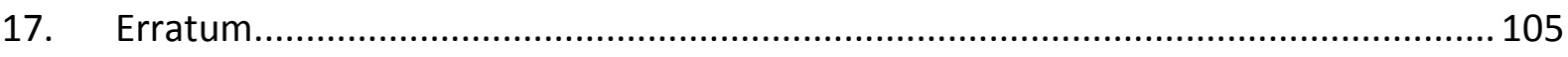

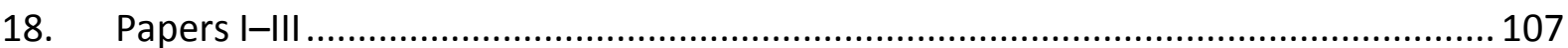




\section{Acknowledgements}

First of all, I would like to sincerely thank all of my supervisors. You have complemented each other and made important contributions to this work.

I would like to thank my principle supervisor at the University of Oslo, Dr. Vigdis Vindenes, for being generous with your time, giving qualified and enthusiastic guidance, providing help with the many practical aspects of carrying out this work, and for having a positive attitude towards this project. Thank you also for allowing me to be in your section to finish my thesis. I am very thankful to my principal supervisor at the Maastricht University, Professor Jan Ramaekers, who invited me to Maastricht to conduct the driving study. You are very knowledgeable and efficient. It was a privilege to work with you and all the highly qualified colleagues at the NP\&PP.

To Professor Jørg Mørland, who was my initial principle supervisor at the University of Oslo and later my co-supervisor; I am thankful for you introducing me to the fields of clinical pharmacology, toxicology and scientific research in a highly competent and inspiring way. I am also grateful for many interesting discussions on different projects, including this thesis, over the years.

I am thankful to my co-supervisor, Dr. Hallvard Gjerde, for your thoroughness and your insightful comments, and for always taking the time to discuss any matter concerning this work.

I am grateful to the Norwegian Ministry of Transport and Communication for the grant provided to conduct the driving study.

I wish to thank all the participants in the driving study, and the staff and students at the Maastricht University who helped to carry it out. A special thanks to Irma and Henk Brauers for planning and performing the driving tests, Anita van Oers for all the assistance, Nadia Hutten for contributing to the data collection, and Dr. Cees van Leeuwen for the medical screening. 
I want to thank the leaders at the Department of Forensic Sciences, Oslo University Hospital, who facilitated and made it possible to carry out this project: Liliana Bachs, who initially approved the PhD project; Truls Simensen for supporting my study period abroad; and Marianne Arnestad, for being flexible with regards to the routine work and providing time for me to finish my thesis. I am also thankful to Håvard Furuhaugen for performing the analysis of the blood and oral fluid samples.

I would like to thank all of my friendly and skilled colleagues at the Section for Forensic Toxicological Assessment, Oslo University Hospital, who contributes to a pleasant working atmosphere. A special thanks to Stine Marie Havig for her advices on English grammar. I am thankful to family and friends for their support. To my parents, I am grateful that you have always encouraged my education.

Above all, I thank my beloved husband and sons.

Oslo, January 2020

Maren Cecilie Strand 


\section{Abbreviations and definitions}

BAC

BMP

$C_{\max }$

CNS

CTT

CYP

DAT

DRUID

DUID

$\triangle \mathrm{SDLP}$

Drug driving

Drink driving

DSST

DT

KSS

LOD

LOQ

MMP

OMT

Per se

PBT

PVT

RTC

SCTI

SDLP

$\mathrm{T}_{\max }$
Blood alcohol concentration

(unit is $\% \mathrm{~m} / \mathrm{m}$ or $\% \mathrm{~m} / \mathrm{v}$; g alcohol per 100 gram or $100 \mathrm{ml}$ blood)

Buprenorphine-maintained patients

Maximum concentration level (in blood)

Central nervous system

Critical tracking test

Cytochrome P450 (group of enzymes)

Divided attention task

Driving under the Influence of drugs, alcohol and medicines

(European project)

Driving under influence

Driving under influence of drugs and alcohol

Delta (change) in SDLP (cm)

Driving after intake of non-alcohol drugs

Driving after intake of alcohol

Digit symbol substitution test

Determination test

Karolinska sleepiness scale

Limit of detection

Limit of quantification

Methadone-maintained patients

Opioid maintenance treatment

By itself; in itself

Postural balance test

Psychomotor vigilance test

Road traffic crash

Simplified clinical test of impairment

Standard deviation of lateral position

Time to peak drug concentration in blood/plasma 
UFOV

Useful field of view

UPLC-MS/MS Ultra-high-performance liquid chromatography tandem mass spectrometry

QT interval Interval between $Q$ wave and T wave of the heart's electrical cycle (ECG) 


\section{List of papers}

The thesis is based on the following papers:

Paper I

Strand MC, Fjeld B, Arnestad M, Mørland J. Can Patients Receiving Opioid Maintenance Therapy Safely Drive? A Systematic Review of Epidemiological and Experimental Studies on Driving Ability With a Focus on Concomitant Methadone or Buprenorphine Administration. Traffic Injury Prevention. 2013;14(1):26-38.

Paper II

Strand MC, Vindenes V, Gjerde H, Mørland J, Ramaekers JG. A clinical trial on the acute effects of methadone and buprenorphine on actual driving and cognitive function of healthy volunteers. British Journal of Clinical Pharmacology. 2018;85(2):442-53.

Paper III

Strand MC, Ramaekers J, Gjerde H, Mørland J, Vindenes V. Pharmacokinetics of single doses of methadone and buprenorphine in blood and oral fluid, and correlation with effects on psychomotor and cognitive functions.

Revised manuscript published in September 2019: Journal of Clinical Psychopharmacology. 2019;39(5):489-93. 


\section{Funding}

Paper I was written as part of the Driving under the Influence of Drugs, Alcohol and Medicines (DRUID) research consortium, funded by European Union grant TREN-05-FP6TRS07.61320-518404-DRUID, with additional funding from the Norwegian Research Council and the Norwegian Institute of Public Health.

The work related to Paper II and III was funded by the Norwegian Institute of Public Health and Oslo University Hospital, in addition to grants from the Norwegian Ministry of Transport and Communications (reference number 11/1601). The Department of Forensic Sciences was transferred from the Norwegian Institute of Public Health to Oslo University Hospital on January $1^{\text {st }} 2017$. 


\section{Summary \\ Background/aims}

Driving under the influence of drugs and alcohol are major contributors to the high frequency of road traffic crashes globally. Methadone and buprenorphine are among the twenty drugs most frequently detected in apprehended drivers suspected of drug driving in Norway. However, research investigating drug induced traffic impairment after use of methadone and buprenorphine has hardly been performed.

We aimed to provide an overview of the current scientific literature studying the effects of these drugs on crash risk and driving-related performance. We further performed a clinical study with actual on-road driving to investigate the acute effects of two single, analgesic doses of both methadone and buprenorphine on driving performance in opioid-naïve subjects, including neurocognitive tests and pharmacokinetic measures.

\section{Methods}

For Paper I, we performed a systematic literature review of the current scientific literature on traffic-related effects of methadone and buprenorphine. Epidemiological studies on traffic risk and experimental studies on performance of traffic relevant skills were included.

For Papers II and III a clinical trial was performed , using a five-way, double-blind, randomized, placebo-controlled, double-dummy, cross-over design, to study on-road driving and driving relevant neurocognitive tests in healthy subjects after a single dose of methadone ( 5 or $10 \mathrm{mg}$ ) and buprenorphine $(0.2$ or $0.4 \mathrm{mg}$ ). Blood and oral fluid were collected throughout the test days. Paper II describes the effects of both drugs on driving and neurocognitive tests. In Paper III we analyzed the correlations between drug concentrations in blood and effects on the neurocognitive tests including driving, and report drug concentrations in blood and oral fluid as well as oral fluid/blood concentration ratios.

\section{Results and conclusions}

The review revealed that recent epidemiological studies found an increased crash risk in male patients treated with methadone and an increased odds ratio for being responsible for the crash in injured drivers exposed to either methadone or buprenorphine. Studies on patients in opioid maintenance treatment found that both drugs to some degree impaired 
performance relevant to safe driving. Few studies had investigated the acute effects of methadone and buprenorphine on driving related skills in healthy volunteers, and none of these tested on-road driving.

Our clinical trial showed some dose-dependent effects of both drugs on driving related skills, even though the administered doses are considered to be low. Buprenorphine $0.4 \mathrm{mg}$ significantly impaired driving measured with the standard deviation of lateral position (SDLP). Mild effects on driving related skills were measured, but large individual variations were observed. For both drugs, four out of 22 subjects terminated the driving test due to sleepiness. Some significant positive correlations between drug concentration in blood and effects on neurocognitive testing were found for buprenorphine, but not for methadone. Large individual differences in pharmacokinetics were observed for both drugs, in blood as well as in oral fluid. Concentrations of buprenorphine in blood were in general very low and concentrations above the limit of qualification were found only in one third of the blood samples.

Our results imply that caution regarding driving is required when initiating opioid treatment and adjusting opioid doses, and patients should thus be informed accordingly, to avoid impaired driving and being involved in traffic accidents. 


\section{Sammendrag}

\section{Bakgrunn/formål}

Kjøring i påvirket tilstand er medvirkende årsak til et stort antall trafikkulykker globalt. Metadon og buprenorfin er blant de tjue psykoaktive stoffene som oftest påvises i prøver fra bilførere mistenkt av politiet for ruspåvirket kjøring i Norge. Det er imidlertid gjennomført svært få studier når det gjelder trafikkrelevant påvirkning etter bruk av metadon og buprenorfin.

Vi har unders $\varnothing k t$ hva som foreligger av vitenskapelige studier hvor effekten av disse stoffene på kjørerelaterte ferdigheter og risiko for trafikkulykker er studert. Videre gjennomførte vi en klinisk studie hvor de akutte effektene av lave smertestillende doser av metadon eller buprenorfin hos opioid-naive personer ble undersøkt ved reelle kjøring på motorvei, inkludert nevrokognitive tester og farmakokinetiske målinger.

\section{Metode}

Artikkel I er en systematisk litteraturgjennomgang av studier som har undersøkt trafikkrelaterte effekter av metadon og buprenorfin. Epidemiologiske studier av trafikkrisiko og eksperimentelle studier av effekter på trafikkrelevante ferdigheter ble inkludert.

Artikkel II og III omfatter en femveis, dobbelt blindet, randomisert, placebokontrollert, dobbelt dummy, overkrysningsstudie for å studere effektene på kjøring og kjørerelevante ferdigheter av enkeltdoser med metadon ( 5 eller $10 \mathrm{mg}$ ) og buprenorfin (0,2 eller 0,4 mg) gitt til friske frivillige. Det ble tatt blod- og spyttprøver i løpet av testdagene. Artikkel II beskriver virkningene av begge legemidler på bilkjøring og nevrokognitive tester. I artikkel III analyserte vi sammenhengen mellom stoffkonsentrasjoner i blod og effekter på de nevrokognitive testene inkludert kjøring. Konsentrasjoner av metadon og buprenorfin ble målt i både blod og spytt, samt spytt/blod konsentrasjonsratio, ble rapportert.

\section{Resultater og konklusjon}

Oversiktsartikkelen viste at nyere epidemiologiske studer har avdekket en $\varnothing$ kt risiko for å være involvert i trafikkulykker for mannlige pasienter som behandles med metadon, og en $\emptyset k t$ sannsynlighet for å være skyld i trafikkulykker for skadde sjåfører som hadde brukt metadon eller buprenorfin. Studier av pasienter i vedlikeholdsbehandling med opioider viste 
at både metadon og buprenorfin til en viss grad svekket trafikkrelevante ferdigheter. Det er få studier som har unders $\varnothing$ kt de akutte effektene av metadon og buprenorfin når det gjelder kjørerelaterte ferdigheter hos friske frivillige, og ingen kjørestudier var gjennomført.

Den kliniske studien viste doseavhengige effekter av begge legemidler på enkelte av de nevrokognitive testene selv om dosene som ble gitt anses lave. Buprenorfin 0,4 mg medførte signifikant $\varnothing$ kning av «vingling i vegbanen» (SDLP). Generelt ble det funnet moderate kliniske effekter av legemidlene, men store individuelle forskjeller ble observert. Fire av 22 deltakere avsluttet imidlertid kjøringen på grunn av søvnighet etter inntak av både metadon og buprenorfin. Signifikant korrelasjon mellom konsentrasjon i blod og noen av effektene på de nevokognitiv testene ble vist for buprenorfin, men ikke for metadon. Det ble observert store individuelle forskjeller i farmakokinetikk for begge legemidlene, både i blod og spytt. Konsentrasjonene av buprenorfin i blod var generelt veldig lave og bare en tredjedel av blodprøvene hadde konsentrasjoner av buprenorfin over påvisningsgrensen.

Resultatene viser at det bør utvises forsiktighet med hensyn til kjøring ved oppstart av behandling med opioider og ved justering av opioid-doser. Pasienter som behandles med disse legemidlene bør informeres om dette, for å unngå påvirket kjøring og ikke bli involvert i trafikkulykker. 


\section{Samenvatting}

\section{Achtergrond/doel}

Rijden onder invloed van alcohol of drugs dragen in belangrijke mate bij aan het hoge aantal verkeersongevallen wereldwijd. Methadon en buprenorfine behoren tot de twintig geneesmiddelen/drugs die het vaakst worden aangetoond bij bestuurders aangehouden op verdenking van het rijden onder invloed in Noorwegen. Onderzoek naar verkeersgerelateerde effecten na het gebruik van methadon en buprenorfine is echter nauwelijks uitgevoerd.

We wilden meer te weten te komen over de bestaande kennis over de effecten van deze geneesmiddelen op rijvaardigheid en verkeersongevallen. We wilden ook een klinisch onderzoek uitvoeren met een rijtest om de acute effecten van analgetische doseringen van methadon en buprenorfine bij opiaat-naïeve personen te onderzoeken, inclusief neurocognitieve tests en farmacokinetische metingen.

\section{Methode}

In paper I werd een overzicht gegeven van de huidige wetenschappelijke literatuur over verkeersgerelateerde effecten van methadon en buprenorfine. Een systematisch literatuuronderzoek werd uitgevoerd om epidemiologische studies en experimentele studies naar de invloed van deze stoffen op ongevalsrisico en rijvaardigheid te beoordelen.

Vervolgens werd een 5-wegs, dubbelblind, gerandomiseerd, placebo-gecontroleerd, dubbel dummy crossover onderzoek uitgevoerd (paper II en III) om rijvaardigheid en relevante neurocognitieve functies te bestuderen in gezonde personen na een enkele dosering methadon (5 of $10 \mathrm{mg}$ ) of buprenorfine $(0,2$ of 0,4 mg). In paper II worden de effecten van beide geneesmiddelen op rijvaardigheid en de neurocognitieve tests beschreven. In papier III analyseerden we de correlaties tussen geneesmiddelconcentraties in bloed en effecten op de neurocognitieve tests en rijvaardigheid, en geneesmiddelconcentraties in bloed en speeksel evenals speeksel / bloed-concentratieratio werd gerapporteerd.

\section{Resultaten en conclusies}

De review bracht aan het licht dat recente epidemiologische studies vonden een verhoogd risico op verkeersongevallen bij mannelijke patiënten die werden behandeld met methadon 
en een verhoogd risico op schuld bij verkeersongevallen na gebruik van methadon en buprenorfine. Onderzoek bij patiënten die een onderhoudsbehandeling met opioïden ontvangen wees uit dat beide geneesmiddelen tot op zekere hoogte de verkeersgerelateerde vaardigheden negatief beïnvloedden. Verder zijn er weinig studies uitgevoerd naar de acute effecten van methadon en buprenorfine op rijvaardigheid bij gezonde vrijwilligers, en geen rijstudies zijn uitgevoerd.

De klinische studie toonde enkele dosisafhankelijke effecten van beide geneesmiddelen op rijvaardigheid. Buprenorfine 0,4 mg verslechterde aanzienlijk de rijvaardigheid zoals gemeten met de standaard deviatie van de laterale positie (SDLP), een maat voor slingergedrag. De invloed van opiaten op rijvaardigheid was over het algemeen mild, maar individuele variantie was hoog. Vier van de 22 proefpersonen beëindigden voortijdig hun rijtest vanwege slaperigheid na beide medicijnen. Enkele correlaties tussen geneesmiddelconcentratie in bloed en effecten op neurocognitieve testen werden gevonden voor buprenorfine, maar niet voor methadon. Grote individuele variaties werden ook waargenomen met betrekking tot de farmacokinetiek van beide geneesmiddelen. Concentraties van buprenorfine in het bloed waren in het algemeen laag en in slechts een derde van de bloedmonsters was de buprenorfine concentraties boven de bepaalbaarheidsgrens.

De resultaten impliceren dat voorzichtigheid met betrekking tot autorijden vereist is bij het initiëren van behandeling met opioïden en bij het aanpassen van opioïde doses, en patiënten moeten hierover worden geïnformeerd om rijden onder invloed en verkeersongevallen te voorkomen. 


\section{Introduction}

\subsection{Prologue}

Driving under the influence (DUI) of drugs and alcohol represents a significant risk of road traffic crashes $(1,2)$. The impairing effects of alcohol on driving are well studied and the increased risk of road traffic crashes when driving under the influence of alcohol is acknowledged and regulated in most countries through legal limits for driving under the influence of alcohol.

Driving under the influence of psychoactive drugs, i.e. both medicinal and illicit, have over the last years also been recognized as a major risk factor for road traffic crashes. This is in particular well studied for benzodiazepines (anxiolytic and hypnotic drugs) and cannabis, and to some extend for stimulants like amphetamine, methamphetamine and MDMA (3). The effects of opioids on driving are, however, less studied, both with regards to the risk of road traffic crashes and the impairing effects on driving and driving related skills $(3,4)$.

Methadone and buprenorphine are opioids used as analgesics for moderate to severe pain, and are also widely used as maintenance treatment to persons with heroin addiction. Both drugs are easily available on the illicit street drug market and illegal use is regularly reported. Methadone and buprenorphine are both among the top twenty drugs detected in blood samples from drivers apprehended by the police for DUI in Norway. Both drugs are potent central nervous depressants and are likely to induce driving impairment. Despite the frequent use of methadone and buprenorphine, both in opioid maintenance treatment (OMT) and illicit use, there are hardly any studies to assess driving relevant impairment after administration of methadone or buprenorphine, neither on crash risk nor neurocognitive performance. 


\subsection{Thesis outline}

This thesis includes a summary of the current scientific literature investigating crash risk related to exposure to methadone and buprenorphine as OMT as well as experimental studies on traffic-relevant neurocognitive performance in opioid-naïve subjects after single dose administration and in OMT patients. Furthermore, the thesis includes the first on-road driving study, performed after administration of two different single doses of methadone and buprenorphine in opioid-naïve subjects, including drug concentrations in blood and oral fluid. The thesis does not include control groups administered different alcohol doses, since such effects are thoroughly investigated in previous studies performed in Professor Ramaekers research group. Furthermore, on-road driving or an experimental study investigating traffic-relevant impairment after OMT have not been performed.

The introduction presents an overview of knowledge regarding DUI of drugs and alcohol, prevalence of drug use in normal traffic as well as in fatally injured drivers. The legislation regulating DUI in Norway is described, as well as methods for research on crash risk related to drug exposure and drug induced traffic impairment. To be able to relate the effects from the experimental studies to drug concentrations, relevant information regarding pharmacokinetics and pharmacodynamics of opioids in general are included, and for methadone and buprenorphine in particular. 


\subsection{Driving under the influence (DUI) of alcohol or other drugs}

\subsubsection{Alcohol}

It is well documented that DUI of alcohol represents one of the most important single factors that contributes to motor vehicle crashes worldwide (5-8). A correlation between blood alcohol concentrations (BACs) and crash risk has been established $(9,10)$, as well as a strong relationship between BACs and degree of impairment (8).

Many studies have provided scientific evidence to the effects of alcohol on driving performance and traffic safety, e.g. (8-10). Of particular importance for evaluating the relationship between BACs and traffic risk were two large-scale case-control studies. "The Grand Rapids study" was a large study where 5,985 drivers involved in traffic accidents in Grand Rapids, Michigan from July 1962 to June 1963 were compared with a control group of 7,598 drivers (9). BAC was one of several variables analyzed and a relationship between the relative crash risk and BACs was established. The accident risk was shown to be significantly higher for drivers with BACs of $0.8 \%$ and higher. This study was later replicated; data from 2,871 crashes were collected in Long Beach, California, and Fort Lauderdale, Florida, in periods between 1997 and 1999 (10), and other large studies have been performed as well (11-13). The crashes were compared to a matched control group of drivers selected from the same time and location (10). The results from the Long Beach/Fort Lauderdale study were mainly in line with the findings from the Grand Rapids study. However, the elevated relative crash risk for BACs higher than $0.1 \%$ were more pronounced than initially estimated.

The effects of alcohol on neurocognitive functions are well documented in numerous studies, especially complex tasks such as (simulated) driving and divided attention $(8,14)$. It is also well established that alcohol produces impairment in a concentration-related manner $(15,16)$. Since alcohol is the best documented drug in relation to driving impairment, it is suitable as a benchmark substance for other drugs. Alcohol has been shown to exponentially increase crash risk with increasing BACs and is therefore used to determine clinical relevance of drug-induced impairment. BAC of $0.05 \%$ is frequently used as a limit for clinical relevant, as well as in legislation regulating DUI of alcohol in several countries, since the effects at this alcohol level deteriorates traffic relevant skills $(17,18)$. 


\subsubsection{Non-alcohol drugs}

Over the last years, more attention has been given to the increasing number of road traffic crashes related to drug-impaired driving $(5,19,20)$, which has been recognized as a public safety issue worldwide (21). The most commonly detected psychoactive non-alcohol drugs found in blood samples from drug impaired drivers are stimulants (e.g. amphetamines), cannabis, benzodiazepines and opioids. These substances might be used both as prescribed medicinal drugs, but also as illicit drugs. They are known to be able to impair cognitive and psychomotor performance relevant to safe driving $(4,22,23)$, but despite this, no other psychoactive substances have been examined to the same extent as alcohol.

Figure 1 illustrates the relative risk of being involved in serious or fatal traffic injuries in relation to drug and/or alcohol use. Epidemiological studies of non-alcohol drugs have shown that amphetamines have the highest risk of road traffic crash (RTC) involvement, when looking at single substances (3). Increased RTC risk has also been found for cocaine, cannabis, benzodiazepines and opioids. The use of cannabis, medicinal or illicit opioids increases the risk of a serious or fatal injury when involved in a crash with 1-3 times, while cocaine increases the risk 2-10 times (1). Combined use of multiple drugs and BACs between 0.05 to $0.08 \%$ increases the risk 5-30 times. The highest risk (20-200 times greater) is seen in cases with alcohol in combination with any psychoactive medicinal or illicit drug, or in cases with $\mathrm{BAC}>0.12 \%(1,13)$. However, combined drug and alcohol use might be overlooked, since drugs are not always analyzed in all alcohol-positive DUI cases (21), and varies between different countries. 


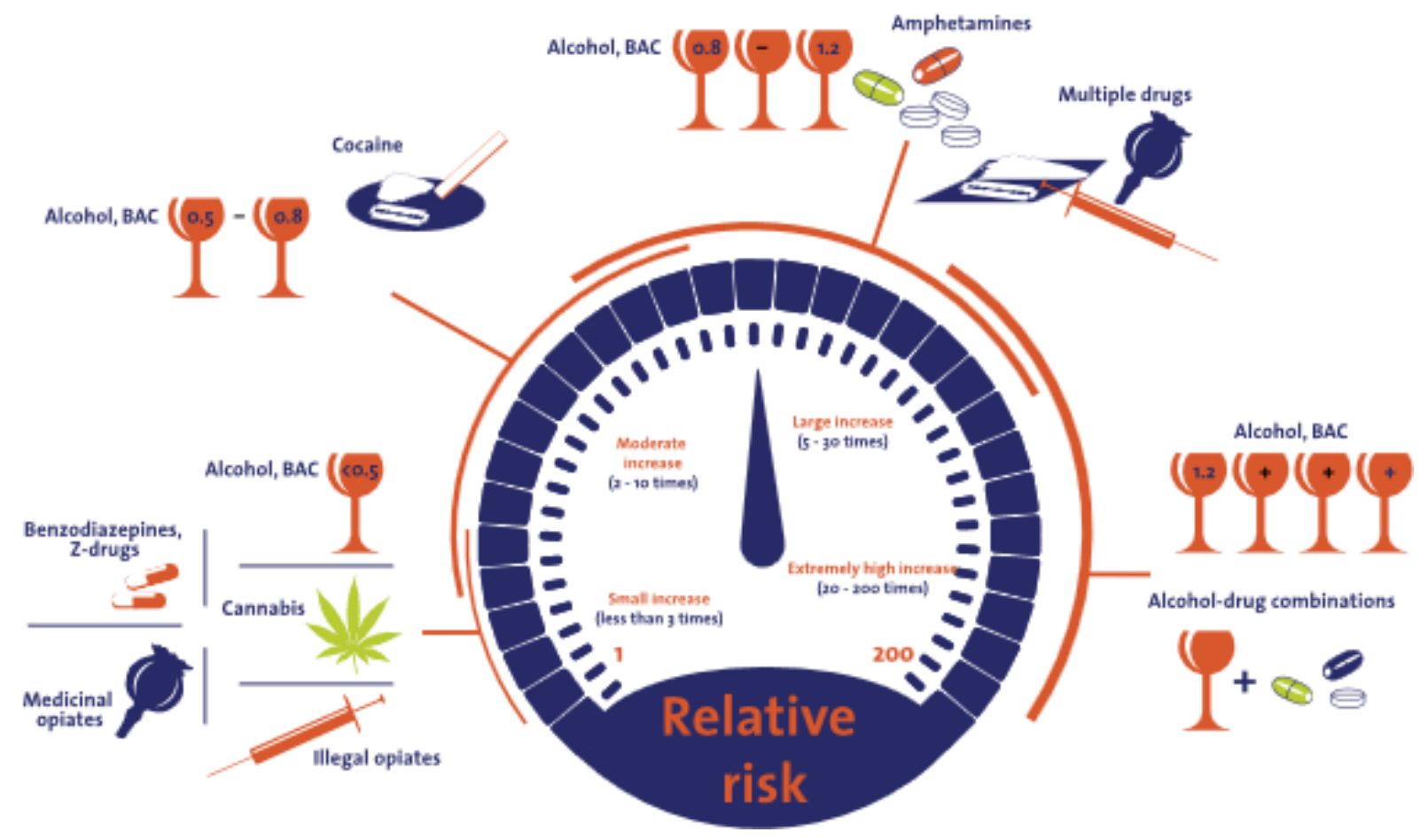

Figure 1 The figure illustrates the relative risk of being involved in serious or fatal traffic injuries in relation to drug and/or alcohol use. The use of medicinal or illicit opioids has a low relative risk (with an increase of less than 3 times) of a serious or fatal injury. The combination of alcohol with any drug or high BACs have an extremely high increase in relative risk of up to 200 times. With permission, www.SWOV.nl

There are few studies on crash risk associated with use of opioids (3), and very few such studies investigating methadone and buprenorphine (24-26). Opioids are potent psychoactive drugs, and drivers using prescribed opioids have significantly increased risk of crash involvement and crash culpability (27). Epidemiological studies performed after 1998 have found an association between opioid use and RTCS while experimental studies reveal only moderate effects of opioids on traffic relevant tests $(3,4)$. Epidemiological studies on methadone and buprenorphine in OMT are few and show divergent results $(26,28)$.

A review summarizing experimental studies, published between 1998 and 2015, on impairing effects seen after administration of single doses of different psychoactive drugs in healthy volunteers, has recently been performed (4). The review included studies with onroad driving, driving simulators and performance tests relevant to driving. Regarding the opioids, the review concluded that the results were ambiguous(4); some studies found 
significant effects on cognitive and/or psychomotor performance after administration of fentanyl (29) and oxycodone (30), while other studies found no significant effects for oxycodone $(31,32)$ and codeine $(33)$. A different review summarized the acute effects of several opioids, including methadone and buprenorphine, and concluded that opioids may affect neurocognitive performance depending on the type of opioid and dose administered (34). When summarizing the results of studies on driving performance after opioid administration it was found that opioids are likely to impair functions relevant to driving and are more pronounced in opioid-naïve persons than after long-term use (35). It has been suggested that the reason for the variable results could be the sensitivity of the different tests and/or the sensitivity of the participants to drug-induced effects (4). Overall, the studies showed that opioids can have some impairing effects on cognitive and psychomotor performance in healthy volunteers, but the effects seemed moderate with no clear dose response relation.

Some short-term studies suggest a dose-response relationship for impairment using trafficrelevant tests after methadone and buprenorphine administration (36), but very few such studies have however measured drug concentrations in blood. No studies have compared the effects of methadone and buprenorphine with the effects of ethanol at different concentration levels (28).

\subsubsection{Prevalence of drug use in drivers}

\subsubsection{Prevallence of drug use in the driving population}

The prevalence of drug use in normal traffic can be examined by road-side surveys, and is important to know to be able to estimate the accident risk for different drugs. These results are thus combined with the results from blood samples from apprehended and crashinvolved drivers.

A study from 2011 among the general population of European drivers reported an estimated prevalence of alcohol use of $3.48 \%$, illicit drug use of $1.9 \%$, impairing medicinal drug use of $1.36 \%$, alcohol-drug combination of $0.37 \%$ and drug-drug combination of $0.39 \%$ (37). Methadone and buprenorphine were among the medicinal and illicit drugs detected. The study included almost 50,000 randomly selected drivers from thirteen countries. The data 
shows that alcohol by far is the most common psychoactive substance detected in European drivers, followed by illicit drugs and medicinal drugs.

The situation is however different in Norway, where a roadside-survey performed in 20162017 among 5,034 drivers showed a prevalence of $1.7 \%$ for illicit drugs, 3.0 \% for medicinal drugs and $0.2 \%$ for alcohol (38), see Figure 2 . Thus, while medicinal drugs, including methadone and buprenorphine, are the most commonly detected drugs in traffic, the prevalence of alcohol is very low.

\section{Prevalence of drugs in regular traffic}

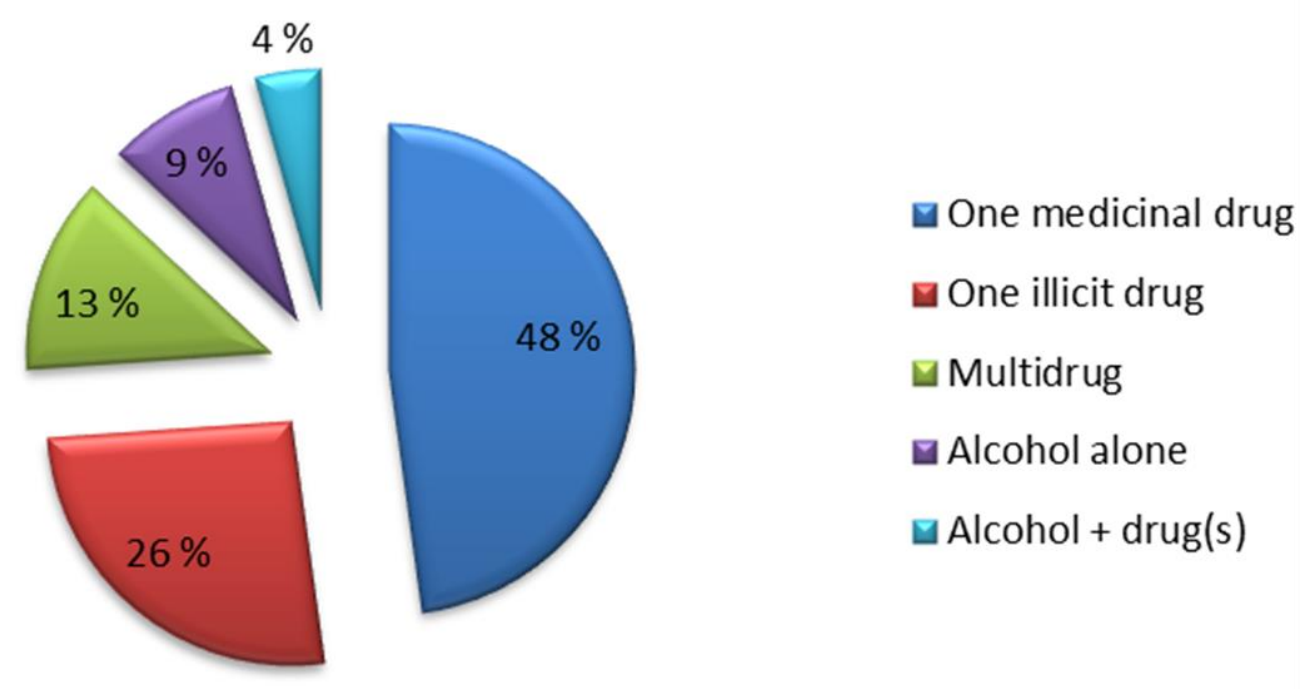

Figure 2 Pie chart of the distribution of positive findings of psychoactive substances in oral fluid samples from random drivers in regular traffic in Norway in 2016-2017 (independent of concentration level) (38). One or more drugs were present in close to $5 \%$ of the cases. Approximately half of the samples that tested positive contained one medicinal drug while $26 \%$ contained one illicit drug.

The most prevalent substances detected in blood samples from drivers apprehended by the police suspected of impaired driving in Norway in 2018 were cannabis (42 \%), benzodiazepines (40\%), alcohol (37\%) and amphetamine (33\%) (39). The most frequently detected opioids in blood samples from drivers suspected for DUI of drugs in 2018 were 
buprenorphine (3\%), morphine (3\%) and methadone (2\%); and these drugs were all among the top twenty drugs detected (39).

Another Norwegian study investigated 112,348 drivers suspected of drug driving from 1990 to 2015 (40). In total, $63 \%$ tested positive for drugs, of which $18 \%$ had opioids in their blood. Methadone was detected in $1.9 \%$ of the drug positive samples and buprenorphine in $0.9 \%$. The number of drivers testing positive for opioids was low compared to other drug classes (i.e. alcohol, benzodiazepines, cannabis and stimulants).

In the majority (98\%) of the blood samples where methadone was detected, in samples from apprehended drivers in Norway, illicit drugs were detected in combination (41). The extensive use of other drugs among this group makes it difficult to assess the methadone effects on psychomotor skills. Furthermore, combination of multiple drug use is associated with a higher risk of serious or fatal injuries in crashes than use of medicinal or illicit opioids alone, see Figure 1. In the same study, $66 \%$ of the drivers reported prescribed use of methadone. If the majority of these drivers are OMT patients, this indicates that a large proportion is not following the OMT regulations where use of illicit or sedating drugs is prohibited.

\subsubsection{Prevalence of drug use in fatal road traffic crashes}

The prevalence of drink and drug driving in fatal road traffic crashes varies between different countries. A report from the European DRUID project, which included data collected from 9 countries between 2006 and 2009, showed that one or more substances (mutually exclusive), including methadone, were detected in $28-53 \%$ of drivers fatally injured in different countries (42). More recent numbers from the United States show that approximately one-third of all traffic crash fatalities in 2017 involve drunk drivers (43), while close to $44 \%$ of fatally injured drivers tested positive for drugs in 2016 (44). Almost $20 \%$ of the fatally injured drug-positive drivers were positive for some opioid, and methadone was one of the most frequent opioids detected at $8 \%(44)$.

In Norway the number of fatalities is low compared with other countries, but further reduction in the number of road traffic deaths continues to remain a high priority for the authorities, in accordance with the zero vision strategy (45). In 2017, a total of 107 persons (approximately 2 per 100000 inhabitants) were killed in road traffic crashes in Norway (46). 
This is the lowest number of traffic deaths in 70 years. The low number of fatal traffic crashes in Norway compared to the rest of the world is probably due to consistent and high focus on traffic safety measures through decades, including legislation, law enforcement for DUI cases and public information campaigns.

Data from killed drivers in Norway between 2005 and 2015 showed that medicinal drugs, i.e. benzodiazepines and opioids, were present in approximately $11 \%$ of the cases, and both methadone and buprenorphine were detected among the opioid cases (47). The prevalence of medicinal opioids, including methadone, in fatally injured drivers was $1.7 \%$ in Norway between 2006 and 2009 (42).

It has been estimated that around $21 \%$ of all fatal road traffic crashes in Norway are related to impaired driving due to alcohol, medicinal or illicit drugs (48). This number is probably underestimated as $30 \%$ of all fatal crashes are not investigated for alcohol or drugs by analyzing blood samples from the drivers (49). The distribution of the different drugs and combinations detected in killed rivers in Norway is shown in Figure 3. 


\section{Prevalence of drugs and alcohol in fatalities}

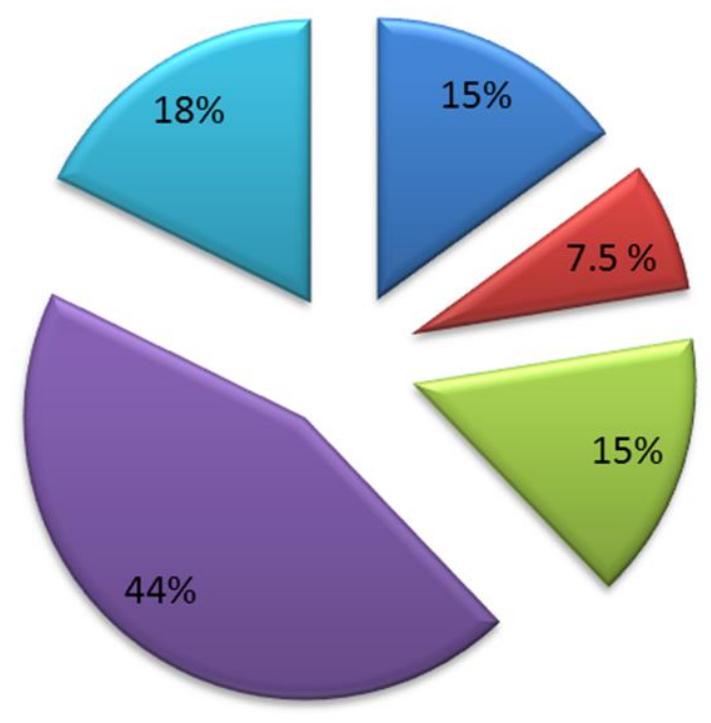

One medicinal drug

$\square$ One illicit drug

$\square$ Multidrug

Alcohol alone

$\square$ Alcohol $+\operatorname{drug}(\mathrm{s})$

Figure 3 Pie chart of the distribution of drugs and alcohol among drivers fatally injured in road traffic crashes in Norway in the period 2005 - 2018 (concentration levels comparable to BAC of $\geq 0.02 \%$ ). One or more drugs were present in more than $34 \%$ of the cases. Alcohol and alcohol in combination with other drug(s) were most frequently observed in samples that tested positive. Data from Oslo University Hospital's RTC research database $(n=706)$.

\subsubsection{DUI legislation in Europe}

An important measure to regulate driving behavior is through legislations to make sure that the public complies with traffic rules and regulations, e.g. speed limits. Most countries have implemented concentrations limits in blood for DUI of alcohol $(50,51)$. Even though the relationship between BAC and degree of impairment is generally accepted, the legal limits for driving under the influence of alcohol vary between different countries. E.g. several Eastern European countries including Russia have a legal limit of $0.00 \%$, most Western European countries have a legal limit of $0.05 \%$ while England and Northern-Ireland have the highest BAC limit of $0.08 \%$.

Norway was the first country to establish a per se limit for DUI of alcohol in 1936 (52). The BAC limit was initially $0.05 \%$, but in 2001 the limit was reduced to $0.02 \%$ for political 
reasons. The intention of the law has been to punish impaired driving and furthermore to signal that alcohol use and driving should not be combined.

As a consequence of the increasing awareness of the impairing effects of non-alcohol drugs, and the increase in drug driving, several countries have also introduced legal limits for psychoactive drugs other than alcohol $(36,53-55)$. There are three types of principles applied for driving under the influence of drugs (DUID) legislation: impairment laws, zero tolerance laws and per se limits. Throughout Europe multiple approaches have been introduced, e.g. zero-limits and LOQ-limits, per se limits, and impairment laws (56). Legislative per se limits were first introduced in Denmark in 2007 (54), in Norway in 2012 (36), in England and Wales in 2015 (53), and in the Netherlands in 2017 (55).

Norway was the first country to implement limits for graded sanctions for non-alcohol drugs in addition to per se limits in the Road Traffic Act (36). Per se limits have been established for 28 psychoactive drugs, while limits for graded sanctions, corresponding to the degree of impairment corresponding to BACs of 0.05 and $0.12 \%$, have been established for 22 of the 28 drugs. The drugs include several benzodiazepines, stimulants like amphetamines and MDMA, cannabis, GHB and opioids including methadone and buprenorphine. After the implementation of the per se law the number of blood samples collected in suspected DUID cases increased by $20 \%$ (57) and a reduction of medicinal and illicit drug use among the general driving population in the southeastern parts of Norway has been observed (38).

\section{4. $\quad$ Research on impairing effects of drugs on driving}

Driving is a complex task requiring integration of psychomotor, cognitive, and visual-spatial skills, decision making, divided attention, working memory, and behavioral and emotional control $(58,59)$. Epidemiological studies can be used to study crash risk and crash culpability, while driving related skills can be tested using experimental studies. In addition, real-life studies, like DUID cases and drivers involved in road traffic crashes, provide information on the effects of substance use on safe driving. There are distinct advantages and limitations of the different types of studies (see also sections 8.4.1 and 8.4.2); therefore, all types of studies are essential to assess the effects of substance use on driving (60). E.g. while epidemiological studies have an observational approach and describe how real-life drugexposed drivers perform in normal road traffic, experimental studies are essential to 
investigate the potential a specific psychoactive drug has to induce traffic-relevant impairment.

For alcohol, a strong correlation between crash risk and BACs has been established, as for the relationship between BACs and impairment (61). Less documentation exists for other psychoactive substances.

\subsubsection{Crash risk investigated by epidemiological studies}

Epidemiological studies are used to determine crash risk in large populations $(3,60)$. One main advantage of epidemiological studies is that actual driving situations are observed.

Thereby factors other than specific drug effects are also taken into account, such as insight in driving ability, willingness to drive after taking the drug, ability to compensate for impairing effects, etc. Furthermore, epidemiological studies allow a large number of drivers to be included, and hard endpoints relevant to traffic safety, such as road traffic crashes or fatalities, are often studied.

The main limitations of epidemiological studies are selection bias, information bias, and confounders (60). Selection bias is caused by the selection of individuals. Randomization of selection of drivers must be proper to ensure that the sample is representative for the population intended to be studied. E.g. if participation is voluntary, persons using psychoactive drugs might refuse to participate, leading to an underestimation of drug use. By using data from road traffic registries high participation rates can be attained and this ensures that the drivers are representative to the general driving population. Examples of information bias are incorrect classification of substance exposure or different classification methods for cases than for controls. Another contributor to information bias is studies based on self-reported drug use or crash involvement. Confounders are variables that might affect the crash risk estimates, like age, sex, driving experience, time of day, personality, impulsivity, or cultural aspects. E.g. the time of day or the day of the week could have significant influence on the odds ratio of crash risk as the prevalence of use of certain drugs and types of persons driving at different times of the day are different in weekends and at night-time compared to everyday and daytime $(2,38)$. Another limitation regarding information from epidemiological studies is that few studies have provided estimates of crash risk related to drug dose or drug concentrations in blood (62-64). Few such studies 
have been performed due to the small number of cases with known drug concentrations in blood, resulting in a low statistical power.

Epidemiological studies can be divided into the following types:

1) Pharmacoepidemiological Cohort Studies on road traffic crash (RTC) involvement

2) Case-Crossover Studies

3) Case-Control Studies on alcohol and drug use in RTC-involved drivers compared to non-RTC-involved drivers

4) Responsibility Studies, i.e. studies on alcohol and drug use among drivers responsible for RTCs compared with non-responsible RTC-involved drivers

\subsubsection{Pharmacoepidemiological cohort studies on RTC involvement}

These studies compare the crash involvement between two groups, typically one group exposed to a psychoactive substance and a non-exposed control group. Drug exposure is usually based on records in prescription registries, while crash involvement cases are found in road traffic crash databases, hospital or police records, or insurance databases.

The strengths of these studies are that drivers in actual traffic are studied and that a large number of drivers (and controls) can be included. Furthermore, it allows calculation of crash risk associated with prescription of medicinal drugs. Limitations are that prescription data only provide information on whether medicinal drugs are dispensed at a pharmacy, but not if they are used or used as prescribed. Furthermore, the disease initiating the prescription of a medicinal drug may itself be deleterious to safe driving, and any use of additional medicinal or illicit drugs that can influence driving skills is not known. RTC involvement does not provide information on responsibility as the driver might not be the one responsible for the accident.

\subsubsection{Case-crossover studies}

A case-crossover study examines the crash rate in a cohort of drivers who have received a prescription drug. With a case-crossover study design the drivers are their own controls; i.e. the drivers which have taken a drug are compared with themselves when they have not taken the drug. The advantage of cases being their own controls is that many confounders can be eliminated, such as age, sex, driving experience and personality. On the other hand, it 
might in some cases be difficult to distinguish between the underlying disease itself, which may also influence the crash risk, and the prescribed drug.

\subsubsection{Case-control studies}

Case-control studies compare prevalence of drug use among drivers involved in RTCs (i.e. cases) with a control group not involved in RTCs. This type of study is often regarded as the best epidemiological method to calculate the association between the exposure (substance use) and the outcome (crash risk). The crash risk can be expressed as an odds ratio (OR). The main advantages of these studies are that drivers in normal road traffic are included and that both medicinal and illicit drugs are studied. Confounding factors in such studies might be analyses of drugs in different matrixes for cases and the control group (e.g. blood versus urine) or different analytical methods, which makes it difficult to directly compare the results, and furthermore lack of adjustments for age, sex and time and day of week.

\subsubsection{Responsibility studies}

Responsibility studies are also known as culpability studies, and are often classified as a type of case-control studies. This type of study was designed to do an assessment of the driver's responsibility in a road traffic accident (65). Drivers involved in a crash are identified as being partly or mainly responsible for a RTC (cases) or not responsible (controls). However, it may be difficult to determine responsibility, which is the main limitation of these studies. The main advantage of these studies is that blood is usually collected from all the drivers and drug concentrations in blood are an objective measure of substance use. The concentrations can indicate degree of drug impairment. Furthermore, a strength of this study design is that real drivers in normal road traffic are studied.

\subsubsection{Measuring driving performance (experimental studies)} In experimental studies, the effects of psychoactive substances on cognitive and psychomotor performance relevant to driving are studied (4). These studies should be randomized (when using between-group designs), include a placebo control group, administer different doses, and include a so-called benchmark substance, to be able to compare to the effects of another drug/treatment $(60,66)$.

The literature on traffic safety covers a large number of experimental tests, but there is no agreed hierarchy with regard to relative test-importance. An expert group (66) has 
recommended that validated tests on three core levels of behavior constitute the best basis for evaluating whether a certain drug (or dose) represents a traffic risk. The three levels are:

1) Automative behavior, e.g. tracking and sustained attention;

2) Control behavior, e.g. skills like overtaking, maintaining distance, divided attention and motor performance; and

3) Executive planning behavior like risk taking and information processing (e.g. categorization tasks)

Furthermore, an expert panel proposed a consensus protocol for assessing drug driving (67). Five essential driving ability domains were indicated: (1) alertness/arousal, (2) attention and processing speed, (3) reaction time/psychomotor functions, (4) sensory-perceptual functioning, and (5) executive functions. The experts stated that "a drug that impairs performance in any of these domains at a magnitude known to be associated with increased crash risk is presumed to have a negative impact on driving safety".

Tests for measuring drug effects on driving-related skills should be supported by theoretical models of driving behavior and empirical evidence of their validity (14). Lane keeping and passing cars are operations on a maneuver level, and these operations should be performed fast and effortless (68). Tests of visual attention, psychomotor function and executive control are considered highly relevant to the maneuvering level when assessing impairing effects of drugs on driving $(69,70)$. Many of the studies on non-alcohol drugs lack, however, a benchmark substance; the use of an established set of tests sensitive to traffic-related effects; or the measurement of drug concentrations in blood and other matrixes $(4,36)$.

The main advantages of experimental studies are the low number of participants needed for a significant power to detect drug-induced impairment; they allow individual drugs to be investigated rather than drug groups; the investigators have full control on doses administered; and sensitive and validated tests may be applied (60).

Main limitations are administration of only low doses, due to ethical reasons (i.e. high doses, combined drug use or repeated doses are missing); hangover or withdrawal symptoms after repeated or large doses cannot easily be studied; participants know they are being tested 
(i.e. can thereby possibly compensate for impairment) and the setting might be somehow unrealistic; and the performed tests may not be relevant to driving performance (60).

Another limitation is the possible learning-effects when tests are repeated without training; this could bias the results as performance can improve over time. Acute tolerance may develop, which means that the impairing effects may be different at the same drug blood concentration, when increasing and decreasing. Furthermore, several studies are missing assessment of subjective measures (e.g. feeling "high") as well as subjective assessment on fitness to drive (60). This might indicate if the test person is willing to drive after taking the substance in a normal setting, even though it has been shown that drivers can poorly predict their own driving impairment (71).

The use of a benchmark substance increases comparability of impairment levels (66). Alcohol is well studied and is often used as benchmark substance as a concentration-effect relationship has been documented for several tests. A benchmark substance like alcohol can therefore provide information on the magnitude of impairment when compared to effects and effect sizes of a given drug. Furthermore, concentration-effects of alcohol can demonstrate that a test is sensitive and has been undertaken properly (72).

Both high sensitivity and validity of the tests used in neuropsychological studies are important to ensure good quality of the research. The sensitivity of a test is high if it is able to detect the impairing effects of a relatively low dose of a psychoactive substance (14). Validity is how well a test measures what it intends to measure $(73,74)$. Validity can refer to several aspects of experimental methods, like external validity (the generalizability of the results of a test, e.g. how well test subjects represents the general population) $(75,76)$, ecological validity (how representative the findings are of the real world or tasks, e.g. whether an on-road driving study generalizes to real-life driving ) (76, 77); face validity (whether a test subjectively appears to measure what it actually measures, e.g. does the test subjects assess a driving simulator as a naturalistic impression of driving) (76); construct validity (the degree to which a test measures what it purports to be measuring, e.g. whether neurocognitive tests in a study of drug effects on driving measure driving skills or effects relevant to driving) (77); predictive validity (the ability of a measure to predict what it theoretically should predict, e.g. whether a driving test or neurocognitive tests actually can 
predict crash risk in real road traffic) (78); and internal validity (how well a causal relationship between a dependent and an independent variable can be tested, e.g. whether drug effects are the only possible explanation to the effects observed on driving skills) (76, 79).

Psychomotor and cognitive functions relevant for driving can be tested in experimental studies using several different methods:

1) Actual on-road driving;

2) Simulator driving;

3) Testing of separate psychomotor functions, e.g. attention and reaction time; and

4) Testing batteries of several cognitive- and/or psychomotor functions

\subsubsection{On-road driving studies}

The on-road driving test was developed in the Netherlands and has been applied in psychopharmacological research for more than 30 years $(77,80)$. It is considered the golden standard for measuring drug effects on driving $(15,81)$. The on-road driving test is performed in normal traffic on a public highway and reflects actual driving and associated risks. The primary outcome is the standard deviation of lateral position (SDLP) which is a measure of the "weaving" of the car or road tracking control, see Figure 4 . The test has been applied in several studies of alcohol and a large variety of psychoactive drugs such as cannabis, MDMA, benzodiazepines, antihistamines and antidepressants, e.g. (81-87), but only two studies including opioids have been conducted $(31,88)$. 


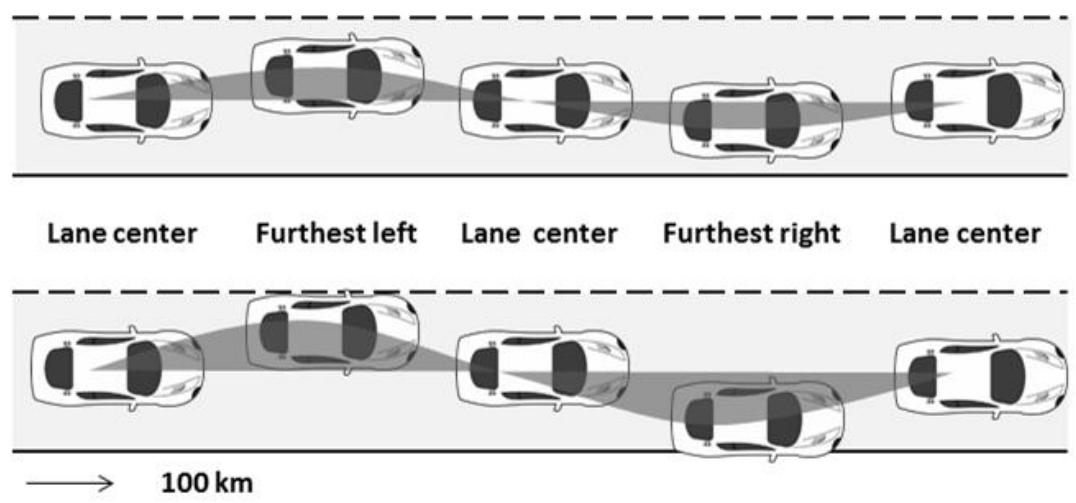

Placebo

(e.g. SDLP=16cm)

Sedating drug

(SDLP increases)

Figure 4 The standard deviation of lateral position (SDLP) is a measure of tracking error or "weaving". The figure illustrates how the SDLP increases after use of a sedating drug. (by J. Ramaekers, 2018)

SDLP was one of the first standardized driving measures for increasing doses of alcohol (81). A recent pooled data analysis study stated that BACs of $0.05 \%$ were associated with a mean increase of the SDLP of $2.5 \mathrm{~cm}$, which has been defined as the minimal cut-off value to represent clinical relevance (81). It has been shown that change in SDLP after alcohol intake is strongly correlated to crash risk, indicating that the SDLP shows drug-impairing effects on driving and might also predict crash risk (89).

Main advantages of the on-road driving test are that it measures overall vehicle control, has a low learning effect, and test subjects have a high motivation to perform the test. Main limitations are the risk of accidents and unexpected incidents, and a long duration of the test. Furthermore, the on-road driving test measures road tracking control, a highly automated behavior, and thereby to a less extend complex driving skills requiring conscious control.

The on-road driving test has a high external validity which means that the results can be applied to a general population and a high ecological validity because it is performed in normal traffic and the results can be generalized to real-life settings (14). 


\subsubsection{Driving simulator studies}

Driving simulators can be used to perform a computer simulation of a driving task. Simulated driving makes it possible to study different types of driving situations, e.g. driving in rural or urban areas, during daytime or nighttime, under challenging situations or exposed to unexpected events. The main advantages of driving simulators are that the tasks can be standardized and the data safely acquired. Main limitations are that driving simulators cannot replicate real driving conditions completely, and the subject's responses and risk taking may be different in the simulated driving setting than in real traffic. Furthermore, many subjects experience simulator sickness, which can interfere with the results.

Driving simulators can also be used to measure SDLP and has a high external validity like onroad driving studies. The increase in SDLP following alcohol intake has been shown to be comparable in simulated driving and real driving (90). Furthermore, a dose-response relationship was found between higher BAC and increasing SDLP for simulator driving and on-road driving on a closed circuit (91).

\subsubsection{Neurocognitive tests}

Neurocognitive tests are sensitive to the impairing effects of psychoactive substances and can be used to assess potential driving impairment. These tests can never reproduce the complexity of driving skills completely, but can provide important information on neurocognitive functions essential to safe driving. Many different functions can be tested, e.g. attention (divided and sustained), vigilance, tracking, visual functions, reaction time and en-/decoding.

Experimental studies investigating effects of alcohol and drugs on driving and driving-related skills have shown that tests of tracking and attention are among the most sensitive tests (92). A recent study compared the relative sensitivity of psychomotor tests for three doses of alcohol; leading to BACs of 0.02, 0.05 and $0.08 \%$ (92). It was revealed that the Divided Attention Task (DAT) was significantly impaired after all alcohol doses compared to placebo. The Psychomotor Vigilance Test (PVT) and the Balance Test (PBT) was impaired at BACs of 0.05 and $0.08 \%$. The PVT is often applied in sleep research to assess drowsiness following sleep deprivation in drivers $(92,93)$, and DAT and PVT are considered to be considerably valid in assessing potential driving impairment. 


\subsection{Opioids: use, pharmacodynamics and pharmacokinetics}

Opioids are widely used analgesics and regarded as among the most effective drugs for the treatment of pain. Opioids are drugs that exert their effects mainly through binding to opioid receptors. Opioid receptors are distributed in the brain, the spinal cord, on peripheral neurons and the digestive system. Opioids produce analgesia, sedation, respiratory depression, suppression of cough, euphoria and constipation, and are potentially addictive. Frequent unwanted effects are nausea and vomiting. Acute overdosing can lead to coma and respiratory depression and can be fatal. Common for all opioids is that their effects are blocked by opioid antagonists such as naloxone. It is known that tolerance develops, although to various extents, to many of the effects of opioids (94).

There are three major subtypes of opioid receptors: Delta $(\delta)-$, kappa $(\kappa)-$, and $\mathrm{mu}(\mu)-$ receptors (95). Animal studies have shown that mu-opioid receptors (MORs) alone are responsible for both therapeutic and adverse actions of morphine (95). Furthermore, MORs are the key molecular target for other opioids such as methadone.

The blood-brain barrier separates the circulating blood from the blood and extracellular fluid in the central nervous system (CNS). Only small, lipid-soluble molecules can cross this barrier freely. Transport of larger molecules is selective via endocytosis or transcytosis (96). Opioids cross the blood-brain barrier by ATP-binding cassette (ABC) transporters (97), while Pglycoprotein (P-gp) mediates efflux of opioids at the blood-brain barrier. Both methadone and buprenorphine are substrates of $\mathrm{P}$-gp (97).

Large variation in clinical response has been reported for opioid analgesics (98). The reasons for the variability are not fully understood, but it has been suggested that allelic variants determining the composition of opioid receptor and slight differences in receptor-binding profiles between opioids could play a role. Metabolic variability may also influence response to opioids in terms of efficacy and tolerability.

Opioids have large potential for misuse and addiction. High doses may have euphoric effects, which after repeated use may cause craving, and development of tolerances causes the user to steadily increase the doses. Opioid misuse is the most common cause of drug-related deaths (99-102), but the preferred substances may differ between countries. In Norway, heroin used to be the most commonly drug causing fatal overdoses, but in recent years the 20 
number of methadone and buprenorphine related fatalities have increased (99).

Buprenorphine is at present the most commonly used opioid by people who inject drugs in Finland (103), while methadone is the most common cause of overdoses in Denmark (104). Other countries have experienced serious problems with overdoses by fentanyl or oxycodone $(101,105)$. At present, misuse of the latter two substances does not constitute a serious problem in Norway.

\subsubsection{Opioid-maintenance treatment (OMT)}

OMT is a long-term intervention attempting to stabilize and rehabilitate persons with heroin addiction. The substitute drugs used in OMT are mainly methadone or buprenorphine. The OMT medications have long half-lives and prevent withdrawal symptoms and reduce cravings. A total of 628,000 persons received opioid substitution treatment in Europe in 2016 (106), while 7,622 patients received OMT with either methadone or buprenorphine in Norway at the end of 2017 (107).

The main aim of rehabilitation with OMT is to return to daily life activities. If daily doses are stable and there is not abuse of other psychoactive drugs, there is a possibility to be able to drive a car. Driving might be pivotal to be able to return to work, maintain relationships and participate in activities. Regulations to permit driving under OMT vary between European countries: in most countries driving during treatment is permitted, but in some countries, like the Netherlands, Lithuania and Slovakia, driving during OMT is prohibited (108). However, restrictions related to driving by OMT patients are often justified by public interests, like traffic safety. Drivers with limited driving skills and/or who pose an increased risk of road traffic crashes are prevented from driving, like persons driving under the influence of psychoactive substances.

In Norway it is permitted to drive during OMT if the following requirements are met:

- treatment under proper supervision and follow up by a known physician;

- stable dose for a minimum of 1 year;

- $\quad$ and no use of sedative or illicit drugs, the latter for a minimum of 1 year. 
While it is well known that the combination of two or more psychoactive drugs significantly increases the risk of serious or fatal injury in traffic (109), the time to develop tolerance to the impairing effects of methadone and buprenorphine is not well studied.

A reduction in convictions for DUI among Norwegian OMT patients in treatment as compared to pre-treatment has been shown (110). During treatment a reduction of almost $40 \%$ was seen, indicating that OMT is an effective tool to reduce convictions for DUI among opioid-dependent persons.

\subsubsection{Methadone}

Methadone is a full synthetic, long-acting opioid, primarily used in OMT of persons with heroin addiction. It is, world-wide, the most frequently prescribed drug with this indication $(41,111)$. Methadone is also widely used as an analgesic. Methadone was developed in Germany during World War II as a morphine substitute (112), see Figure 5 for chemical structure. It was approved for use in the USA in 1947.

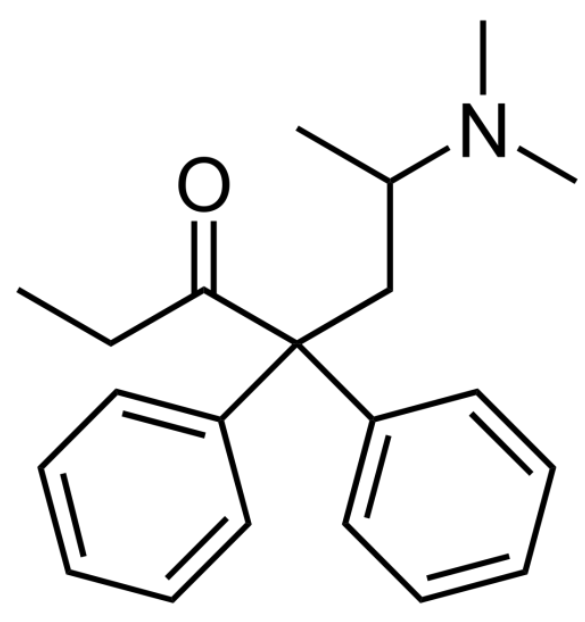

Figure 5 Molecular structure of methadone (Source: Wikipedia, no "fair use" file)

Methadone can be administered per oral as tablets or mixture, or parenteral via injections e.g. epidurally or intravenously. Methadone can be detected in blood 15-45 minutes after oral administration, with average peak plasma concentrations at 2.5-4 hours. An up to 17fold inter-individual variation has been reported for methadone concentrations in blood after a given dose (113). The oral bioavailability averages $85 \%(114)$, but a wide variation 
has been observed with a range of $36-100 \%$ (113). Methadone is highly bound to plasma proteins and a mean free fraction of $10-14 \%$ has been measured (113). Methadone has a long half-life of 24-60 hours (115). Methadone and morphine are approximately equipotent as analgesics when taken parentally, but as a result of drug accumulation, methadone produces marked sedative effects with repeated administration (112). Administration of methadone, being an agonist with strong affinity to the $\mu$-receptor, increases the effects of other opioids being present at the same time. Methadone displays large inter-individual variability in its pharmacokinetics (113) and apparently also in its pharmacodynamics.

A regular dose of methadone in pain treatment is 5-10 $\mathrm{mg}$ per oral 3-4 times per day. A regular dose of methadone in maintenance treatment is between $60-130 \mathrm{mg} / \mathrm{day}$, and is usually administered as a solution. In opioid-naïve patients, the recommended starting dose is $2.5 \mathrm{mg}$ every $8-12 \mathrm{~h}$ with a dose increase by $2.5-5 \mathrm{mg}$ increments every $5-7$ days. A single dose of $10 \mathrm{mg}$ methadone per oral produced an average peak blood concentration of 34 $\mathrm{ng} / \mathrm{mL}$ in healthy men (114). For opioid-tolerant patients, an appropriate methadone-tomorphine conversion ratio ranges from 1:5 to 1:20 (115). It is not recommended to initiate treatment with methadone in doses higher than $30 \mathrm{mg}$ per day in any patient (115). Doses of $50 \mathrm{mg}$ or less have been reported to cause fatalities in nontolerant adults (112).

The pharmacological activity is mainly due to the active stereoisomer levomethadone, also known as (R)-methadone (112). Racemic methadone contains both (R)-methadone and the dextrorotatory (S)-methadone isomer in a 50/50 mixture. Methadone is metabolized to 2ethylidene-1,5-dimethyl-3,3-diphenylpyrrilidine (EDDP) mainly by Cytochrome P450 (CYP2B6) $(116,117)$. CYP2B6 expression can influence the concentration of methadone in blood. Poor metabolizers (CYP2B6*6/*6 carriers) are shown to have higher concentrations of methadone in blood after intake (118). A recent study found that patients homozygous for CYP2B6*6 had a $90 \%$ higher methadone serum concentration/dose (C/D) ratio (119). CYP2B6 polymorphism can be tested by genotyping.

Long-term treatment with high doses of methadone is associated with QTc interval (interval between $Q$ wave and T wave of the heart's electrical cycle) prolongation, arrhythmia and sudden death (120). The use of electrocardiography screening prior to methadone treatment has therefore been recommended in Norway (121). 


\subsubsection{Buprenorphine}

Buprenorphine is a partial opioid agonist/antagonist and semi-synthetic opioid which binds to $\mu$ - and $\mathrm{k}$-receptors in the brain, see Figure 6 for molecular structure. Buprenorphine has been introduced as an alternative to methadone in maintenance therapy (122), but is also widely used as an analgesic. The effect of maintenance treatment with buprenorphine is possibly attributed to the slow reversible binding to $\mu$-receptors. Buprenorphine has a wide therapeutic range due to its agonist/antagonist effects, which limits its depressant effects especially on respiratory and cardiac functions (123). Buprenorphine was manufactured as an injection in the UK from 1978 to treat severe pain. The sublingual formulation was sold from 1982.

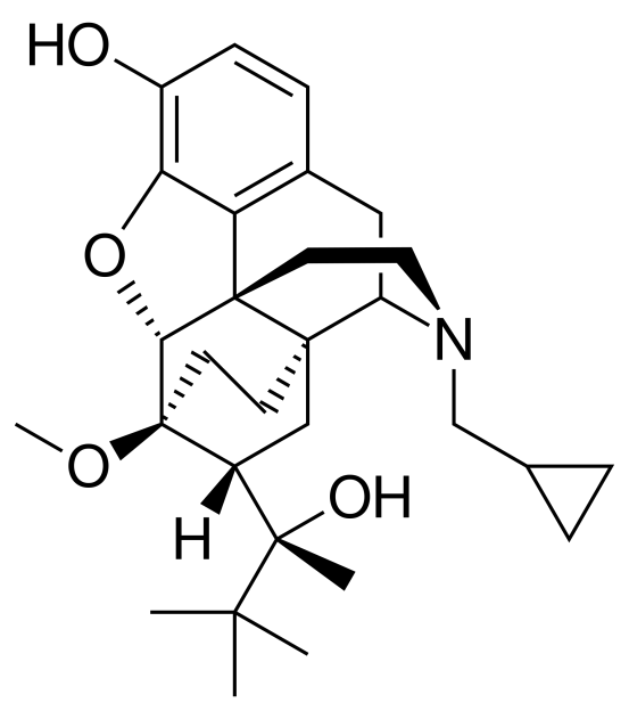

Figure 6 Molecular structure of buprenorphine (Source: Wikipedia, no "fair use" file)

Buprenorphine undergoes extensive first-pass metabolism and has a low bioavailability when administered orally (only $10 \%$ of the intravenous route) (124). Buprenorphine is administered parenteral either sublingual, transdermal or via injections e.g. intravenously or intramuscularly. The bioavailability after sublingual administration is $30-50 \%$ of the intravenous route (124). Average peak plasma concentrations after sublingual intake have been reported at 0.8-1.3 hours (112) and ranging from 40 minutes to 3.5 hours (125). Linear relation between concentrations of buprenorphine in plasma and doses (ranging from 1-32 mg sublingual) has been shown in non-dependent subjects (126). Buprenorphine is highly 
protein bound (96\%) and has a large volume of distribution (125). Buprenorphine readily crosses the blood-brain-barrier, and crosses the placenta during pregnancy and also into breast milk (125).

A regular dose of buprenorphine in pain treatment is $0.2-0.4 \mathrm{mg}$ sublingual up to $3-4$ times daily. A regular dose of buprenorphine in maintenance treatment is between $8-16 \mathrm{mg} /$ day sublingual. Single doses of sublingual buprenorphine to healthy subjects produced the following peak blood buprenorphine concentrations: $1.6 \mathrm{ng} / \mathrm{mL}$ after $2 \mathrm{mg}$ (127), $3.3 \mathrm{ng} / \mathrm{mL}$ after $4 \mathrm{mg}(128)$ and $5.8 \mathrm{ng} / \mathrm{mL}$ after $8 \mathrm{mg}(129)$.

Buprenorphine is metabolized to conjugated buprenorphine and norbuprenorphine (an active metabolite), mainly by uridine 5 '-diphospho-glucuronosyltransferase (UGT1A3) and CYP3A4. There is no known polymorphism of these enzymes and therefore genotyping is not relevant. However, a number of drugs inhibits and induces CYP3A4 which can affect buprenorphine metabolism, e.g. erythromycin inhibits 3A4, while carbamazepine and phenytoin induces $3 \mathrm{~A} 4$.

\subsection{Current knowledge gaps}

The association between traffic crash risk and the use of methadone and buprenorphine is poorly documented. No comprehensive review on the effects of buprenorphine and methadone on cognitive and psychomotor task performances had been published; a systematic review was therefore required. Few experimental studies on buprenorphine and methadone of relevance to road traffic safety had been performed; none included on-road driving. More relevant and better designed studies were therefore needed in order to assess the effects of those opioids on the ability to drive safely. 


\section{Aims}

The overall aim of this thesis was to provide more knowledge about the impairing effects of methadone and buprenorphine in relation to driving.

The specific aims of the thesis were:

- To summarize the current knowledge regarding crash risk and impairing effects on driving after administration of methadone and buprenorphine (Paper I)

- To investigate whether methadone and buprenorphine cause traffic relevant impairment using an on-road driving test and neurocognitive tests (Paper II)

- To investigate if there is a dose- and/or concentration-effect relationship for methadone and buprenorphine (Papers II and III)

- To investigate the pharmacokinetic properties of methadone and buprenorphine in blood and oral fluid (Paper III) 


\section{Materials and methods}

\subsection{A systematic literature review}

Our institute was invited to participate in the European DRUID project in 2006 (130). One of the tasks assigned was to conduct a systematic literature search of the current scientific literature on the treatment with methadone or buprenorphine related to the effects on cognitive- and psychomotor functions relevant to driving in experimental studies, including epidemiological studies of patients receiving maintenance treatment with either methadone or buprenorphine.

\subsubsection{Search strategy}

Searches were conducted in the databases MEDLINE, EMBASE, and PsycINFO. Searches for experimental studies were conducted throughout the month of March of 2010, and searches for epidemiological studies were conducted throughout the month of June of 2010.

The following search words were used for the epidemiological studies: Accident involvement; accident risk; car accident; car driver; car driving; case control; cohort; crash; culpability; driver; driving ability; driving accident; driving performance; driving skills; epidemiology; fatal; highway safety; injured; killed; odds ratio; pharmacoepidemiology; relative risk; road safety; roadside survey; traffic accident; traffic safety; and vehicle.

For the experimental studies the following search words were used: Aggression; aggressive behavior; attention; automobile driving; cognition; cognitive function; cognitive process; driving ability; error detection; hypnotics and sedatives; impulsive behavior; impulsivity; judgment; memory; motor skills; psychomotor effect; psychomotor impairment; psychomotor performance; sedation; sedatives; steering; tracking; vigilance; and visual perception.

To retrieve as much relevant literature as possible the defined words were searched using two separate methods: 1) As controlled vocabulary (i.e. using own vocabulary/thesaurus of the databases); and 2) As free text words (key words). To broaden the search the relevant words were combined with the Boolean operator 'OR'. The result was then limited to one of the following types of studies: Experimental, quasi-experimental and controlled. No limits were made as to publication year or publication language. Finally, the search strategy was combined with the words methadone, levomethadone, and/or buprenorphine. 
Epidemiological studies containing risk analysis were included in the review. In addition, several articles, including a number of reviews, were screened as sources of reference for the primary research literature.

Inclusion criteria for the experimental studies were: performed in humans only; subjects had to be either patients in maintenance therapy, opioid-dependent abusers (current drug abuse), or healthy volunteers (with no known history of drug abuse); reported drug concentrations and/or doses; including a control group (placebo and/or no drug/baseline); measuring objective effects (drug use while driving and/or performing tasks relevant to driving); a minimum of 5 participants; and the study had to be published in a scientific journal.

The primary search included about 1,750 titles; approximately 1,500 titles of experimental studies and approximately 250 titles of epidemiological studies, see Figure 7. Full-text articles of experimental studies were selected from the primary search by one medical expert based on the inclusion criteria. The selected articles, consisting of approximately 100 experimental studies, were evaluated by two medical experts, who selected the final articles according to the same inclusion criteria. In addition, approximately 250 epidemiological titles with abstracts were retrieved from the primary search and assessed by one medical expert. The selected full-text articles, consisting of approximately 40 epidemiological studies, were finally assessed by two medical experts. Finally, 59 articles were included in the review; 54 experimental studies and 5 epidemiological studies. 


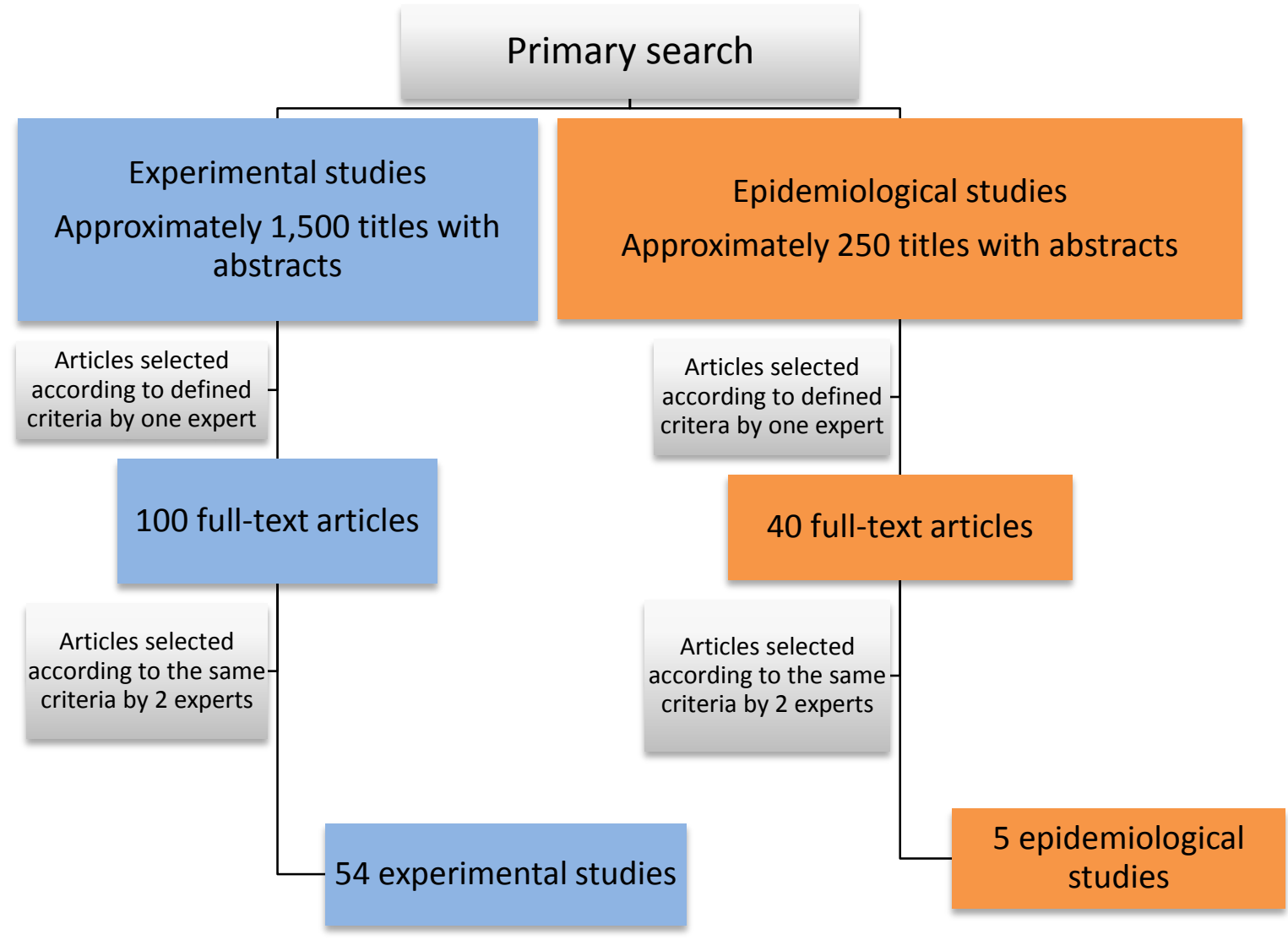

Figure 7 Flow-chart showing the process of the literature search of experimental studies and epidemiological studies on methadone and buprenorphine, and the number of articles retrieved at the different stages of the search.

\subsection{A clinical on-road driving study}

We conducted a placebo controlled study on the impact of buprenorphine and methadone on on-road driving and cognitive performance. All tests were validated and represented all levels of behaviors as recommended for drug d riving research; (1) automative behavior, (2) control behavior, and (3) executive planning behavior (66), see chapter 8.4.2.

Healthy volunteers with significant driving experience were recruited through local advertisements and participants were included after a medical screening. After inclusion the participants performed a training session for the driving test and the computer tests. The volunteers participated in five study days each. A timeline of the test day is shown in Figure 8. 


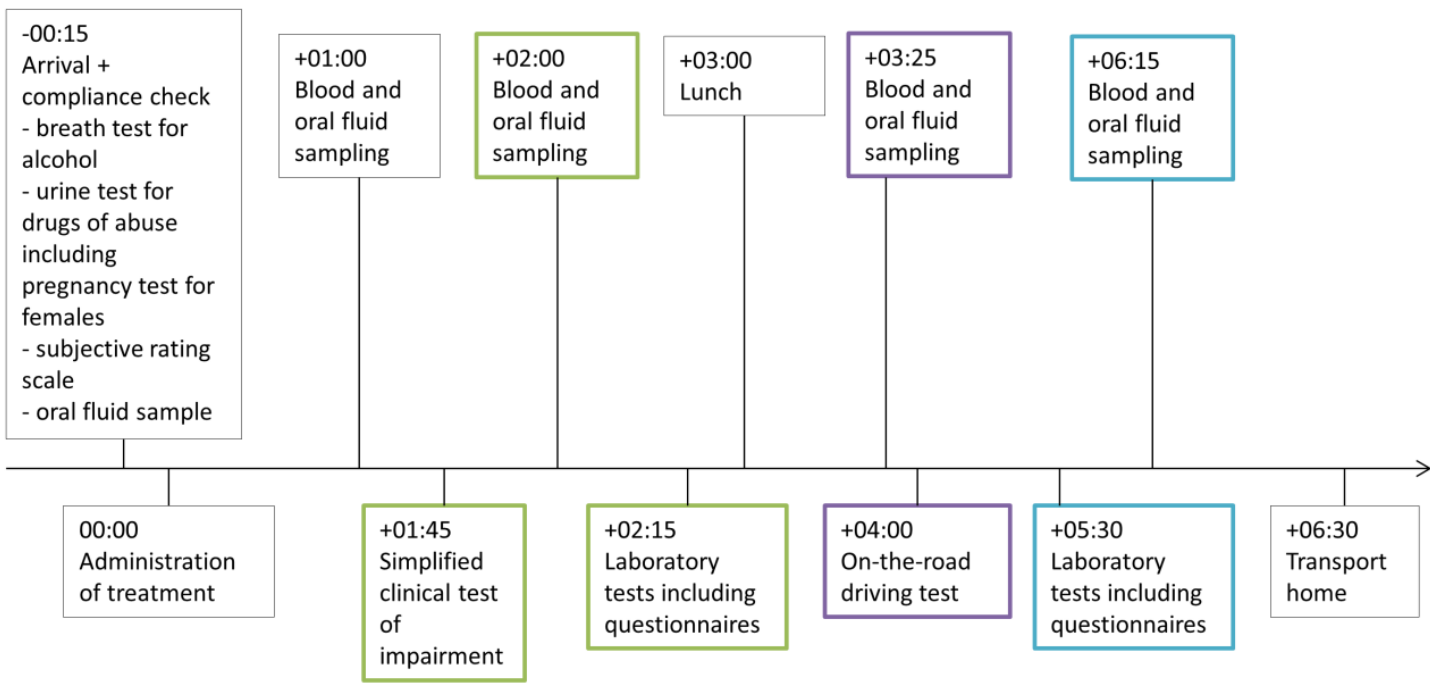

Figure 8 The timeline of a test day (from Paper II).

\subsubsection{Procedure for the clinical study}

On arrival, urine was screened for drugs (methamphetamine, cocaine, THC, morphine, benzodiazepines and amphetamine), a pregnancy test was performed, and breath alcohol was analyzed. Participants were asked to refrain from consuming caffeine on test days and alcohol intake 24 hours prior to test days. The Groningen Subjective Quality of Sleep Questionnaire was used to assess sleep quality the night before test days.

Blood and oral fluid were collected throughout the test day. The on-road driving test was performed 4 hours after treatment administration. Before and after the driving test, i.e., 2.5 and 5.5 hours after treatment intake, participants performed two sessions of laboratory testing (i.e. morning and afternoon session). Each session consisted of the PVT, the Critical Tracking Task (CTT), the DAT, the Digit Symbol Substitution Test (DSST), the Useful Field of View Test (UFOV), the PBT, and the Vienna Test System - Determination Test (DT/S1). Two sessions were performed to see how the blood drug concentrations and effects changed over time, and also to take acute tolerance into account. Before the driving test, a standardized light lunch was served. After completion of a test day, participants were transported home by a driving instructor. 


\subsubsection{Subjects}

Twenty-two healthy volunteers (11 males, 11 females) were included after screening of 29 volunteers in total. Three subjects were excluded based on the exclusion criteria (prolonged QT-interval, CYP2B6 poor metabolism and high drug abuse potential) and the remaining six were "drop outs" (e.g. due to lack of time to participate or personal circumstances). The volunteers were $23-49$ years old with a mean age of 36 years. None of the volunteers used opioid analgesics regularly at the time of testing.

In order to be eligible to participate in the study, each participant had to meet all of the following inclusion criteria:

- Healthy males or females, in the opinion of the medical supervisor, based on a physical examination, medical history, vital signs, electrocardiogram, and the results of blood chemistry and hematology tests, and urine analysis

- $\quad$ Aged between 23 and 50 years

- Body mass index (weight/length ${ }^{2}$ ) between 19 and $29 \mathrm{~m}^{2} / \mathrm{kg}$

- Possession of a valid driving license for 4 years or more

- Driving experience of at least 5,000 km per year on average

- Good sleeper

Subjects who meet any of the following criteria were excluded from participation in the study:

- Sleep disorders such as insomnia and narcolepsy

- History of or current drug or alcohol abuse

- Current use of psycho-active medication, and inability to stay abstinent during the study

- Excessive alcohol use, defined as drinking more than 14 (females) / 21 (males) units of alcohol per week

- Excessive caffeine use, defined as drinking 5 or more cups of coffee per day

- Smoking more than 10 cigarettes per day

- History or presence of drug/alcohol abuse, including experience with heroin, methadone and buprenorphine 
- Intake of any opioid within 3 months before the study

- Use of any drug that is considered to influence the test drugs, including trade herbal products

- History of severe allergic disease

- History of significant mental, cardiovascular, renal or hepatic disorder, or other significant disease as judged by the investigator

- Positive pre-session urine sample of any of the following substances: ethanol, benzodiazepines, tetrahydrocannabinol, cocaine, amphetamines or opioids

- Poor metabolism due to CYP2B6 polymorphism

- Prolonged QT-interval (history of or presence at screening)

- Use of any drug that is known to inhibit or induce CYP3A4 activity

- Women who are pregnant or breastfeeding

- No use of a reliable contraceptive

All volunteers had to sign an Informed Consent Form at the time of the screening.

Absence of drug abuse or drug abusing potential was important. Each volunteer was screened with regards to drug abuse using the Alcohol Use Disorders Identification Test (AUDIT) and the Drug Use Disorders Identification Test (the DUDIT). Each participant also had to test negative for drugs and alcohol during screening and on test days.

There is reason to believe that in several of the drug driving cases where the driver tests positive for methadone or buprenorphine, neither of the drugs are prescribed. The test subjects in the current clinical study could therefore represent persons outside maintenance treatment with recreational (and occasional) use of these drugs, as well as drug-naïve persons receiving these drugs in relation to pain treatment.

\subsubsection{Drug doses}

On each test day participants received two capsules containing methadone or placebo and two sublingual tablets containing buprenorphine or placebo, according to a double-dummy procedure.

Methadone $5 \mathrm{mg}$, methadone $10 \mathrm{mg}$, buprenorphine $0.2 \mathrm{mg}$, buprenorphine $0.4 \mathrm{mg}$ and placebo were administered in a randomized order. Methadone and buprenorphine doses of 34 
the same magnitude have been administered to opioid-naïve users in previous studies (131134). The dose of methadone frequently used for pain relief is $10 \mathrm{mg}$ per oral 3 times daily (135). Temgesic ${ }^{\circledR}$ (buprenorphine) is used in pain treatment in doses of 0.2-0.4 mg sublingual up to 3-4 times daily (136). A single dose of buprenorphine $0.8 \mathrm{mg}$ sublingual is equivalent to morphine $60 \mathrm{mg}$ per oral, while a single dose of methadone $20 \mathrm{mg}$ per oral is equivalent to morphine $60 \mathrm{mg}$ per oral (137). These doses are considered equivalent with regards to analgesic effects.

Methadone was administered as capsules while buprenorphine was administered as sublingual tablets. Methadone (methadone capsules and placebo capsules) and buprenorphine (buprenorphine sublingual tablets and placebo sublingual tablets) were purchased, blinded and labelled by the University Pharmacy of Nijmegen (the Netherlands) and Tiofarma (Oud-Beijerland, the Netherlands), respectively, according to the Good Manufacturing Practice guidelines. The tablet containers are shown in Figure 9. 


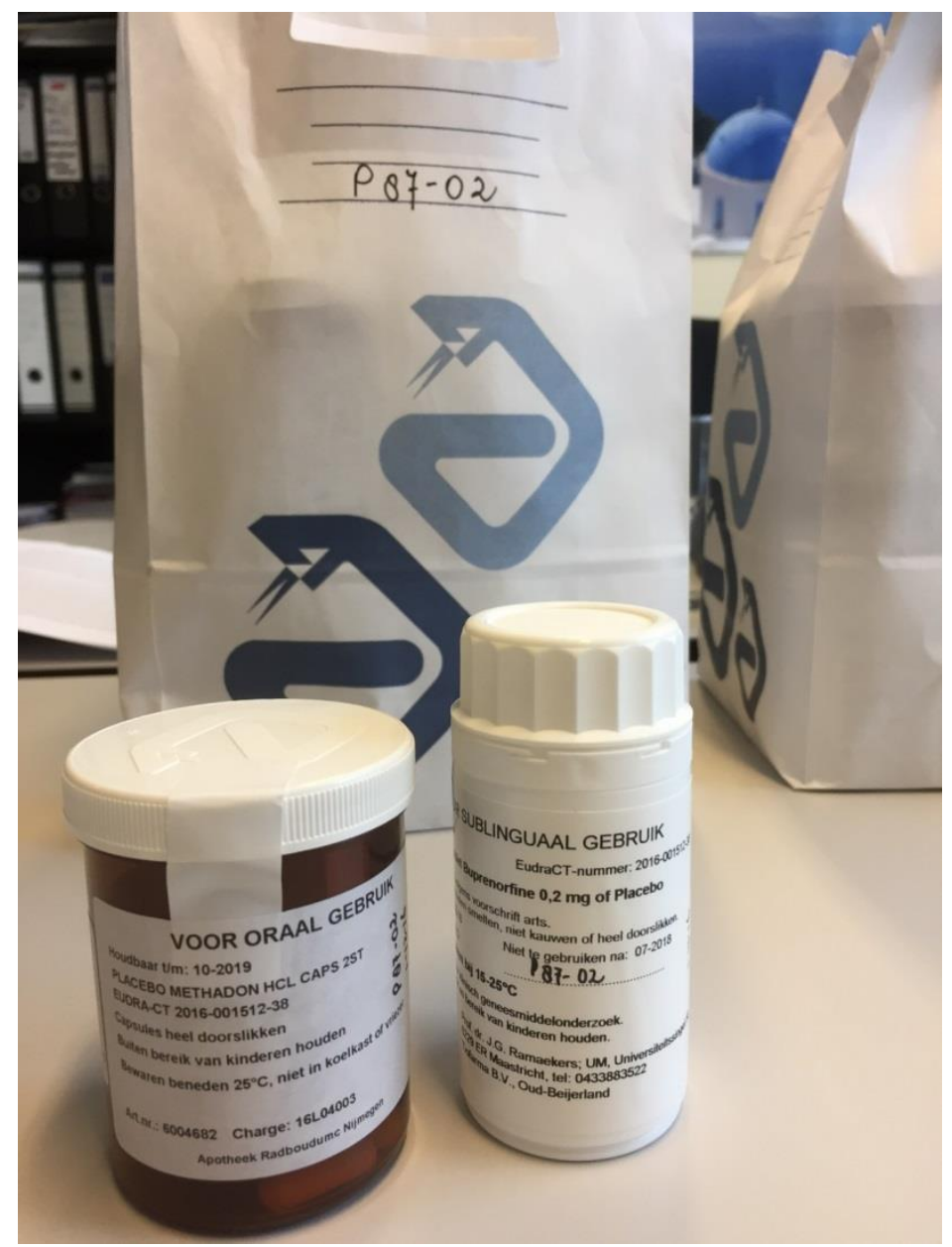

Figure 9 The packaging of the methadone capsules and the buprenorphine tablets before blinding. The tablet containers were masked to hide the information regarding the content. One set of two containers identical to the ones on the photo, containing two capsules and two tablets, respectively, were used for each subject on each test day. (Photo: M. Strand 2016)

\subsubsection{Actual Driving Performance (On-Road Highway Driving Test)} In the On-Road Highway Driving Test (80) the subjects operate a specially instrumented car over a $100 \mathrm{~km}$ primary highway circuit maintaining a constant speed (95 km/h) and a steady lateral position between the delineated boundaries of the right (slower) traffic lane, see Figure 4. An electro-optical device mounted at the back of the car continuously measures lateral distance separating the vehicle and the left lane-line, see Figure 10 and Figure 11. This signal is stored on an on-board computer disk file for later editing and analysis. The offline editing routine involved removal of all data segments that revealed signal loss, disturbance, or occurrence of overtaking maneuvers, see Figure 13 . The remaining data are then used to calculate means and variances for lateral position and 
speed. SDLP (in centimeters) is taken as the primary outcome variable, see Figure 4. SDLP is a measure of road tracking error; in practical terms, it is a composite index of allowed weaving, swerving, and overcorrecting. The test duration is approximately one hour.

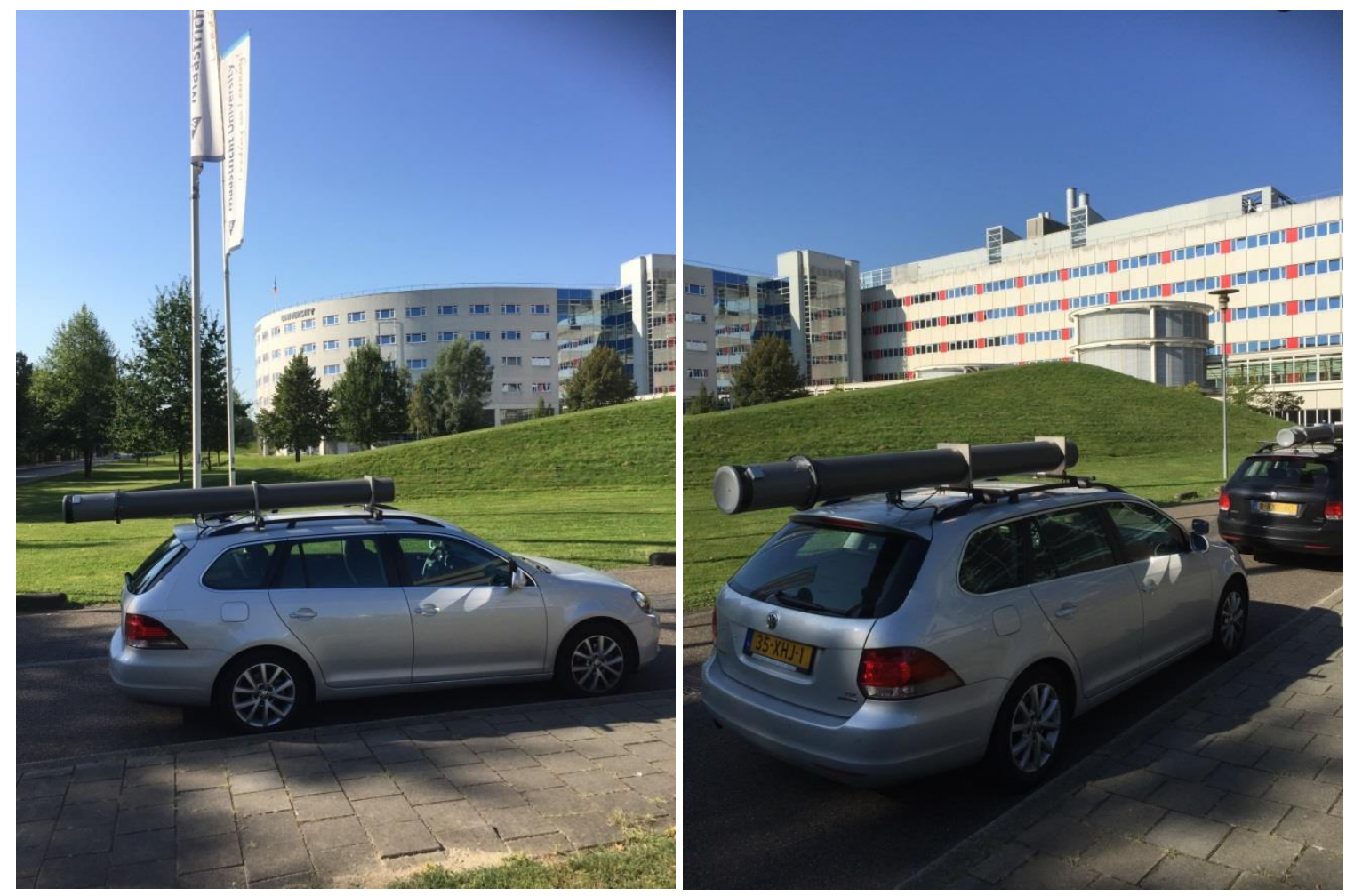

Figure 10 Two of the test cars parked outside the Maastricht University. (Photo: M. Strand 2016) 


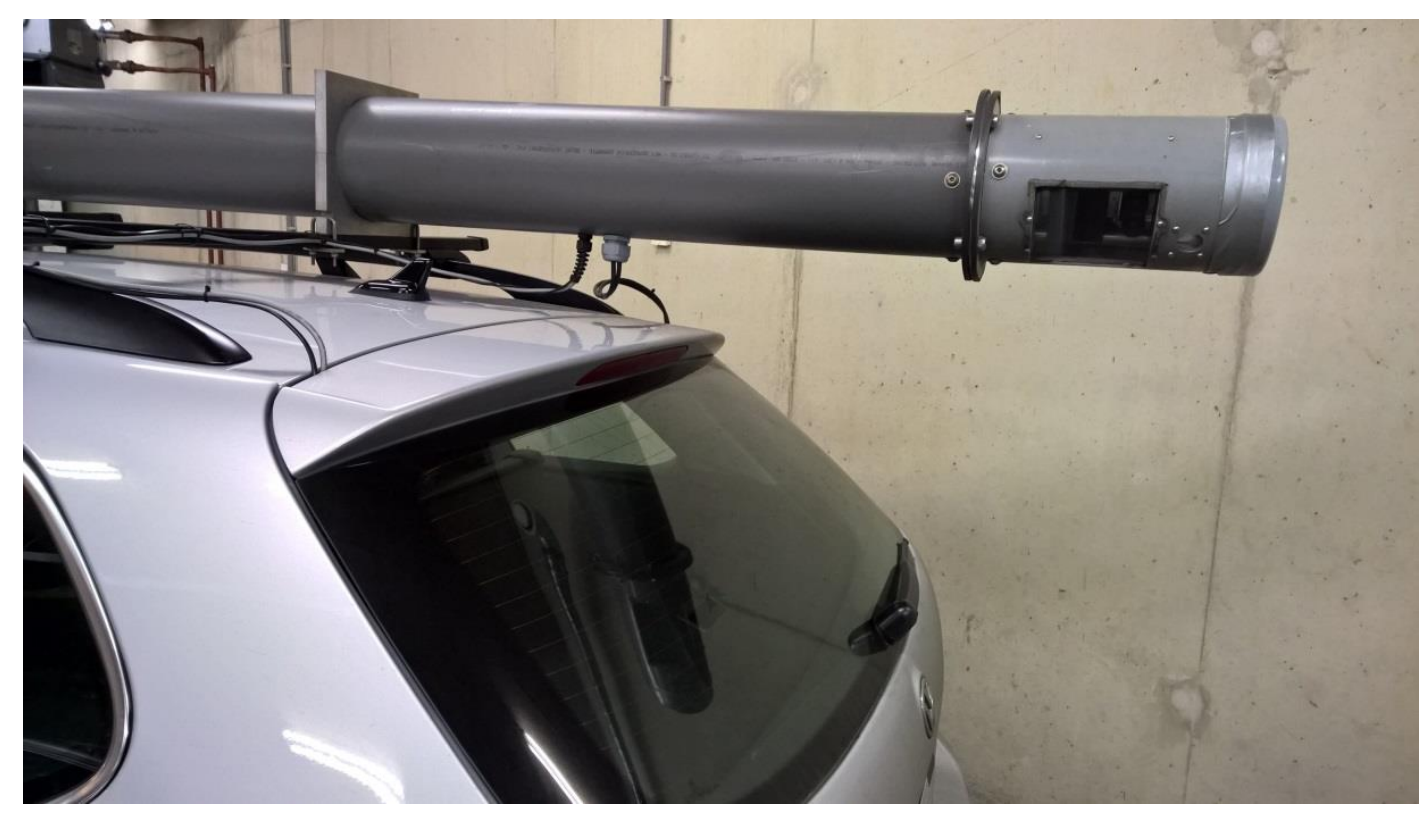

Figure 11 The tube containing the camera measuring the distance to the lane line or the edge line during the highway driving is attached to a car top carrier on the automobile roof. (Photo: H. Gjerde 2016)

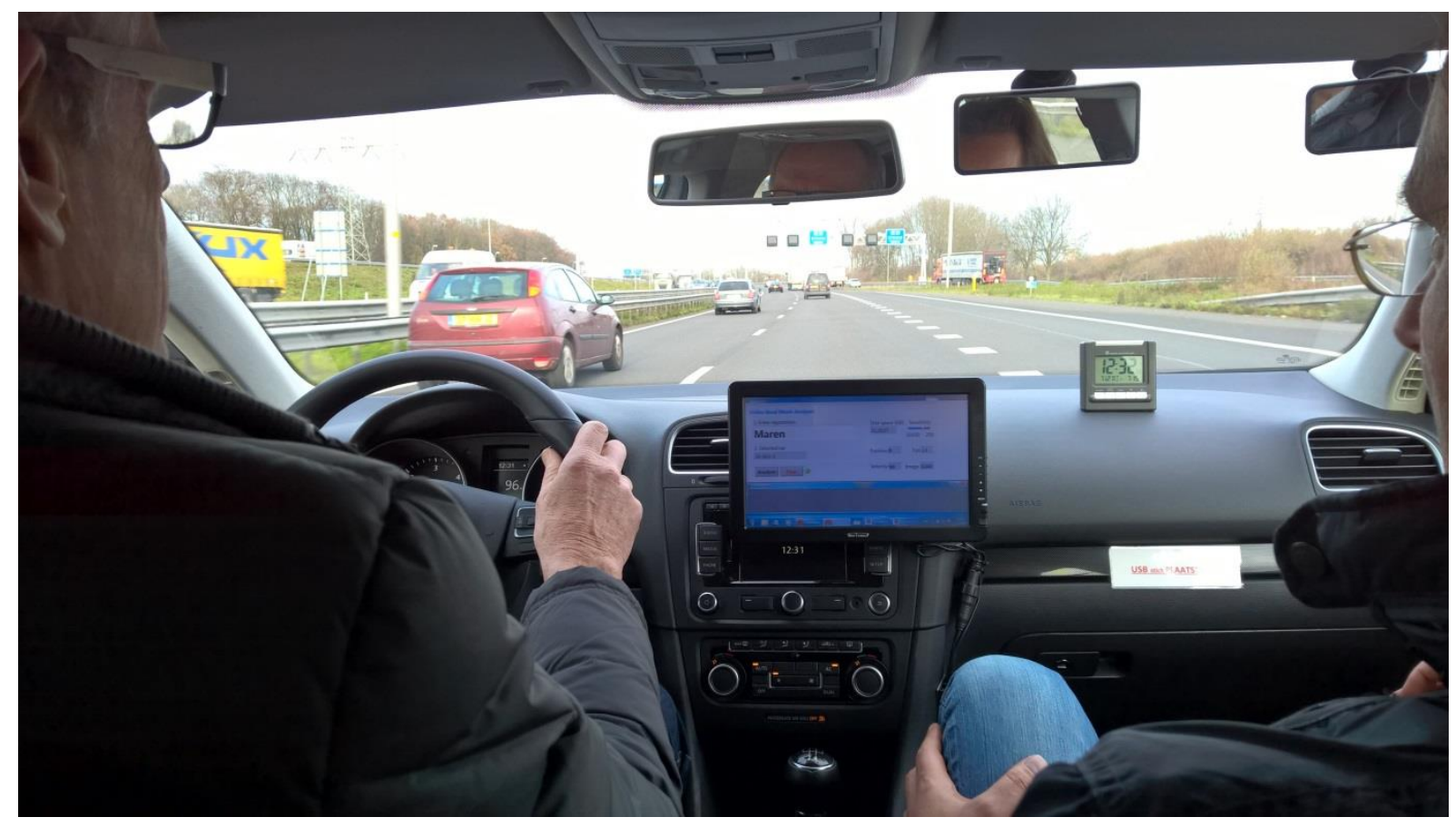

Figure 12 Professor Mørland driving one of the test cars, assisted by Professor Ramaekers, on the test circuit on Highway A2 from Maastricht. (Photo: H. Gjerde 2016) 


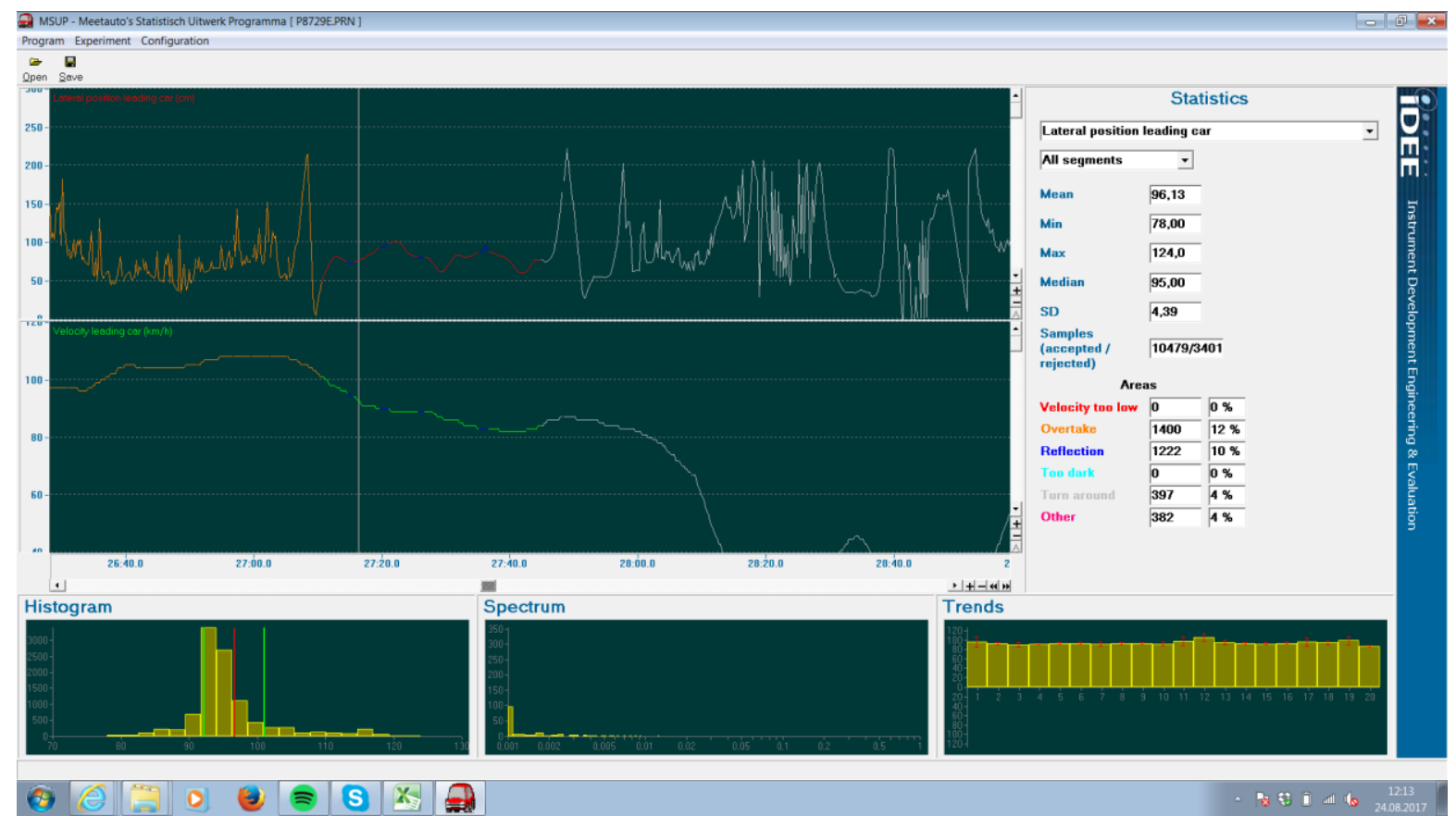

Figure 13 The data from the on-road driving test was manually edited to remove the sections of overtake, turn around, too low velocity and disturbances on the signal caused by reflections. (Screenshot from editing by M. Strand 2017)

\subsubsection{Selected performance Tests}

The selected neurocognitive tests have shown in previous studies to be sensitive to impairing effects of psychoactive substances $(14,93)$.

\subsubsection{Critical Tracking Task (CTT)}

The CTT measured the ability to control an unstable error signal in a first-order compensatory tracking task (138), see Figure 14. This test is designed to measure psychomotor (eye-hand) coordination. Tracking skills are especially important at the operational/control level of driving behavior (e.g., keeping the car in a steady position within the lane). Subjects are instructed to keep an unstable bar in the middle of a horizontal plane by counteracting or reverse its movements with the aid of a joystick. The frequency of cursor deviations at which the subject loses control is the critical frequency. The test comprises five trials. The final score (in rad/s) was determined from the average of all but the lowest and the highest scores in five trials. The test duration was approximately 3 minutes. 


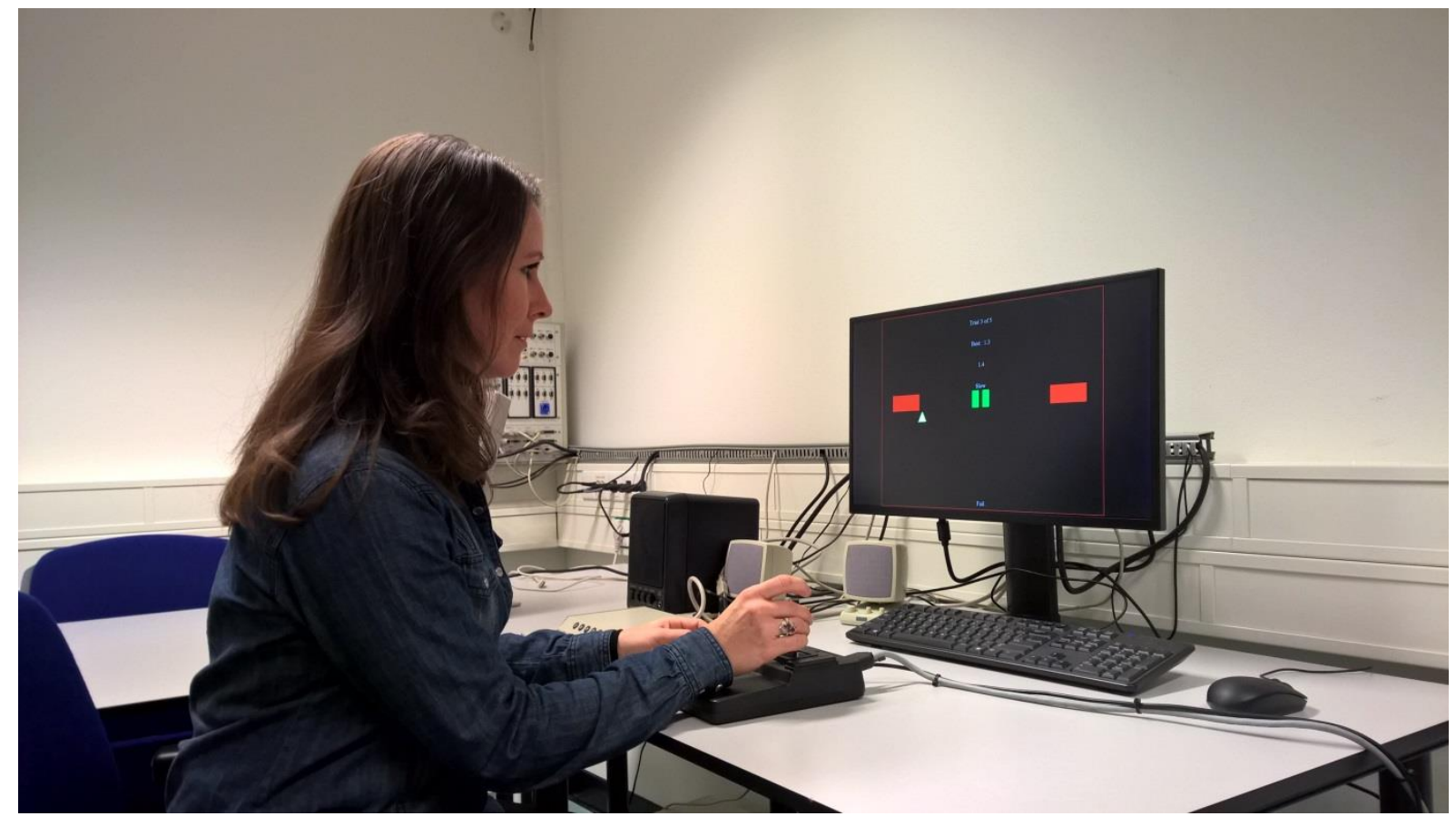

Figure 14 Dr. Vindenes performing the Critical Tracking Task using a joystick to balance the yellow triangle between the green bars on the screen. The test measures psychomotor coordination and is a test of automative behaviour. (Photo: H. Gjerde 2016)

\subsubsection{Divided Attention Task (DAT)}

The DAT measured the ability to divide attention between two simultaneously performed tasks (139). In the primary task, the subject performed the same tracking task described above (CTT), yet at a constant level of difficulty set at $50 \%$ of the participant's maximum capacity. In the secondary task, the subject monitored 24 peripheral displays in which single digits changed asynchronously at 5-s intervals. Subjects were instructed to remove their foot from a pedal as rapidly as possible whenever the digit " 2 " appeared. This signal occurred twice at every location, in random order, at intervals of 5-25 s. Tracking error (DAT-ER, in $\mathrm{mm}$ ) and average reaction time to targets (DAT-RT, in milliseconds), control losses, hits, misses and false alarms were the respective performance measures. The test duration was approximately 20 minutes. Figure 15 shows two volunteers performing the DAT simultaneously in two separate test rooms. 


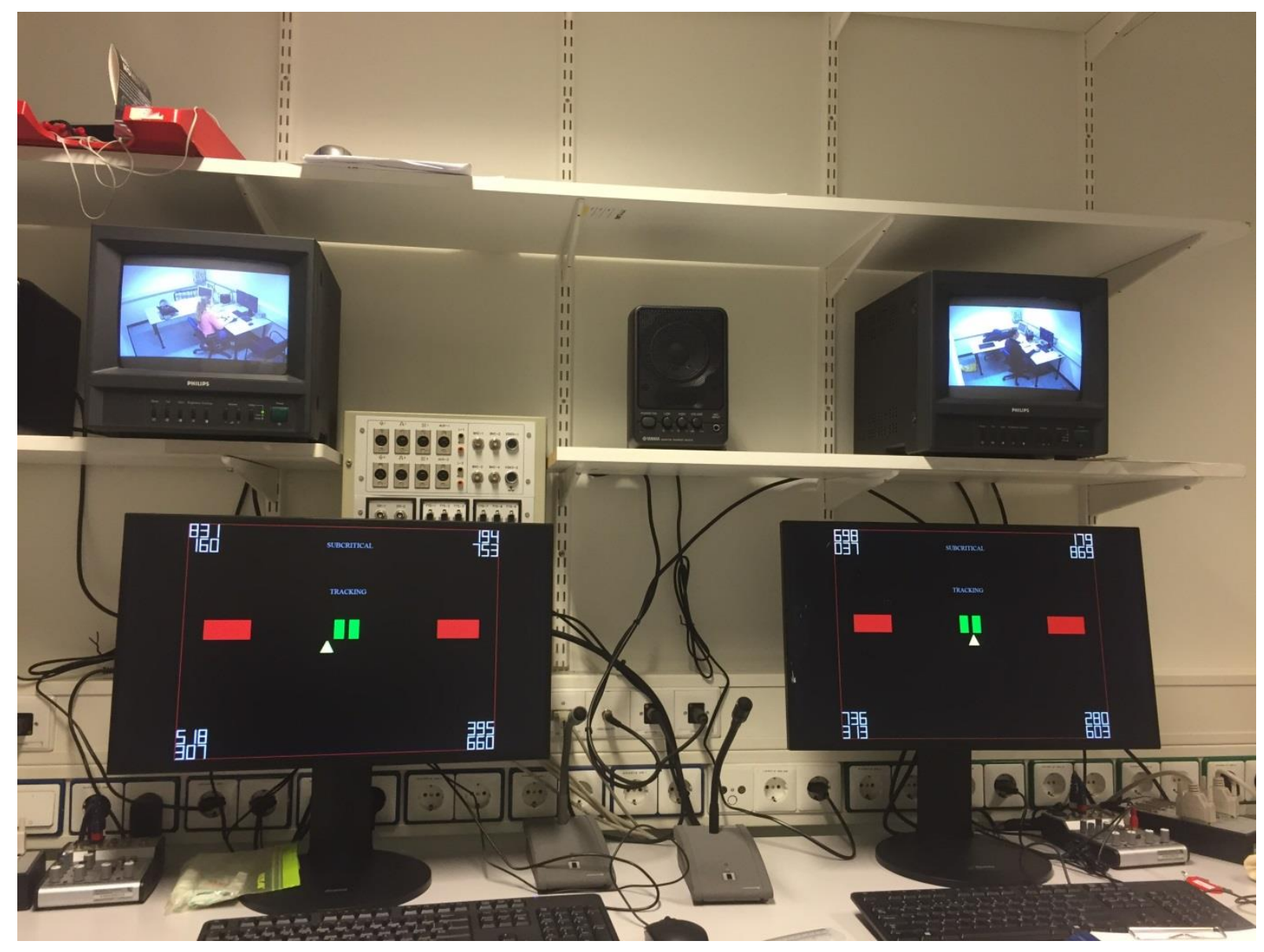

Figure 15 Two participants being monitored while performing the DAT in two separate rooms. The test measures the ability to divide attention between two simultaneously performed tasks and is a test of control behavior. (Photo: H. Gjerde 2016)

\subsubsection{Psychomotor vigilance task (PVT)}

The (PVT) measured sustained vigilant attention by assessing the reaction time in response to a visual stimulus (140). The visual stimulus came from a counter in the center of a computer screen running at random intervals between 2 and $10 \mathrm{~s}$. The subject had to react to the onset of the counter as quickly as possible by pressing a response button, see Figure 16. Duration of the task was 10 minutes. This task has often been used to assess the impact of sleep loss on performance. 


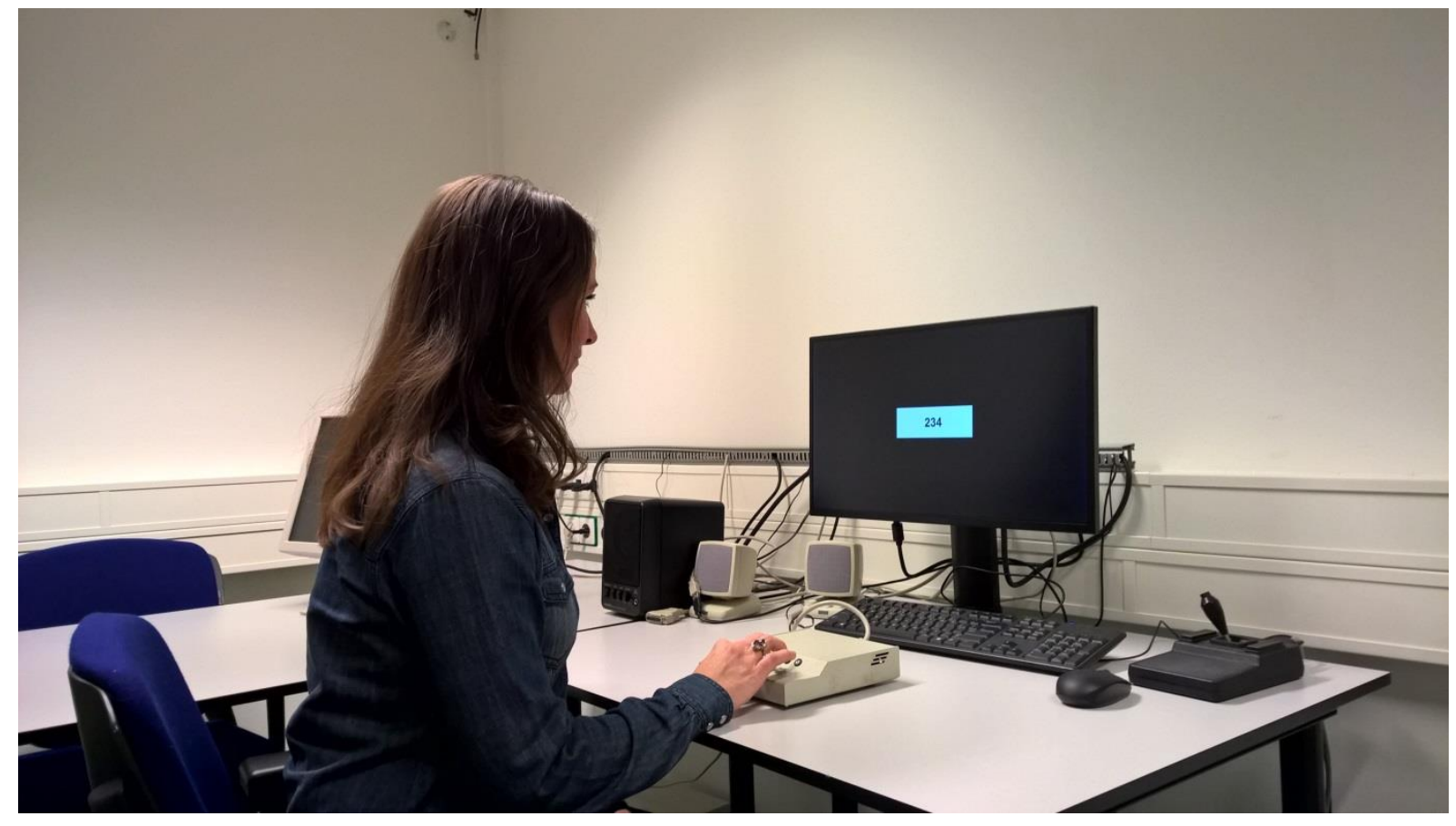

Figure 16 Dr. Vindenes performing the PVT, which measures sustained vigilant attention by assessing the reaction time in response to a visual stimulus and is a test of automative behavior. (Photo: H. Gjerde 2016)

\subsubsection{Digit Symbol Substitution Test (DSST)}

The DSST (141) measured executive attention and processing speed, and is a test of recognition. A computerized version of the original paper-and-pencil test taken from the Wechsler Adult Intelligence Scale was used (142). The subject was shown briefly an encoding scheme consisting of a row of squares at the top of the screen, wherein nine digits were associated randomly with particular symbols. The same symbols were presented in a fixed sequence at the bottom of the screen as a row of separate response buttons. The encoding scheme and the response buttons remain visible while the subject was shown successive presentations of a single digit at the center of the screen. The subject was required to match each digit with a symbol from the encoding list as rapidly as possible by clicking the corresponding response button, using the mouse, see Figure 17 . The number of digits encoded correctly and in total, respectively, within 3 min were the performance measures. 


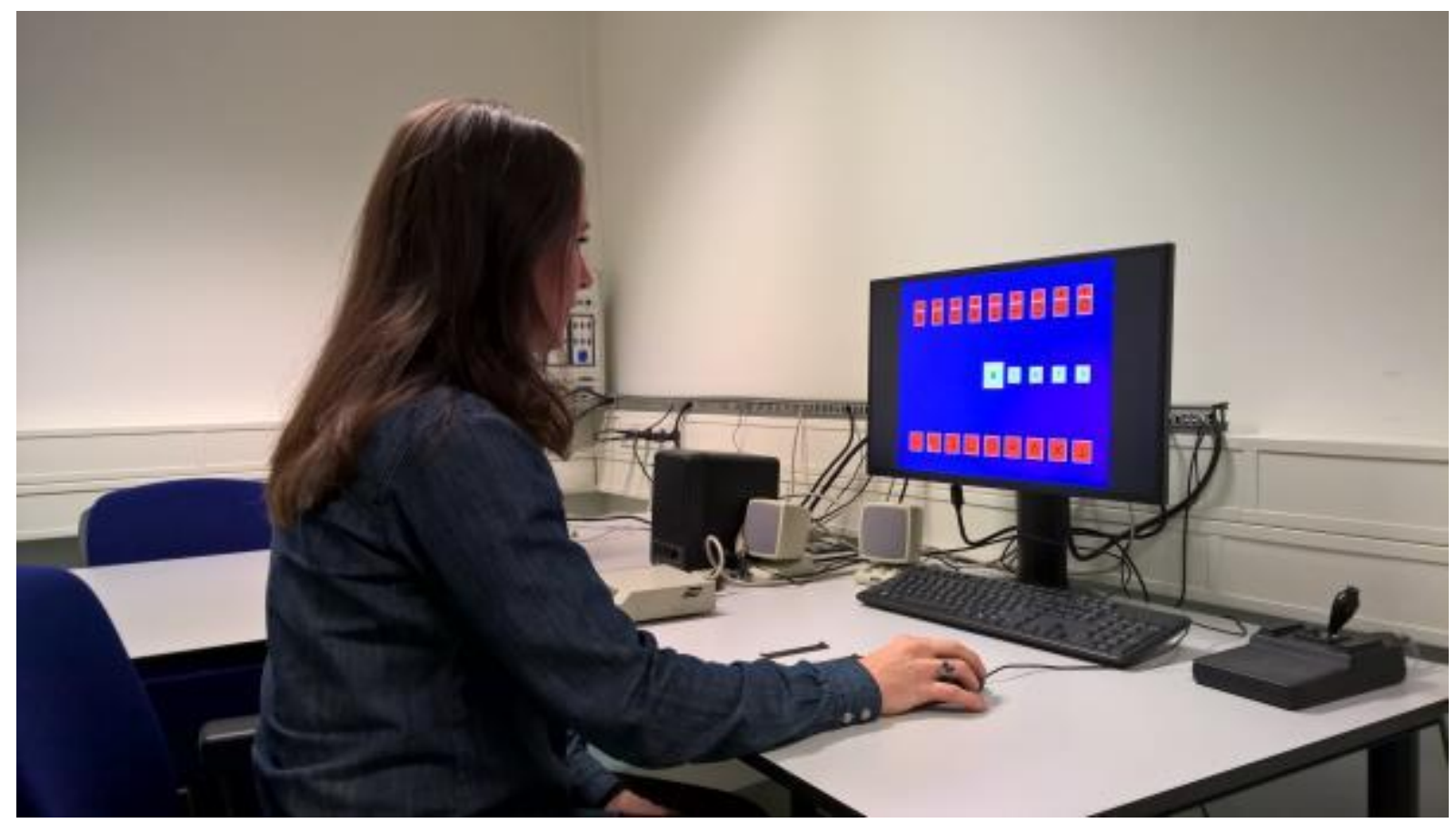

Figure $17 \mathrm{Dr}$. Vindenes performing a computerized version of the DSST. The DSST measures executive attention and processing speed and is a test of executive planning behavior. (Photo: H. Gjerde 2016)

\subsubsection{Ballance Test (PBT)}

Balance was measured using the AMTI AccuSway System for Balance and Postural Sway Measurement (Advanced Mechanical Technology, Inc., Watertown, MA, USA) force platform $(143,144)$. Postural sway is a test of how much you move when trying to stand still and was assessed by measuring the length of the path of the centre-of-pressure (COP), and the area of the $95 \%$ confidence ellipse enclosing the COP (A95), see Figure 18. The test was conducted in two trials: one trial with the subjects' eyes open and one trial with eyes closed, both with feet apart at hip's width. The test duration was 60 seconds for each trial. 

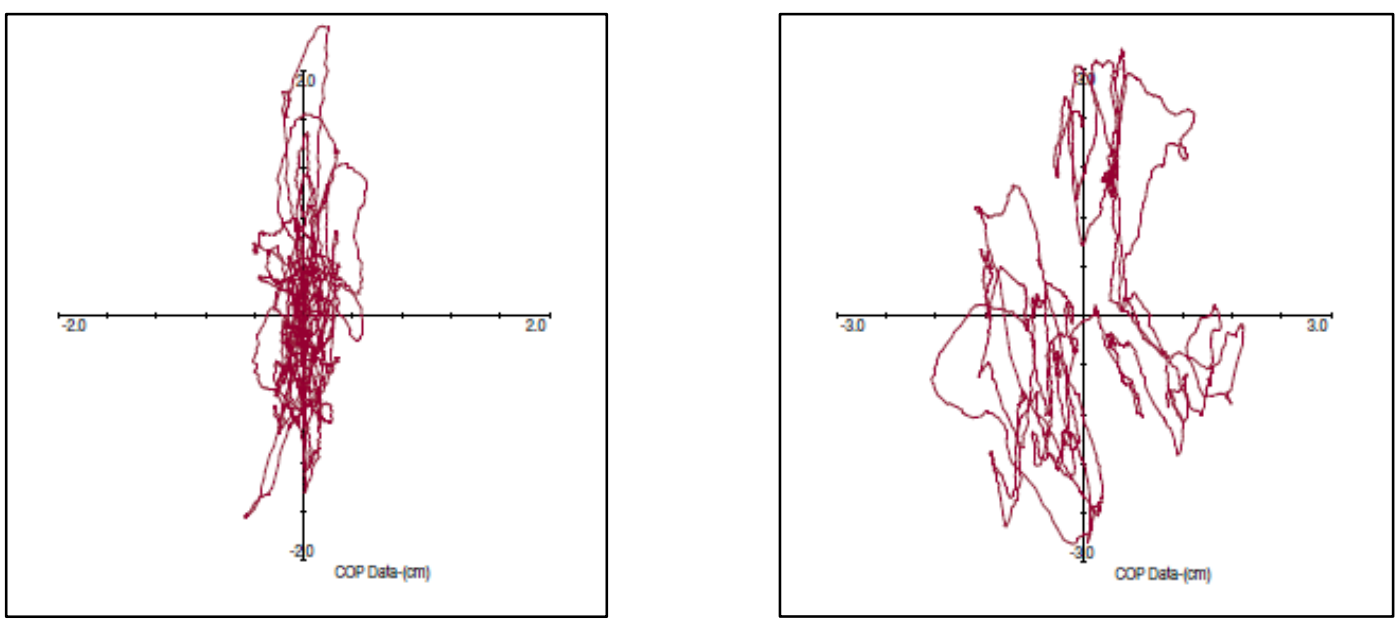

Figure 18 The PBT test measuring the centre-of-pressure (COP) in the placebo morning condition with eyes closed (left panel) and buprenorphine $0.4 \mathrm{mg}$ morning condition with eyes closed (right panel) of subject 9. Postural sway is a test of how much you move when trying to stand still and the figure shows that the subject is swaying more in the drug condition as indicated by the red line. PBT is a test of automative behavior.

\subsubsection{Useful Field of View (UFOV)}

The UFOV (145) was tested by using a computerized version with mouse including three increasingly difficult, visually presented subtests: stimulus identification, divided attention, and selective attention, see Figure 19. The first subtest, which measured processing speed under the lowest demand conditions, required participants to identify a target presented at a central fixation point on the screen. The target (silhouette of a $2 \mathrm{~cm}$ by $1.5 \mathrm{~cm}$ truck or car) was presented on a black background in a $3 \mathrm{~cm} \times 3 \mathrm{~cm}$ fixation box. The second subtest, which measured processing speed for a divided attention task, involved identification of this central target along with localization of a simultaneous peripheral target $(2 \mathrm{~cm} \times 1.5$ $\mathrm{cm}$ silhouette of a car) presented at one of 8 radial locations. The third subtest, which measured processing speed for a selective attention task, included these two tasks, but also included visual distractors (triangles of the same size and luminance as the targets) arranged in concentric circles around the peripheral target. Each trial consisted of four display screens: 1) a fixation box, 2) a test stimulus, 3) a full-field, white-noise visual mask, and 4) a response screen. The white noise visual mask was presented following the stimuli in order to control display duration and to eliminate after images. Measures registered were total detection time per task (1-3) and total detection time all. 


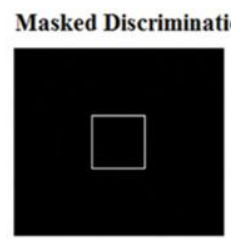

$2000 \mathrm{~ms}$

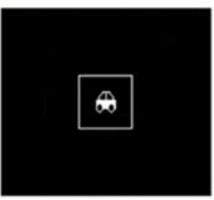

$16.7-500 \mathrm{~ms}$

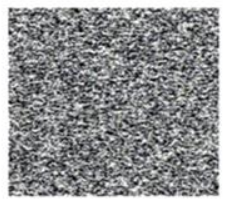

$1000 \mathrm{~ms}$

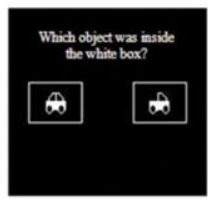

Until response

Divided Attention

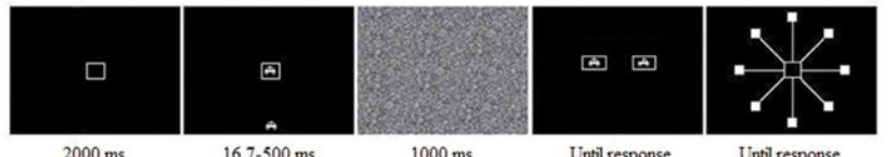

$2000 \mathrm{~ms}$

$16.7-500 \mathrm{~ms}$

$1000 \mathrm{~ms}$

Until response

Until response

Divided + Selective Attention

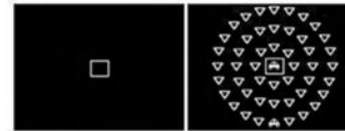

$2000 \mathrm{~ms}$

$16.7 .500 \mathrm{~m}$

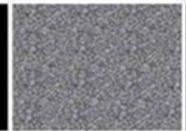

$1000 \mathrm{~ms}$

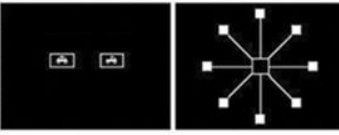

Until response

Until response

From: Relationships Between Divided Attention and Working Memory Impairment in People With Schizophrenia

Schizophr Bull. 2014;40(6):1462-1471. doi:10.1093/schbul/sbu015

Schizophr Bull | ( ) The Author 2014. Published by Oxford University Press on behalf of the Maryland Psychiatric Research

Center. All rights reserved. For permissions, please email: journals.permissions@oup.com

Figure 19 UFOV is a test measuring executive planning behavior. The upper panel shows the first subtest: stimulus identification. The middle panel shows the second subtest: divided attention. The lower panel shows the third subtest: selective attention. Used with permission: Oxford University Press.

\subsubsection{Determination test (DT/S1)}

This test was used to measure 'resilience of attention and reaction speed under conditions of sensory stress'. The task of the respondent was to identify various stimuli and to react to them by pressing the respective corresponding response buttons, using the response panel of the Vienna Test System, see Figure 20. The test was administered as a computerized adaptive test whereby the presentation time of the stimuli adjusts itself to the reaction speed of the respondent. However, unlike classic computerized adaptive tests, this test form presents the stimuli a little faster than would be optimal given the respondents' reaction speed, thus resulting in a condition of sensory stress. Measures registered were median reaction time and number correct. 


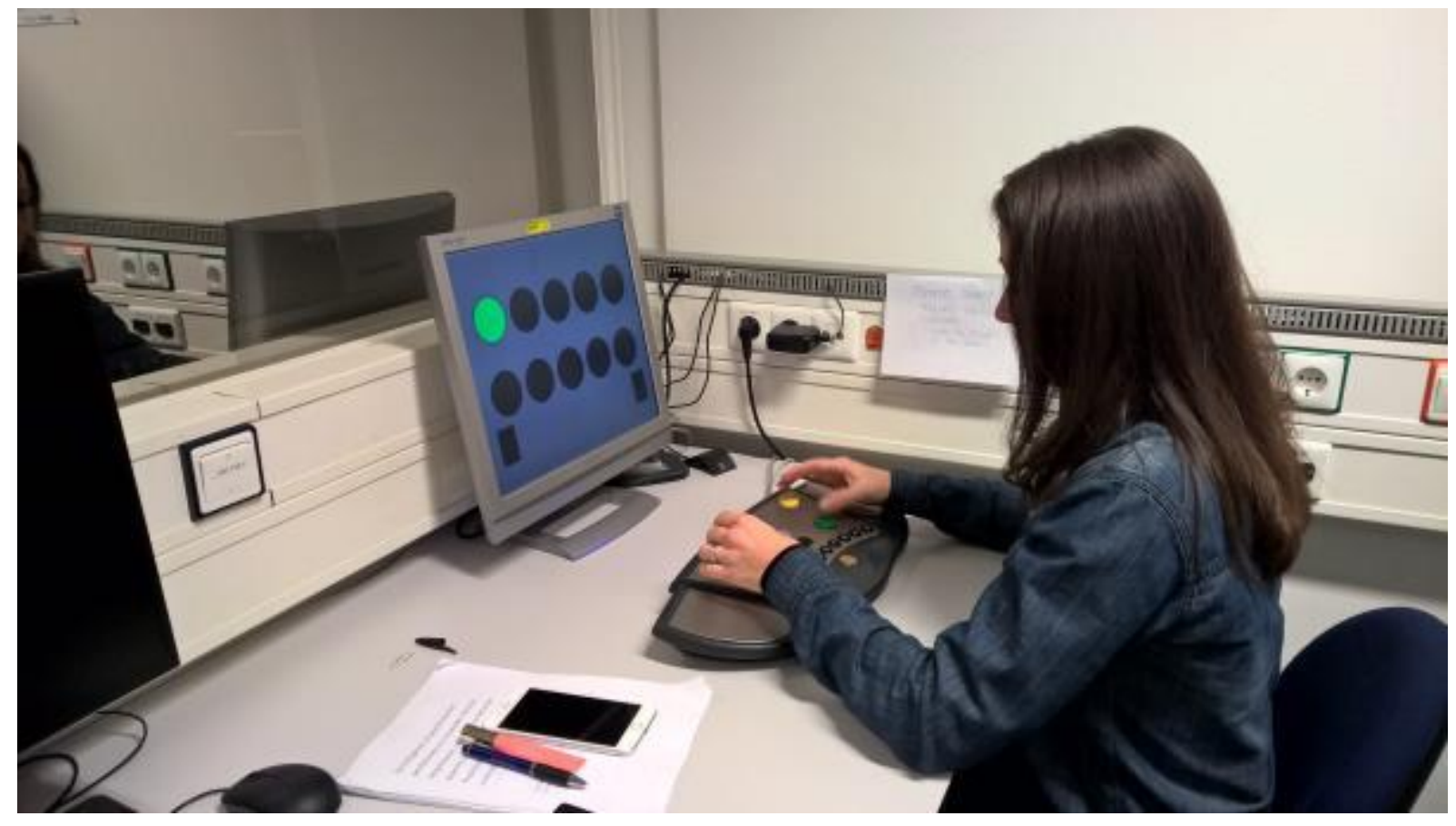

Figure $20 \mathrm{Dr}$. Vindenes performing the Determination test (DT/S1) which measures resilience of attention and reaction speed under conditions of sensory stress and is a test of executive planning behavior. (Photo: H. Gjerde 2016)

\subsubsection{Simplified clinical test of impairment (SCTI)}

The clinical test of impairment (CTI) used by the police in DUI cases in Norway consists of 25 tests and observations related to common signs of drug impairment. Examples are: memory, eyes (pupils, nystagmus, convergence-insufficiency), balance and motor coordination, cognitive function, alertness and appearance (146). After conducting all tests, the physician concludes whether the person is not impaired, lightly impaired, moderately impaired, severely impaired or that it is not possible to make a conclusion. These tests are used in Norway by doctors working for the police with suspects driving under the influence of drugs.

Five subtests from the Norwegian CTI were selected: gait-on-line test, turn-on-line test, finger-to-finger test, finger-to-nose test, and Romberg's test (standing steady on one leg for at least $5 \mathrm{~s}$ with arms stretched out and eyes closed) (147). For each of the five subtests, the performance was measured and scored as either "habitual", "somewhat deviant", or "deviant". The overall impression of the subject, being the sixth subtest, was graded as either "not impaired", "slightly impaired" or "moderately impaired". The volunteers were assessed approximately $1.5 \mathrm{~h}$ after drug intake on each study day. 


\subsubsection{Subjective rating scales}

\subsubsection{Mood Rating Scale (Bond and Lader)}

Subjective evaluations of mood and apparent sedation were assessed by using a series of visual analogue scales $(100 \mathrm{~mm})$ (63). Subjects rated their subjective feelings on a 16 -item mood scale which provided three factor analytically defined summary scores for 'alertness', 'contentedness', and 'calmness'.

\subsubsection{The Karolinska sleepiness scale (KSS)}

The KSS is a subjective rating scale with scores that range from 1, "extremely alert," to 9, "very sleepy, great effort to keep alert, fighting sleep" (62). Participants are instructed to report their experienced sleepiness during the preceding $10 \mathrm{~min}$. Reyner and Horne modified the original scale by adding verbal descriptions to intermediate steps, which do not have any descriptions in the original version (75). The modified scale was used in our study.

\subsubsection{Groningen Subjective Quality of Sleep Questionnaire}

The Groningen Subjective Quality of Sleep questionnaire (76) was filled out at the beginning of a test session to assess the subject's sleep quality and sleep duration of the previous night. This questionnaire scored sleep complaints, ranging from 0 (good sleep) to 14 (bad sleep). The participant could proceed to drug administration and testing with a score $\leq 6$.

\subsubsection{Drug analyses}

The blood and oral fluid samples were collected by trained personnel and stored in a freezer within 15 minutes after sampling. Eventually, all samples were transported on dry ice from Maastricht to Oslo for analyses.

\subsubsection{Blood}

Four blood samples were collected during each test day, see Figure 8, using 5-ml Vacutainer ${ }^{\circledR}$ tubes containing sodium fluoride ( $20 \mathrm{mg}$ ) and sodium heparin (143 IU). Concentrations of methadone and buprenorphine in whole blood were determined by ultra-high-performance liquid chromatography-tandem mass spectrometry (UHPLC-MS/MS) (148); the method was slightly modified for the determination of methadone and buprenorphine by adding relevant calibration standards.

The limit of quantification (LOQ) in blood (defined as the lowest concentration complying with a precision RSD of $15 \%$ ) was $0.15 \mathrm{ng} / \mathrm{mL}$ for methadone and $0.09 \mathrm{ng} / \mathrm{mL}$ for 
buprenorphine, whereas the limit of detection (LOD) was $0.05 \mathrm{ng} / \mathrm{mL}$ for methadone and $0.009 \mathrm{ng} / \mathrm{mL}$ for buprenorphine.

\subsubsection{Oral fluid}

Five oral fluid samples were collected during each test day, see Figure 8, using the Quantisal Oral Fluid Collection Device, which was supposed to collect about $1 \mathrm{ml}$ of oral fluid to be diluted with $3 \mathrm{ml}$ preservation buffer present in the collection device. Drug concentrations in oral fluid-buffer mixtures were determined using ultrahigh-performance liquid chromatography-tandem mass spectrometry (UHPLC-MS/MS) after 96-well supported liquid extraction (149).

All samples were weighed to determine the amount of oral fluid collected (assuming that $1.00 \mathrm{~mL}$ weighs $1.00 \mathrm{~g}$ ), and concentrations in neat oral fluid were calculated. This calculation was done by multiplying the concentration in oral fluid $(\mathrm{ng} / \mathrm{mL})$ by the oral fluid volume $(\mathrm{mL})$ $+3 \mathrm{~mL}$ (amount of buffer) and dividing this by the oral fluid volume $(\mathrm{mL})$.

The LOQ in neat oral fluid was $0.31 \mathrm{ng} / \mathrm{mL}$ for methadone and $0.47 \mathrm{ng} / \mathrm{mL}$ for buprenorphine, whereas the LOD was $0.046 \mathrm{ng} / \mathrm{mL}$ for methadone and $0.07 \mathrm{ng} / \mathrm{mL}$ for buprenorphine.

\subsubsection{Statistics}

\subsubsection{Sample size}

An a priori statistical power analysis using $G^{*}$ power $3(150)$ showed that in order to detect effects of $f=0.25$ of the within subject variable (SDLP) a total of 20 participants would be adequate, using a two-sided $t$-test with $95 \%$ power at a significance level of $5 \%$. This was based on a retest reliability of at least 0.70 as found for unmedicated healthy young and middle-aged participants in previous studies, and an estimated mean increase of $2.4 \mathrm{~cm}$ in SDLP on driving performance of social drinkers while their blood alcohol level was $0.5 \mathrm{mg} / \mathrm{ml}$ in a study by Louwerens and colleagues (16). For balancing purposes, we aimed to include 25 participants.

In addition, we expected a drop-out rate of approximately $10 \%$, which meant that approximately 2 participants might drop-out during screening. Therefore, we needed to recruit a minimum of 27 participants, preferably an equal number of men and women. We continued inclusion until enough participants were included, and eventually ended up with 11 men and 11 women. 
10.2.8.2. Methods to test relationship between measurements

All analyses were conducted using SPSS $^{\circledR}$ Statistics version 25 (IBM Corporation, Armonk, NY, USA).

\subsection{Paper II}

Descriptive statistics for pharmacodynamic and pharmacokinetic parameters included $\mathrm{n}$, mean, and standard error or standard deviation. Statistical summaries were presented by the different conditions (methadone $5 \mathrm{mg}$, methadone $10 \mathrm{mg}$, buprenorphine $0.2 \mathrm{mg}$, buprenorphine $0.4 \mathrm{mg}$ and placebo).

All measures (i.e. the on-road driving test (including SDLP); the neurocognitive tests; the simplified clinical test of impairment; and the subjective measures) were analyzed and compared between methadone $5 \mathrm{mg}$, methadone $10 \mathrm{mg}$, buprenorphine $0.2 \mathrm{mg}$, buprenorphine $0.4 \mathrm{mg}$ and placebo. We were interested in the drug effects within subjects, and not between groups. The global model used was the analysis of variance (ANOVA), i.e. General Linear Model (GLM) - Univariate Measures. This model included two fixed factors, i.e. the factor Treatment (five levels) and the factor Time (two levels), and a random factor for Subject. This analysis was followed by an analysis of the main effect of treatment, separate contrasts between drug treatments and placebo, and a low dose vs. high dose contrast for each opioid. Additionally, a non-inferiority analysis was performed on the SDLP data to determine clinical relevance of drug-induced changes relative to placebo. Noninferiority was concluded if the upper limit of the $95 \% \mathrm{Cl}$ of the mean difference between drug and placebo was $<2.5 \mathrm{~cm}$. A mean change in SDLP of $2.5 \mathrm{~cm}$ represents a clinically relevant level comparable to that of a BAC of $0.05 \%$.

\subsection{Paper III}

Bivariate correlations were used to evaluate associations between opioid concentrations in blood and opioid-induced changes in driving and neurocognitive performance (concentration in blood $x$ performance) relative to placebo. The assumption was a linear concentration-effect relationship. The concentrations measured 3.5 hours after administration were used to calculate correlation with the driving test. The concentrations measured after 2 and 6.5 hours were used to calculate correlation with the neurocognitive tests and subjective evaluations performed in the morning and afternoon sessions, respectively. Correlations were calculated separately for the morning and afternoon sessions 
to take into account if acute tolerance was developed. To calculate drug-induced change relative to placebo, performance scores during placebo were subtracted from performance scores during methadone and buprenorphine treatment, respectively. Because few correlations were found between drug-induced change in performance and drug concentrations in blood, no such calculations were done for oral fluid.

Concentrations of buprenorphine in blood below the LOQ and above the LOD, see also chapter 10.2.7.1, were included when calculating the correlation between drug-induced change in performance and opioid concentrations in blood. Only drug concentrations above the LOQ were used to calculate oral fluid/blood ratios.

\subsubsection{Ethical considerations}

There were several ethical considerations with regards to our clinical study. Potential serious effects are triggering a potential drug abuse in the volunteers causing potential severe side effects from the tested drugs and the risk of traffic crashes during testing.

Methadone and buprenorphine are potent drugs with an addiction risk. Absence of any drug abuse or drug abusing potential in the participants prior to the study was important. Each volunteer was screened with regards to drug abuse using the AUDIT (the Alcohol Use Disorders Identification Test) and the DUDIT (the Drug Use Disorders Identification Test), and urine drug screening was used to test for the presence of drugs.

Many persons may have a negative impression of these drugs, and methadone in particular, relating it to heroin abuse and addiction and to heavy drug users. It was important that the written information was provided in a clear and very understandable manner and that all aspects and risks of the study were described.

Regarding risk assessment, the volunteers received relatively low doses of methadone and buprenorphine similar to the doses administered to opioid-naïve subjects in previous studies. The doses were also in the range of doses given to opioid-naïve subjects for shortterm pain treatment, e.g. after dental surgery. In addition, administration of drugs orally or sublingually has a lower risk of abuse than intravenous use. Genotyping was performed to exclude any poor metabolizers of methadone. Poor metabolizers are shown to have higher 
concentrations of methadone in blood after intake and thereby have a higher risk of side effects or overdosing.

Studies with opioids require a lot of resources as medically trained staff are necessary to assist the study. A medical doctor was present most of the time during the test days, and the testing facilities were close to the university hospital and ER. Treatment with opioid antagonist naloxone was available in case of symptoms of an overdose. All study assistants were instructed to look for signs of an opioid-overdose: lack of consciousness and/or respiratory depression. All female participants had to take a pregnancy test on the morning of every test day, before drug administration.

About 100 studies have been conducted with the on-road driving test over the last 30 years at the Maastricht University (151). The driving instructors accompanying the participants are very experienced and there have never been any accidents. Still, the possibility that an incident could occur is always present. This could be serious and even fatal, both for the participants, the driving instructor and others present on the highway.

Approval for the clinical study was obtained from the independent Ethics Committee of the Maastricht University and the Academic Hospital Maastricht in The Netherlands (Papers II and III: reference number NL57504.068.16 / METC163031) and the Regional Committees for Medical and Health Research Ethics in Norway (Papers II and III: reference number 2012/319 C). The clinical study was conducted according to the code of ethics on human experimentation established by the Declaration of Helsinki (1964) and amended in Fortaleza, Brazil (2013) and in accordance with the Medical Research Involving Human Subjects Act. 


\section{Results}

\subsection{Paper I}

Can Patients Receiving Opioid Maintenance Therapy Safely Drive? A Systematic Review of Epidemiological and Experimental Studies on Driving Ability With a Focus on Concomitant Methadone or Buprenorphine Administration.

Epidemiological studies performed in the 1970's found that methadone-maintained patients (MMPs) did not have an increased crash risk compared to a control group. More recent studies did however find an increased risk of road traffic crash involvement in male patients treated with methadone and an increased odds ratio for being responsible for the crash in injured drivers exposed to either methadone or buprenorphine. It is difficult to draw firm conclusions with regards to crash risk among OMT patients based on the few studies performed.

Previous experimental studies showed that single doses of methadone and buprenorphine to current opioid users or patients in OMT caused impairment in a minority of the tests, and buprenorphine even improved performance in a few tests. MMPs were impaired as compared to controls in approximately half of the tests, while the few studies comparing performance before and after long-term treatment showed both impairment and improvement from baseline measures. One third of the studies on buprenorphine maintained patients (BMPs) showed no difference in performance compared to controls. Furthermore, individuals in BMPs performed somewhat better than individuals in MMPs, but this could be attributed to reasons other than the treatment drug, like previous (drug) history and subject characteristics.

Only a few studies on the performance of healthy volunteers after administration of single doses of methadone or buprenorphine have been performed. The studies reviewed found that both drugs have impairing potential in opioid-naïve subjects, and some dose-dependent effects were observed after both drugs. The results were somewhat difficult to interpret as none of the studies had included a benchmark substance.

The review revealed that there was a complete lack of experimental studies on the effects of methadone and/or buprenorphine on actual on-road driving. In addition, there was a lack of 
experimental studies using comparator drugs, using standardized tests, and studies measuring blood drug concentrations at the time of testing.

\subsection{Paper II}

A clinical trial on the acute effects of methadone and buprenorphine on actual driving and cognitive function of healthy volunteers.

An on-road driving test was used to assess the acute effects of analgesic doses of methadone and buprenorphine on SDLP. Buprenorphine $0.4 \mathrm{mg}$ mildly impaired driving measured by the SDLP. Neither the low dose of buprenorphine $(0.2 \mathrm{mg})$ nor any of the doses of methadone (5 or $10 \mathrm{mg}$ ) had impairing effects on SDLP. Impairment was however apparent at the individual level as four participants stopped their driving tests during methadone or buprenorphine condition due to sleepiness.

Seven computerized tests were used to evaluate neurocognitive function. In addition, questionnaires were used for subjective measurements like sleepiness, alertness and contentedness. Both opioids produced some cognitive and clinical impairments and increased sleepiness, and these effects were more pronounced after the high doses, see Table 1 and Table 3.

Buprenorphine produced more significant effects compared to methadone. More significant effects were observed in the afternoon compared to the morning for both drugs. Side effects were often observed after both drugs; the most frequently reported side effects were nausea, vomiting, dizziness and tiredness/sleepiness.

Drug concentrations in blood showed that the driving test was conducted around $T_{\max }$ with regards to methadone, but after $\mathrm{T}_{\max }$ for buprenorphine.

\subsection{Paper III}

Pharmacokinetics of single doses of methadone and buprenorphine in blood and oral fluid, and correlation with effects on psychomotor and cognitive functions.

Significant correlations were found between some neurocognitive effects, including SDLP, and buprenorphine concentrations in blood. Subjective measurements of sleepiness and alertness also showed a significant correlation. Most of the positive correlations were found in the morning, which coincides with the $T_{\max }$ of buprenorphine, see Table 2 and Table 4. 54 
Significant correlation between neurocognitive effects and methadone concentrations in blood were only found for DSST in the afternoon.

Concentrations of methadone and buprenorphine in blood and oral fluid showed large interindividual variations, and accordingly also the oral fluid/blood concentration ratios. Buprenorphine concentrations in blood were in general very low and were no longer detected in blood 6.5 hours after drug administration. Only one third of the blood samples had buprenorphine concentrations above the LOQ, while nine of the subjects did not have concentrations of buprenorphine above the LOQ after the low dose of buprenorphine $(0.2$ $\mathrm{mg})$.

\subsection{Additional results}

\subsubsection{Summary of results from the clinical study}

The results from the clinical study (reported in papers II and III) regarding dose- and concentration-related effects are summarized in Table 1, Table 2, Table 3 and Table 4. The results have been summarized to give an overview of the findings that were reported in two separate papers. 
Table 1 Summary of results of the clinical study showing the significant effects as compared to placebo (indicated with ${ }^{*}$ ) as well as the significant dose-related effects between low and high doses (indicated with $\ddagger$ ) in the morning and afternoon condition. Bup = buprenorphine, Met $=$ methadone.

\begin{tabular}{|c|c|c|c|c|c|c|c|c|}
\hline \multirow[b]{2}{*}{ Test } & \multicolumn{4}{|c|}{ Morning } & \multicolumn{4}{|c|}{ Afternoon } \\
\hline & $\begin{array}{c}\text { Bup } \\
0.2 \mathrm{mg}\end{array}$ & $\begin{array}{c}\text { Bup } \\
0.4 \mathrm{mg}\end{array}$ & $\begin{array}{l}\text { Met } \\
5 \mathrm{mg}\end{array}$ & $\begin{array}{l}\text { Met } \\
10 \mathrm{mg}\end{array}$ & $\begin{array}{l}\text { Bup } \\
0.2 \mathrm{mg}\end{array}$ & $\begin{array}{l}\text { Bup } \\
0.4 \mathrm{mg}\end{array}$ & $\begin{array}{l}\text { Met } \\
5 \mathrm{mg}\end{array}$ & $\begin{array}{c}\text { Met } \\
10 \mathrm{mg}\end{array}$ \\
\hline SDLP & - & $*$ & - & - & & & & \\
\hline PVT & - & $*$ & - & - & $*$ & $* / \ddagger$ & - & * \\
\hline CTT & - & * & - & - & - & $* / \ddagger$ & - & - \\
\hline DAT & - & $* / \ddagger$ & - & - & $*$ & $* / \ddagger$ & - & $* / \ddagger$ \\
\hline DSST & - & $* / \ddagger$ & - & - & - & $* / \ddagger$ & - & $* / \ddagger$ \\
\hline $\mathrm{DT} / \mathrm{S} 1$ & - & $* / \ddagger$ & - & $* / \ddagger$ & - & $* / \ddagger$ & - & $*$ \\
\hline UFOV & - & - & - & - & - & $*$ & - & $*$ \\
\hline PBT & - & $* / \ddagger$ & - & - & $*$ & $* / \ddagger$ & $* *$ & $*$ \\
\hline $\begin{array}{l}\text { Tests } \\
\text { showing } \\
\text { impairment }\end{array}$ & $0 \%$ & $57 \%$ & $0 \%$ & $7 \%$ & $40 \%$ & $79 \%$ & $7 \%$ & $64 \%$ \\
\hline
\end{tabular}

Table 2 Summary of results of the clinical study showing significant correlations between drug concentrations in blood and impairment levels observed during on-road driving and neurocognitive performance (indicated with ${ }^{*}$ ) in the morning and afternoon

\begin{tabular}{|l|c|c|c|c|}
\hline & \multicolumn{2}{|c|}{ Morning } & \multicolumn{2}{c|}{ Afternoon } \\
\hline Test & Buprenorphine & Methadone & Buprenorphine & Methadone \\
\hline SDLP & $*$ & - & & \\
\hline PVT & $*$ & - & - & - \\
\hline CTT & - & - & - & - \\
\hline DAT & $*$ & - & $*$ & - \\
\hline DSST & $*$ & - & - & $*$ \\
\hline DT/S1 & - & - & - & - \\
\hline UFOV & - & - & - & - \\
\hline PBT & $*$ & - & - & - \\
\hline Tests showing correlation & $47 \%$ & $0 \%$ & $7 \%$ & $7 \%$ \\
\hline
\end{tabular}


Table 3 Summary of results of the clinical study showing significant effects as compared to placebo (indicated with ${ }^{*}$ ) as well as significant dose-related effects between low and high doses (indicated with $¥$ ) of the SCTI, the KSS and the Bond and Lader (B\&L) in the morning and afternoon condition. Bup = buprenorphine, Met $=$ methadone.

\begin{tabular}{|l|c|c|c|c|c|c|c|c|}
\hline & \multicolumn{5}{|c|}{ Morning } & \multicolumn{3}{|c|}{ Afternoon } \\
\hline Test & Bup & Bup & Met & Met & Bup & Bup & Met & Met \\
$\mathbf{0 . 2}$ & $\mathbf{0 . 4}$ & $\mathbf{5}$ & $\mathbf{1 0} \mathbf{m g}$ & $\mathbf{0 . 2}$ & $\mathbf{0 . 4}$ & $\mathbf{5}$ & $\mathbf{1 0}$ \\
$\mathbf{m g}$ & $\mathbf{m g}$ & $\mathbf{m g}$ & & $\mathbf{m g}$ & $\mathbf{M g}$ & $\mathbf{m g}$ & $\mathbf{m g}$ \\
\hline SCTI & & & & & & & & \\
Walk-on-line & - & $*$ & - & $*$ & & & & \\
\hline Gait-on-line & - & - & $*$ & $*$ & & & & \\
\hline Finger-finger-test & - & $* / \ddagger$ & - & $*$ & & & & \\
\hline Finger-nose-test & - & - & - & - & & & & \\
\hline Romberg's test & $*$ & $*$ & - & $*$ & & & & \\
\hline Overall impression & $*$ & $*$ & - & $*$ & & & & \\
\hline KSS & - & $* / \ddagger$ & - & $*$ & $*$ & $*$ & $* *$ & $*$ \\
\hline B\&L Alertness & - & $* / \ddagger$ & - & $*$ & $*$ & $*$ & $* *$ & $*$ \\
\hline Contentedness & - & $*$ & - & - & $*$ & $*$ & - & - \\
\hline Calmness & - & - & - & - & - & $\ddagger$ & - & - \\
\hline Tests showing impairment & $20 \%$ & $70 \%$ & $10 \%$ & $60 \%$ & $75 \%$ & $100 \%$ & $50 \%$ & $50 \%$ \\
\hline
\end{tabular}

Table 4 Summary of results of the clinical study showing significant concentration-related effects (indicated with ${ }^{*}$ ) of the SCTI, the KSS and the B\&L in the morning and afternoon.

\begin{tabular}{|l|c|c|c|c|}
\hline & \multicolumn{2}{|c|}{ Morning } & \multicolumn{2}{c|}{ Afternoon } \\
\hline Test & Buprenorphine & Methadone & Buprenorphine & Methadone \\
\hline SCTI & - & - & & \\
\hline KSS & $*$ & - & - & - \\
\hline B\&L Alertness & $*$ & - & $*$ & - \\
\hline Contentedness & $*$ & - & - & - \\
\hline Calmness & - & - & - & - \\
\hline Tests showing correlation & $30 \%$ & $0 \%$ & $25 \%$ & $0 \%$ \\
\hline
\end{tabular}




\subsubsection{Concentrations of methadone and buprenorphine in blood}

The mean drug concentrations in blood are given with ranges to demonstrate the large inter-individual differences observed in our data, see Table 5, Figure 21 and Figure 22.

Table 5 Mean concentrations (range) of methadone and buprenorphine in whole blood (ng/mL).

\begin{tabular}{|c|c|c|c|c|c|c|c|c|}
\hline $\begin{array}{c}\text { Time after } \\
\text { drug } \\
\text { administration } \\
\text { (hours) }\end{array}$ & $\begin{array}{c}\text { Buprenorphine } \\
0.2 \mathrm{mg} \\
(\mathrm{ng} / \mathrm{mL})\end{array}$ & $\mathbf{n}$ & $\begin{array}{c}\text { Buprenorphine } \\
0.4 \mathrm{mg} \\
(\mathrm{ng} / \mathrm{mL})\end{array}$ & $\mathrm{n}$ & $\begin{array}{l}\text { Methadone } \\
5 \mathrm{mg} \\
(\mathrm{ng} / \mathrm{mL})\end{array}$ & $n$ & $\begin{array}{c}\text { Methadone } \\
10 \mathrm{mg} \\
\text { (ng/mL) }\end{array}$ & $n$ \\
\hline 1 & $\begin{array}{c}0.07 \\
(0.02-0.17)\end{array}$ & 20 & $\begin{array}{c}0.14 \\
(0.02-0.30)\end{array}$ & 21 & $\begin{array}{c}4.5 \\
(0.0-14)\end{array}$ & 19 & $\begin{array}{c}5.9 \\
(0.0-19)\end{array}$ & 20 \\
\hline 2 & $\begin{array}{c}0.10 \\
(0.04-0.18)\end{array}$ & 21 & $\begin{array}{c}0.18 \\
(0.00-0.33)\end{array}$ & 21 & $\begin{array}{c}9.3 \\
(1.0-14)\end{array}$ & 20 & $\begin{array}{c}17 \\
(6.0-35)\end{array}$ & 20 \\
\hline 3.5 & $\begin{array}{c}0.07 \\
(0.01-0.16)\end{array}$ & 22 & $\begin{array}{c}0.13 \\
(0.04-0.22)\end{array}$ & 21 & $\begin{array}{c}11 \\
(6.0-18)\end{array}$ & 20 & $\begin{array}{c}20 \\
(12-30)\end{array}$ & 20 \\
\hline 6.5 & $\begin{array}{c}0.02 \\
(0.00-0.08)\end{array}$ & 21 & $\begin{array}{c}0.04 \\
(0.00-0.09)\end{array}$ & 20 & $\begin{array}{c}8.0 \\
(3.4-12)\end{array}$ & 19 & $\begin{array}{c}16 \\
(10-22)\end{array}$ & 20 \\
\hline
\end{tabular}




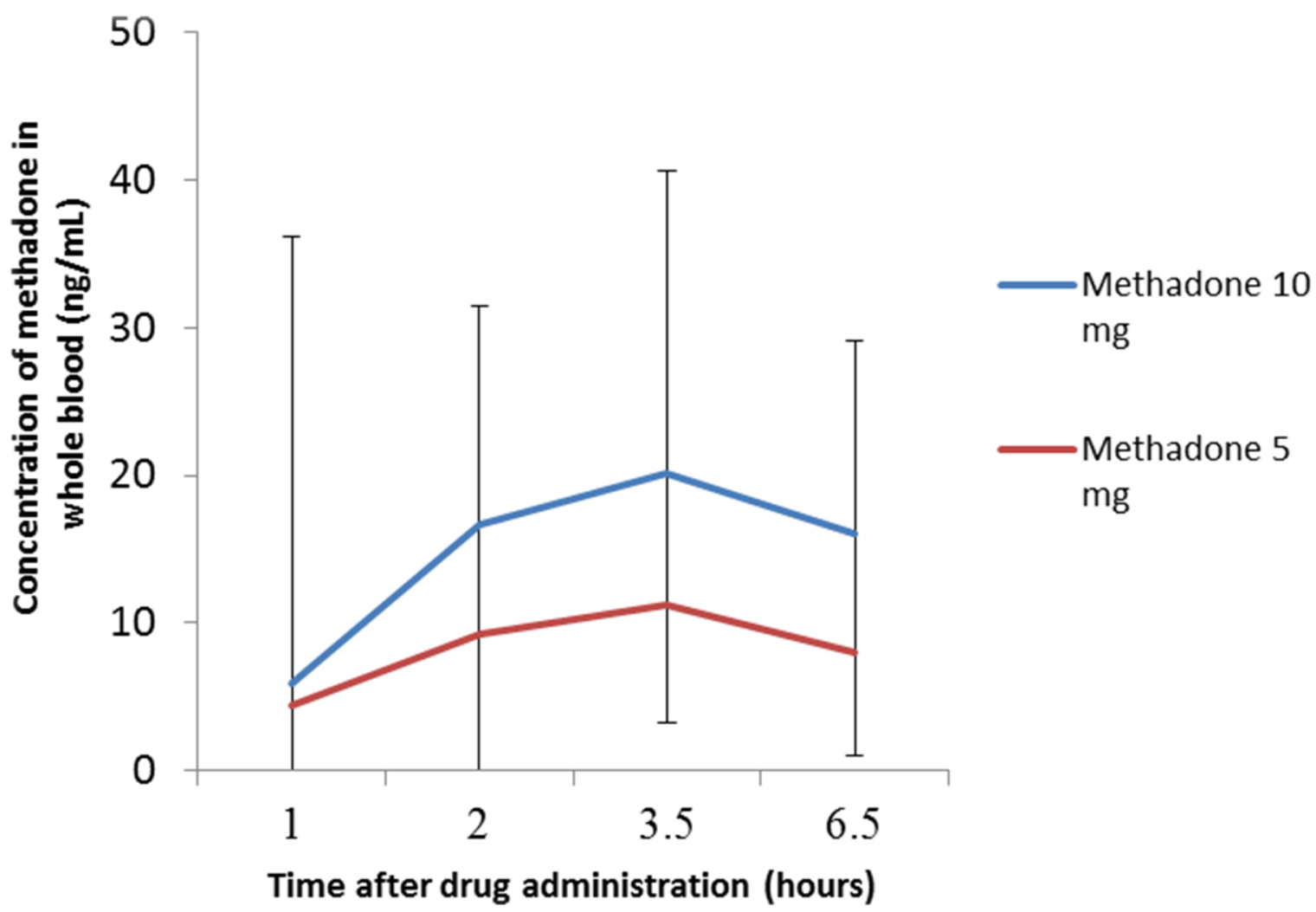

Figure 21 Mean concentrations of methadone in blood after 5 and $10 \mathrm{mg}$, including range for methadone $10 \mathrm{mg}$. The associated concentrations in blood at the time of the neurocognitive tests were measured 2 and 6.5 hours after drug administration in the morning and afternoon, respectively, while the concentrations measured at 3.5 hours were associated with the driving test including SDLP. 


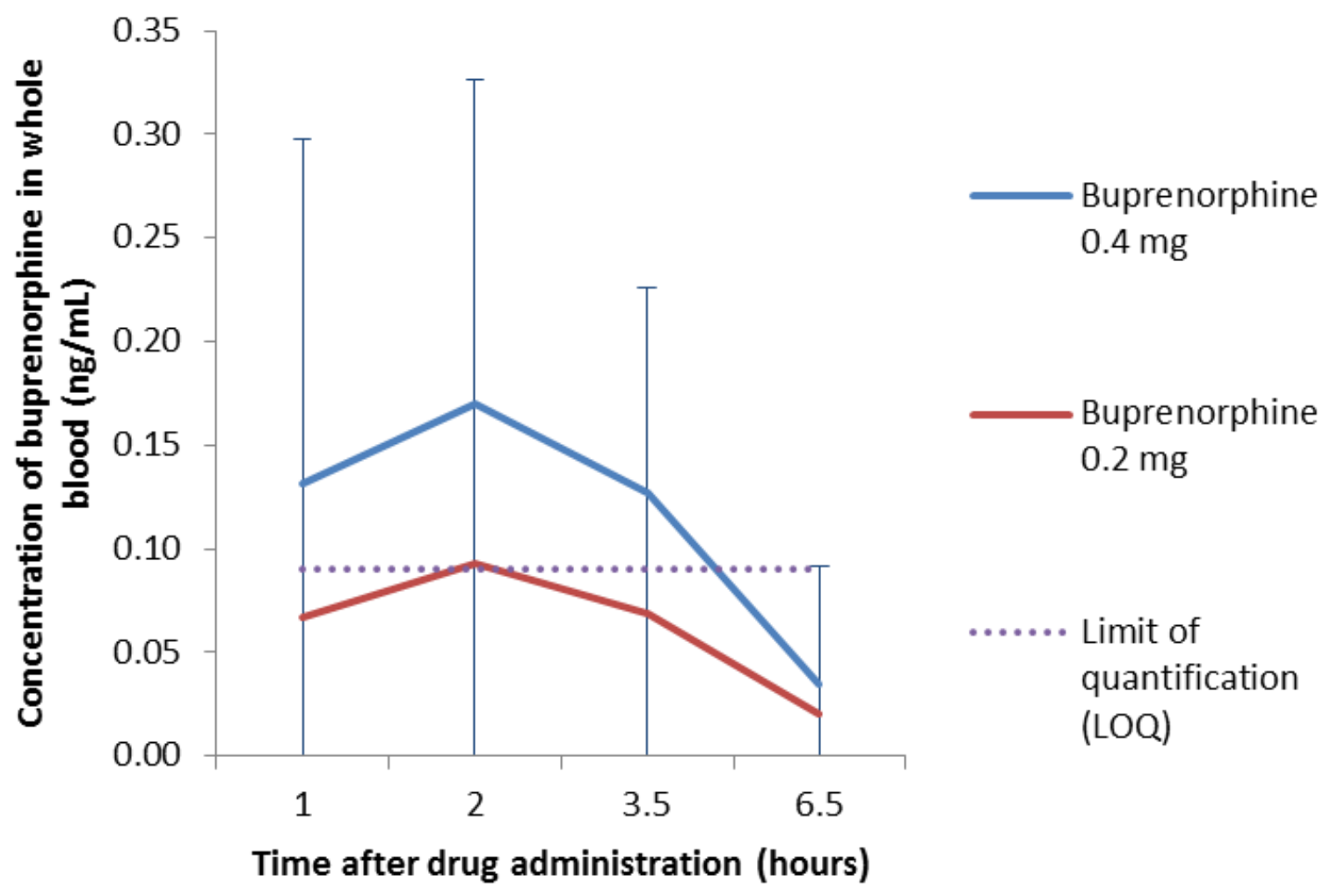

Figure 22 Mean concentrations of buprenorphine in blood after 0.2 and $0.4 \mathrm{mg}$, including range for buprenorphine $0.4 \mathrm{mg}$. Indicated in the figure is also the LOQ of $0.09 \mathrm{ng} / \mathrm{mL}$. The associated buprenorphine concentrations in blood at the time of the neurocognitive tests were measured 2 and 6.5 hours after drug administration for the morning and afternoon, respectively, while the concentrations measured at 3.5 hours were associated with the driving test including SDLP. 


\subsubsection{Predisposing factors for impairment}

I chose to look at two possible factors, i.e. body mass index (BMI) and sex, which could possibly influence concentrations in blood and the degree of impairment. Bivariate correlations were used to evaluate associations between opioid concentrations in blood and sex and BMI, respectively. A significant correlation was found between blood methadone concentrations and sex; analysis showed that females had a higher mean concentration level than men $(r=.263, p=0.019)$. No significant correlation was found between drug concentrations in blood and BMI. Figure 23 show mean methadone concentrations in blood for males, females, $\mathrm{BMI}<24.4$ and $\mathrm{BMI}>24.4$, respectively. Since all mean buprenorphine concentrations in blood were below the LOQ no conclusions could be drawn for buprenorphine.

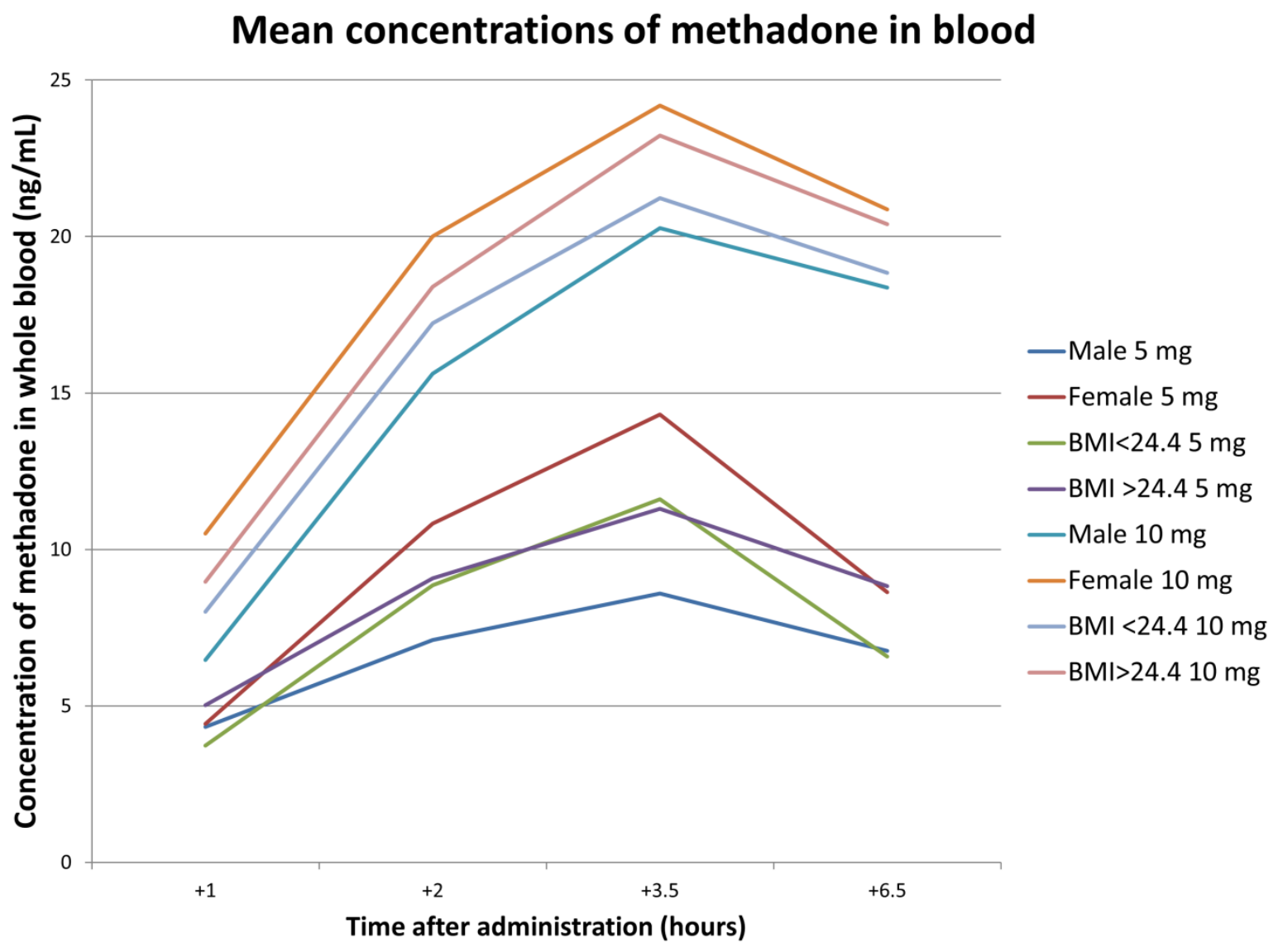

Figure 23 Mean concentrations of methadone in blood for male and females at different BMIs. A significant correlation between concentration of methadone in blood and sex was found. 


\subsubsection{Effect sizes}

Effect sizes (ES) were calculated to determine the magnitude of the effects of the different treatment conditions, using Dunlap's effect size for repeated measures (i.e., tc[2(1-r)/n]1/2) (152) for the DAT, PBT and PVT, see Table 6. Paired samples t-test was calculated for each treatment condition, and the t-value (tc), correlation ( $r$ ) and number of subjects $(n)$ were determined. ES between 0 and 0.2 are considered small, between 0.2 and 0.7 are considered moderate and 0.7 or higher are considered large (153). The ES were compared with the ES of three different levels of BACs (i.e. 0.02, 0.05 and $0.08 \%$ ) that have been investigated in a previous study (92). DAT, PBT and PVT were chosen because they have been shown to be the most sensitive tests to detect impairing effects of alcohol and also to determine the magnitude of the effects of alcohol $(14,92)$.

Table 6 shows that for DAT the low doses of buprenorphine and methadone exceeded the ES of BAC $0.05 \%$, while the ES for the high dose of buprenorphine exceeded the ES of BAC 0.08 $\%$, all treatment conditions were in the afternoon session 6 hours after drug administration. In the "PBT - eyes open" no treatment condition exceeded the ES of BAC $0.05 \%$, while the high doses of both drugs exceeded the ES of BAC $0.05 \%$ in the "PBT - eyes closed" afternoon condition. Finally, the ES of PVT after all treatment conditions in both the morning and the afternoon, except methadone $5 \mathrm{mg}$ in the morning, exceeded the BAC of $0.05 \%$, and the ES of $10 \mathrm{mg}$ methadone (afternoon) even exceeded the ES of BAC $0.08 \%$. 
Table 6 Effect sizes (Dunlap's) of the performance tests DAT, PBT and PVT. The results for three different BAC levels have been published in a previous study and serve as a benchmark substance for our results (92).

Bup $=$ buprenorphine; Met $=$ methadone; $P L A=$ placebo

\begin{tabular}{|c|c|c|c|c|c|c|c|c|}
\hline & $\begin{array}{l}\text { Time of } \\
\text { testing } \\
\text { (h) }\end{array}$ & $\begin{array}{c}\text { PLA } \\
\text { vs } \\
\text { Bup } \\
0.2 \\
\text { mg }\end{array}$ & $\begin{array}{c}\text { PLA } \\
\text { vs } \\
\text { Bup } \\
0.4 \\
\text { mg }\end{array}$ & $\begin{array}{c}\text { PLA } \\
\text { vs } \\
\text { Met } \\
5 \\
\text { mg }\end{array}$ & $\begin{array}{c}\text { PLA } \\
\text { vs } \\
\text { Met } \\
10 \\
\mathrm{mg}\end{array}$ & $\begin{array}{c}\text { PLA } \\
\text { vs } \\
\text { BAC } \\
0.02 \%\end{array}$ & $\begin{array}{c}\text { PLA } \\
\text { vs } \\
\text { BAC } \\
0.05 \%\end{array}$ & $\begin{array}{c}\text { PLA } \\
\text { vs } \\
\text { BAC } \\
0.08 \%\end{array}$ \\
\hline \multirow[t]{3}{*}{$\begin{array}{l}\text { DAT } \\
\text { Reaction time (ms) }\end{array}$} & & & & & & 0.34 & 0.39 & 0.65 \\
\hline & +2 & 0.02 & 0.37 & 0.06 & 0.37 & & & \\
\hline & +6 & 0.59 & 0.82 & 0.41 & 0.37 & & & \\
\hline \multirow[t]{3}{*}{ PBT - Eyes open } & & & & & & 0.39 & 0.77 & 1.5 \\
\hline & +2 & 0.02 & 0.48 & -0.10 & 0.25 & & & \\
\hline & +6 & 0.39 & 0.52 & 0.31 & 0.71 & & & \\
\hline \multirow[t]{3}{*}{ PBT - Eyes closed } & & & & & & 0.22 & 0.62 & 0.96 \\
\hline & +2 & 0.08 & 0.45 & 0.18 & 0.09 & & & \\
\hline & +6 & 0.46 & 0.82 & 0.38 & 0.73 & & & \\
\hline \multirow[t]{3}{*}{$\begin{array}{l}\text { PVT } \\
\text { Reaction time (ms) }\end{array}$} & & & & & & 0.16 & 0.31 & 0.68 \\
\hline & +2 & 0.34 & 0.37 & -0.06 & 0.37 & & & \\
\hline & +6 & 0.60 & 0.63 & 0.44 & 0.73 & & & \\
\hline
\end{tabular}




\section{Discussion}

\subsection{Appraisal of the main findings}

\subsubsection{The current knowledge regarding crash risk and impairing effects on}

driving after administration of methadone and buprenorphine

\subsubsection{Epidemiological studies on crash risk}

The review published in Paper I included five epidemiological studies of traffic risk after exposure to methadone or buprenorphine. The first epidemiological studies on traffic risk were conducted from 1973 to 1977 (154-156). All of these studies showed that there was no difference in accident involvement and seriousness of convictions between methadonemaintained patients and drivers in the control groups. The next epidemiological study was published in 2010 (157), more than 30 years later. The study showed an increased odds ratio for culpability but no association between exposure to methadone and buprenorphine and road traffic crash. Other studies on chronic use of opioids and traffic risk that have been published in recent years support an increased risk of crash culpability in users of methadone and buprenorphine (26) and an increased risk of traffic accident involvement in male methadone users (24).

It is interesting that there is a long time gap between the published epidemiological studies. Methadone-maintained patients and patients with chronic opioid use have been driving during the whole period and traffic crash risk has been studied for several other drugs during this period. One possible explanation for this lack of studies might be that it was not considered necessary to follow up three different studies that all showed no increase in accident involvement among methadone-maintained patients. Another reason could be that driving during OMT and chronic opioid use was considered a marginal problem. The different results between the studies from the 1970's and the more recent studies could however be attributed to methodological differences as discussed in chapter 12.2.1.

\subsubsection{Experimental studies on impairing effects of drugs}

Our review included 54 experimental studies on performance of OMT patients and opioidnaïve subjects after single doses of methadone or buprenorphine. It was not possible to perform a meta-analysis due to the low number of studies included. 
The results showed that methadone and buprenorphine caused some degree of impairment in opioid-tolerant subjects in OMT. This indicates that treatment with both drugs can harm safe driving. On the other hand, impairment was only revealed in a small fraction of the tests, and in some studies improved performance of tests was found. This could indicate that the majority of patients in OMT are fit to drive. It is, however, worth noting that the improvement of neurocognitive performance observed in some OMT patients are not necessarily due to drug effects, but could be attributed to other reasons, e.g. a general improvement of performance following stabilization after treatment and follow-up. It can be difficult to determine the level of impairment acceptable in road traffic for OMT patients compared to other patient groups, or even normal variation in the general driving population. The studies do not provide evidence that there are subgroups with specific characteristics that are more or less fit to drive; i.e. there were no differences between groups when they were classified in long-term versus short-term treatment or high versus low daily dosage. Based on the current knowledge, where considerable individual differences were observed in experiential studies, an individual assessment of fitness to drive is considered to be the best approach to patients in OMT with regards to the ability to drive.

We found that no experimental studies had been performed to study the acute effects of single doses of methadone and buprenorphine on actual on-road driving in healthy volunteers. Furthermore, the previously performed studies had several shortcomings: there was no use of a benchmark substance; few pharmacokinetic measurements were performed; and the tests were not standardized to reveal driving related impairment.

Only eight studies were performed after administration of single doses of methadone and buprenorphine to healthy volunteers. One of the studies was published in 2008 , the remaining studies were from 1997 or older. Similar to the epidemiological studies, the reason for this time gap is probably that the topic was considered a minor problem. Presumably there is a small group of opioid-naïve persons that get opioids prescribed. Driving related impairment is therefore only relevant to very few persons, either when initiating treatment with opioids or during short-term treatment. In the case of short-term 
treatment, e.g. after oral surgery, it is recommended to abstain from driving during the few days of treatment.

Methadone and buprenorphine are not first choice analgesics to opioid-naïve patients, and the question of fitness to drive in relation to such treatment is thus not frequent. Even so, few studies have been conducted to investigate whether these drugs induce traffic impairment, and both drugs are frequently seen in drivers suspected for driving under the influence of drugs. In tolerant subjects the question of impairment will highly rely on the degree of tolerance. Several studies suggest that there are few impairing effects of opioids in opioid-dependent or tolerant patients $(88,158)$.

\subsubsection{Do methadone and buprenorphine cause traffic relevant impairment and is} there a dose- and/or concentration-effect relationship for methadone and buprenorphine?

Previous experimental studies have shown that methadone and buprenorphine have acute impairing effects on driving related skills, and our results from the clinical study are in line with this. An evidence table with a summary of the results from the experimental studies included in the review is shown in Paper I (Table 5). Previous studies have shown a significant decrease in performance of the DSST after buprenorphine administration (134, $159,160)$. We found dose-dependent effects and concentration-effect relationship for the DSST after administration of both methadone and buprenorphine. Buprenorphine has been shown to impair tests of reaction time, while methadone has been shown to induce doserelated impairment of reaction time. We found that buprenorphine alone impaired reaction time (PVT and DAT) in both a dose-dependent and a concentration-related manner. We also confirmed that buprenorphine caused significant impairment on tests of attention.

\subsubsection{Methadone}

No effect was seen on the SDLP after methadone 5 and $10 \mathrm{mg}$, and no correlation between drug concentration in blood and effect was found for the driving test. We did observe some effects on the neurocognitive tests, especially at the higher dose, indicating that methadone has impairing effects on some parts of driving-relevant behavior. However, no correlation was found between methadone concentration in blood and effects on the neurocognitive tests. 
Table 1 shows that methadone $10 \mathrm{mg}$ impaired $64 \%$ of the tests including subtests in the afternoon but only $7 \%$ in the morning. With regards to the clinical relevance of the results, it seems like the high dose of methadone causes impairment in most tests performed and even caused effect sizes exceeding those following a BAC of $0.05 \%$ in a few tests, see Table 6. The question remains whether the impairing effects of methadone would have been more pronounced if higher doses were administered.

The impairing effects of the high dose of methadone on neurocognitive tests were not observed in significant changes in SDLP during on-road driving. However, two driving tests were prematurely terminated after administration of the high dose of methadone, indicating a notable individual variation in impairment levels.

\subsubsection{Buprenorphine}

Buprenorphine $0.4 \mathrm{mg}$ was the only treatment condition that caused significant impairment of the SDLP as compared to placebo. The mean SDLP increase did not exceed the $+2.5 \mathrm{~cm}$ threshold for impairment comparable to a BAC of $0.05 \%$ (i.e. clinical relevance criterion), but the $\mathrm{Cl}$ of the mean change in SDLP $(+2.49 \mathrm{~cm})$ almost included the $+2.5 \mathrm{~cm}$ threshold. However, a correlation was found between concentration of buprenorphine in blood and change in SDLP. The results show that there is a concentration-dependent effect of buprenorphine on the SDLP of the driving test, at least in lower concentration levels such as those measured in our study. Furthermore, the driving test was prematurely terminated on two occasions after administration of the high dose and one occasion after the low dose, indicating significant individual variation in impairment levels.

Buprenorphine $0.4 \mathrm{mg}$ significantly impaired the driving test. Furthermore, impairment was observed after the same dose in $57 \%$ and $79 \%$ of the neurocognitive tests including subtests in the morning and afternoon, respectively. Concentration-effect correlation was observed in $47 \%$ of the tests in the morning, around $\mathrm{T}_{\max }$.

Buprenorphine additionally impaired most of the neurocognitive tests performed. The tests include all three levels of behavior recommended for research to assess driving related drugimpairment. Dose-dependent impairment was observed for most tests when performed in the afternoon, and for some in the morning, see Table 1. Concentration-effect correlations were seen in most of the tests when measured in the afternoon, see Table 2. 
With regards to the clinical relevance of the results from the neurocognitive tests, it can be stated that both the number of tests showing impairment as well as the effect size calculated (for three of the tests) shows that buprenorphine causes impairment of skills related to driving. The effect sizes were comparable to a BAC of $0.05 \%$ for at least some of the tests. It could, however, have been useful to calculate the effect size for all tests performed in our study. In conclusion, it seems that even low doses of buprenorphine are potent when administered to opioid-naïve subjects, and that buprenorphine has impairing effects of relevance to driving skills.

\subsubsection{More pronounced effects in the afternoon condition}

The effects on the neurocognitive tests and the subjective measures were more pronounced in the afternoon as compared to the morning, see Table 1 and Table 3. We observed that $T_{\max }$ for buprenorphine occurred around 2 hours after drug administration, while $T_{\max }$ for methadone was seen after around 3.5 hours. Consequently, all of the tests measured in the afternoon were performed at decreasing drug concentrations in blood, i.e. after the $C_{\max }$. There could be several possible explanations for the observed delay in effect as compared to the $C_{\text {max }}$ : increasing sleepiness during the test day; hysteresis due to time to drug crossing the blood-brain barrier or time to receptor-binding; or effects of active metabolites.

Buprenorphine $0.4 \mathrm{mg}$ impaired the driving test and all of the neurocognitive tests in the afternoon, see Table $1 . C_{\max }$ was observed 2 hours after drug administration. At the time of the testing in the afternoon, the drug concentrations of buprenorphine were below the LOQ, i.e. more pronounced effects were found with descending concentrations.

The increasing percentage of significant effects on neurocognitive tests and subjective measures for both methadone and buprenorphine were not associated with higher drug concentrations in blood. All treatment conditions caused sleepiness and reduced alertness in the afternoon. This could explain the more pronounced effects on neurocognitive tests in the afternoon.

An alternative explanation to the delay in effect as compared with the drug concentrations in blood can be explained by a hysteresis plot, see Figure 24. Hysteresis in drug response means that there is a time delay between the measured drug concentration and the effect response. Buprenorphine hysteresis has previously been described $(161,162)$. Our findings 
suggest a counter-clockwise hysteresis loop for buprenorphine. The most common reasons for counter-clockwise hysteresis lagging is limited access to the receptor site or slow receptor kinetics (163).

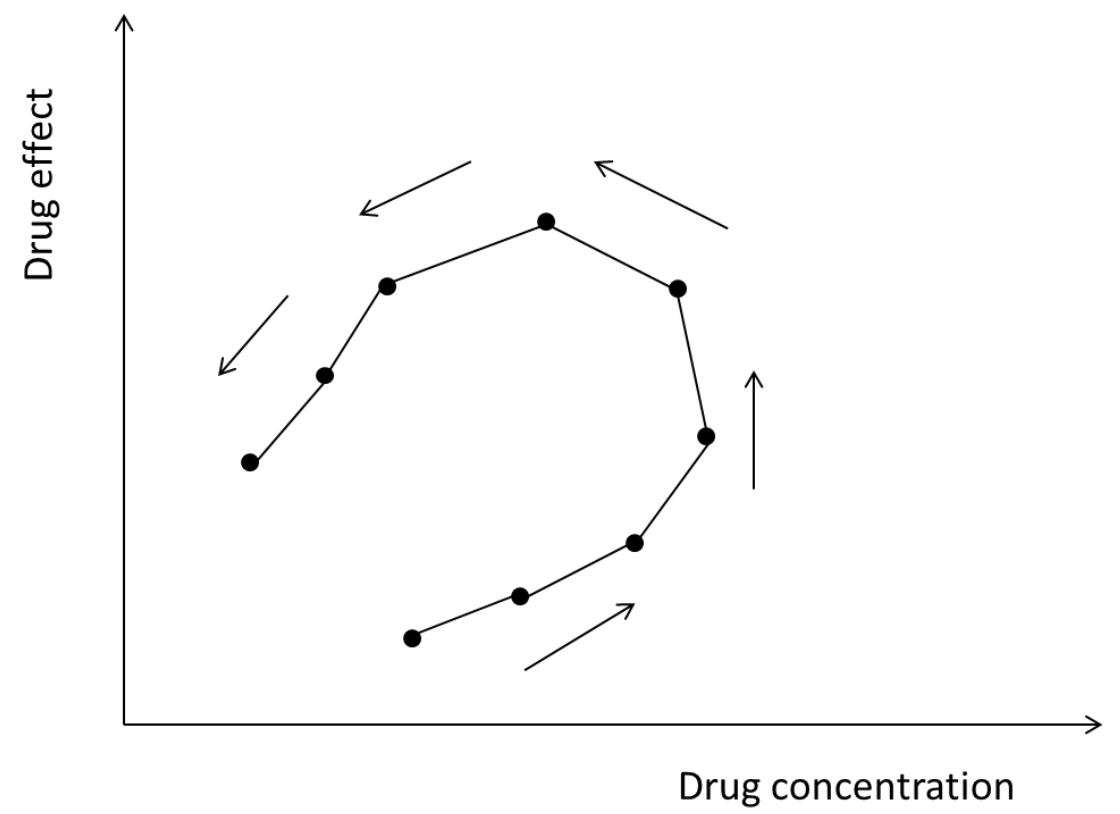

Figure 24 Counter-clockwise hysteresis loop illustrating the lagged drug effect compared with the drug concentrations.

The lag of effects was most pronounced for buprenorphine. Possible explanations to the delayed buprenorphine effects are delay in transport across the blood-brain barrier, efflux of drug across the blood-brain barrier or time to receptor-binding in the CNS.

For morphine a delay in effect has also been described (72), and it was suggested that the delay was due to the metabolism to an active metabolite (morphine-6-glucuronide) which itself contributed to the effects. This does not seem to be the case for methadone as it has no active metabolites. Buprenorphine is, however, metabolized to norbuprenorphine, which is biologically active. The effects of norbuprenorphine have mainly been studied in vitro (164) and in animals (165), and are inconclusive.

\subsubsection{The simplified clinical test of impairment (SCTI)}

The SCTI was performed 2 hours after drug administration, see Table 3 and Table 4 . The low doses of both drugs caused little impairment on the subtests. As both the gait-on-line and 70 
Romberg's test are tests of balance, it could be suggested that both doses of methadone and buprenorphine impair balance. The postural balance test (PBT) was performed both 2 hours and 6 hours post drug-intake. After 2 hours the high dose of buprenorphine impaired the PBT. In the eyes closed condition after 6 hours all treatments impaired the PBT. This also indicates that balance is sensitive to the effects of the opioids tested.

Many of the volunteers seemed unaffected, as observed by the research assistants, and felt fine until the SCTI was performed. Especially the gait-on-line revealed that they were indeed impaired at the time of testing. These results show that balance might be affected by opioids, and that poor balance as revealed by a clinical test could, among other causes, indicate opioid use. The finding might also indicate that caution may be required in persons with pre-existing balance problems, especially elderly, when initiating or adjusting opioid treatment.

Previous studies on opioids and CTI have found that impairment did correlate with morphine concentration in blood after heroin intake (166), while this was not the case after codeine intake (167). We found no correlation between concentration of methadone in blood and overall impression of the clinical test of impairment, see Table 4. This is also shown in a previous study $(n=10)$ (41). Yet, the high dose of both buprenorphine and methadone did affect most of the subtests of the SCTI, see Table 3.

\subsubsection{The pharmacokinetic properties of methadone and buprenorphine in blood and oral fluid}

\subsubsection{Concentrations of buprenorphine and methadone in blood} Mean drug concentrations in blood including range are shown in Table 5,Figure 21 and Figure 22. The ranges were especially large after the high doses of methadone and buprenorphine. E.g. the mean concentration in blood 2 hours after administration of $0.4 \mathrm{mg}$ buprenorphine was $0.38 \mathrm{nM}$, with a range from 0.00 to $0.70 \mathrm{nM}$.

Only $36 \%$ of the buprenorphine concentrations in blood were above the LOQ. After the low dose $(0.2 \mathrm{mg}) 27 \%$ of the blood samples had concentrations above LOQ, while $61 \%$ were above the LOQ after the high dose $(0.4 \mathrm{mg})$. This shows that our samples were in a very low concentration-range for buprenorphine. When extrapolating drug concentrations to levels expected after administration of lower doses, our concentrations of buprenorphine were 
below what would have been expected from previously reported studies. Yet, low concentrations of buprenorphine have previously also been a challenge when studying the pharmacokinetics of buprenorphine (125). The reason is that buprenorphine is very potent; therefore, acute doses and accompanying concentrations in blood are very low.

Since a large proportion of the buprenorphine concentrations were below the LOQ, these concentrations cannot be accurately measured, and the concentrations cannot be used to calculate ratios. Still, concentrations below a certain limit, in this case the LOQ, could be used to evaluate effects as compared to higher concentrations, i.e. calculate correlations. The small variations in accuracy in the lowest range of concentrations are presumably of little importance when comparing low and high concentrations. However, this might constitute a problem if there is a small range in concentrations, i.e. small deviations can cause significant results. In our study both doses of buprenorphine showed large ranges in concentrations in blood, and for this reason we chose to calculate correlations between concentration and effect for buprenorphine.

Poor metabolizers of CYP2B6 were excluded from the study. Thus, the large variation in methadone concentration in blood is not due to variation in CYP2B6 metabolism. Variations in drug concentrations in blood due to metabolism via other CYP-enzymes can, however, not be excluded.

\subsubsection{Concentrations of methadone and buprenorphine in oral fluid} Our results show that reliable concentrations of methadone or buprenorphine in blood cannot be calculated based on concentrations in oral fluid due to large individual variations. Reliable oral fluid/blood ratios have also not been established in previous studies. Oral fluid sampling will therefore not be a useful tool with regards to evaluating degree of impairment in drug drivers.

\subsubsection{Predisposing factors for impairment}

Large inter-individual variations were observed in both the effect (pharmacodynamics) as well as concentrations in blood (pharmacokinetics). This raised the question whether there are any objective predisposing factors to determine which subjects could expect to have more effects and higher concentrations in blood. Variation in effects of opioids is known 
from pain treatment, e.g. non-responders to pain treatment with morphine (168). It is not known if response to pain treatment could also be translated into driving impairment.

While performing the clinical study observations of the subjects were made with regards to effects and side effects, which raised questions whether sex and/or weight (i.e. body mass index or BMI) influenced the degree of impairment. A significant correlation was found between methadone concentrations in blood and sex, with females having significantly higher mean concentrations than males, see Figure 23. Even though women had higher concentration levels of methadone, the SDLP mean values did not differ significantly between the sexes. Some sex differences were found when performing bivariate correlation analysis, but most of the differences were found for the same tests (DAT, CTT and PVT) in all treatment conditions including placebo. Men were significantly more sleepy after buprenorphine administration than women, as measured with the KSS. After administration of methadone, women were less alert than men as measured with the Bond \& Lader.

All mean buprenorphine concentrations in blood were below the LOQ. For this reason no comparison between groups could be made for buprenorphine.

Factors other than sex and BMI seem pivotal to identify persons who are more sensitive to the effects of opioids. Other possible factors that could determine the pharmacodynamics of methadone and buprenorphine are opioid receptors and opioid receptor genes (98) and transport across the blood-brain barrier (97).

\subsubsection{Inter-individual variations in pharmacokinetics and pharmacodynamics}

Few effects were found on group level but large individual variations were seen. An example from our clinical study is a male subject who in the buprenorphine $0.4 \mathrm{mg}$ condition was clearly sedated before conducting the driving test. During the oral fluid sampling, ten minutes before the driving, he almost fell off the chair he was sitting on. He felt able to carry out the driving though, and he did complete half of the test. But after driving approximately 30 minutes he fell asleep while taking the exit from the highway to make the turnaround. He had the highest SDLP measured in the entire study. He was clinically clearly impaired and sedated. Still, he actually drove for 30 minutes. The change in SDLP ( $\triangle S D L P)$ for this subject 
was $8.38 \mathrm{~cm}$ compared to the placebo condition, while the mean $\triangle$ SDLP for the group in the $0.4 \mathrm{mg}$ buprenorphine condition was $1.12 \mathrm{~cm}$.

On the other hand, 6 of the 22 participants ( $27 \%$ ) performed better in the buprenorphine $0.4 \mathrm{mg}$ condition as compared to the placebo condition. Large variations were also observed for drug concentrations in blood. It is worth noting that the three subjects with the highest $\triangle$ SDLP were also the only ones with drug concentrations above the LOQ. There was a positive correlation between drug concentration in blood and change in SDLP after buprenorphine $0.4 \mathrm{mg}$, as described in Paper III.

Large individual variations were also observed for methadone: the mean $\triangle S D L P$ was $0.17 \mathrm{~cm}$ (range from -2.54 to $2.97 \mathrm{~cm}$ ) after $5 \mathrm{mg}$ methadone and $0.42 \mathrm{~cm}$ (range from $-4.51 \mathrm{~cm}$ to $4.46 \mathrm{~cm}$ ) after $10 \mathrm{mg}$ methadone. But neither doses of methadone caused significant impairment of the SDLP compared to placebo. Additionally, four subjects decided to terminate the driving test on six occasions due to sleepiness, in both the methadone and the buprenorphine condition. The question remains whether there are individual factors that would help us to predict which subjects will be more impaired than others when using these drugs, as discussed in chapter 12.1.3.3.

\subsection{Methodological discussion}

\subsubsection{Epidemiological studies in the literature review}

The epidemiological studies performed in the 1970's have one common major limitation: all three studies were based on self-reporting, which could lead to information bias.

Information regarding substance exposure as well as concomitant use of psychoactive drugs other than methadone and buprenorphine might be inaccurate; underreporting is common. Furthermore, self-reported information regarding driving violations and accidents might be inaccurate.

The methods used were different in the studies conducted in the 1970's and after 2010: the 1970 's studies used mainly questionnaires while more recent studies use

incidence/prevalence data to calculate the risk. The results could indicate a difference in the sensitivity of the methods used. 
Only five epidemiological studies on crash risk after exposure to methadone were included in the review, and the number of subjects included were relatively low, ranging from $n=26$ (24) to $n=781$ (154). The low numbers of studies and subjects make it difficult to draw firm conclusions regarding crash risk in this group.

\subsubsection{Experimental studies in the literature review}

There were several methodological limitations in the papers which have been included in paper I: the doses administered varied considerably between the studies; few studies measured drug concentrations in blood; few studies included alcohol as a benchmark substance; past and present drug use was unknown; and the tests used were not standardized. These shortcomings constitute a significant problem when evaluating the results from the papers.

The dosages administered varied between the studies, but there did not seem to be any difference in test results between those who received low and high doses of the drugs. It would be interesting, though, if a separate study was designed to distinguish between low and high doses.

No drug concentrations in blood were measured, and it would have been interesting to know the variation in concentrations among the patients. Furthermore, it would also have been interesting if correlation between drug concentrations in blood and effects were calculated.

Lack of a benchmark substance is a considerable shortcoming and is important to show sensitivity to drug-induced impairment in the participants and to calibrate to other studies.

Past and present drug use is crucial information when evaluating the results in experimental studies. It is important to control for concurrent use of opioids and psychoactive drugs as this could confound the results. A study on MMPs showed that the subjects testing positive for other psychoactive drugs performed markedly worse than those testing negative (169). Drugs other than the drug in question might significantly impair the tests performed, as can drug-interactions. Furthermore, current opioid abusers show more impairment than matched controls (170). Previous abuse/dependence of psychoactive substances could also influence the test results on neurocognitive performance 
depending on the type of drug used, e.g. long-term abuse of opioids is associated with cognitive deficits which may contribute to cognitive impairment (171). On the other hand, tolerance is known to develop to effects of opioids and should also be taken into consideration when impairment is evaluated.

Another shortcoming is the great diversity in tests applied, which makes comparison between studies difficult.

Finally, in studies with OMT patients the subjects are not randomized. Furthermore, the factors determining the selection to treatment groups, i.e. either methadone or buprenorphine treatment, could be the explanation to all differences observed between the groups (i.e. confounding by indication). This could explain why BMPs performed somewhat better than MMPs.

\subsubsection{Selection of tests used in the clinical study}

As opioids have CNS depressant effects, we chose tests for assessing impairment caused by sedation. A review of the literature has shown that a number of tests are preferably used to study such impairment. Experimental studies assessing effects of sedation on driving and driving related skills in healthy volunteers concluded that several performance measures were sensitive to the impairing effects of sedation. SDLP, the primary performance measure in the on-the-road driving test, has been found to be sensitive to the impairing effects of antidepressants (172), antihistamines (173), and residual effects of hypnotics (142, 174, 175).

The on-road driving test has become a gold standard for measuring drug effects on driving (151). Obvious advantages are the realistic driving setting with control of lateral position and speed, adaption to traffic and a long duration of the test. Disadvantages include the inability to assess risk assessments and behavior at unforeseen incidents, e.g. distractions caused by pedestrians or traffic light, and that driving-complex skills are not tested. The primary outcome of the on-road driving test is the SDLP, which measures road tracking and sustained attention. The SDLP has been shown to differ considerably between subjects.

Psychomotor vigilance (176), psychomotor performance (177) and postural control (178) are sensitive domains to measure sleepiness-induced impairment. Moreover, divided 
attention was found to be sensitive to the impairing effects of antidepressants $(172,179)$, antihistamines (173), and residual effects of hypnotics $(142,175)$. Studies conducted with the Vienna Test System (180) showed that the Determination Test is sensitive to druginduced changes $(181,182)$. In a previous study of laboratory tests, it was found that the PVT, DAT and the postural balance test were sensitive to the impairing effects of alcohol in a dose-dependent manner (14). The DAT, PVT and PBT are especially sensitive to the effects of alcohol, and effect sizes of three levels of BACs $(0.02,0.05$ and $0.08 \%)$ have been determined (92).

The SCTI is a selection of the subtests used in the CTI and comprises mainly tests of balance. Other subtests, e.g. tests of memory, could possibly have affected the SCTI outcome differently.

If the study was designed today, it would have been interesting to implement a subjective questionnaire for the volunteers to evaluate their fitness to drive. It would have improved the study to know if, in a naturalistic setting, the subjects would have driven, i.e. how they assessed their own degree of impairment before the driving test; and also, how they felt that the driving test went. This could have provided useful information with regards to patient information on potential driving impairment. If the subjects were aware of the impairing effects, like sleepiness, to such an extent that they would choose not to drive, this could have been translated to the patient's situation.

\subsubsection{Sensitivity of the tests used in the clinical study} It has been suggested that tests other than those sensitive to alcohol might be sensitive to opioids (28). Alcohol is by far the most studied drug which induces driving impairment and it is frequently used as a benchmark substance (14). The standardized on-road driving test has been applied in almost 100 studies and this allowed us to compare the effects on SDLP in the present study with those of alcohol and other drugs from previous studies.

A meta-analysis of the effects of alcohol on driving related skills, performed as part of the DRUID project, found that psychomotor functions, such as reaction time, tracking and driving, were more impaired by alcohol (at a BAC of $0.04-0.059 \%$ ) than cognitive functions like attention, visual functions and en-/decoding (183). The study combined the results from 450 studies with a total of 5,300 findings of alcohol effects on performance. 
A recent review suggests that morphine and possibly other opioids may cause effects on traffic-relevant performance tasks different from those shown to be sensitive to the effects of alcohol (72). The review found that attention and visual functions were the most sensitive to detect impairment after morphine intake, while psychomotor skills and en-/decoding were the least sensitive.

However, this coincides with the findings from a recent review on the sensitivity of tests assessing driving related skills at medium (0.031-0.06\%) to high (0.061-0.10\%) BACs where it was stated that the DAT and the PVT are the most sensitive to the impairing effects of alcohol (92). Moreover, any effect due to buprenorphine or methadone on any psychomotor or cognitive test could potentially be of some importance to traffic safety.

\subsubsection{Lack of benchmark substance in the clinical study}

Lack of a benchmark substance is a considerable shortcoming in several experimental studies. The use of a benchmark substance could be important for several reasons: to show sensitivity to drug-induced impairment in the participants, to confirm sensitivity of the driving test and to calibrate to other studies (77).

We chose not to include alcohol in our clinical study as this drug is already well studied in previous studies at the Maastricht University, using the same on-road driving test and neurocognitive tests, for references see (81). It was considered acceptable to use historical data to interpret our results. Furthermore, the burden for the participants would have been heavier if one more test day was added to the five test days. The study was already a considerable load consisting of five test days separated by a minimum of 10 washout days and including a training session and medical examination on two additional occasions.

Yet, the use of a benchmark substance would have improved the study and strengthened the results. A benchmark substance known to impair SDLP, and where the magnitude of the impairment is known, like alcohol, would have been a useful positive control in our study.

\subsubsection{Time of testing in the clinical study}

Ideally the testing of the effects of the administered drugs should be around the time of $C_{\max }$, i.e. at $T_{\max }$. This is however challenging when two different drugs with non-identical $\mathrm{T}_{\max }$ are tested. Methadone reaches peak plasma concentrations at 2.5-4 hours after per oral intake, while buprenorphine plasma concentrations peak at 0.8-1.3 hours after 
sublingual intake. To maintain a double-blind design, it was not possible to perform the driving test at different times for each treatment. The driving test was performed in the middle of the test day to allow the neurocognitive tests to be performed twice per test day.

\subsubsection{The chosen doses in the clinical study}

The doses administered were chosen based on doses previously given to healthy, opioidnaïve volunteers and equianalgesic doses of morphine.

The possibility that the doses of methadone $(5$ and $10 \mathrm{mg}$ ) could be too low to show significant differences in effects as compared to placebo was discussed during the planning of the study. We did discuss to administer 10 and $15 \mathrm{mg}$ of methadone instead, but methadone $15 \mathrm{mg}$ has never, to our knowledge, previously been administered to opioidnaïve subjects. Methadone is a potent drug with risk of serious side effects such as respiratory depression, and $10 \mathrm{mg}$ was chosen as the highest dose.

Frequent and unpleasant side effects were challenging during the data collection in our study and caused many missing data. The number of side effects would have increased with higher doses, and further the risk that the subjects would not be able to complete all the psychomotor and cognitive tests.

\subsubsection{Predictive validity of the tests used in the clinical study}

It has been argued that the SDLP is only representative for parts of the tasks required for driving (i.e. tracking and sustained attention) and does not measure the more complex tasks related to driving. Yet, a high correlation $(r=0.99)$ has been established between SDLP increment following alcohol intake and the indirect risk of traffic crash involvement (89).

The neurocognitive tests chosen in our study included all three behavioral levels (automative behavior, control behavior, and executive planning behavior) recommended for research on driving performance. It has been found that the DAT and the PVT, and also the PBT, were sensitive to alcohol effects and thereby are considered valid in assessing potential driving impairment (92).

\subsubsection{Measuring drug concentrations in blood in the clinical study} Performing an on-road driving study including blood sampling is crucial if the results are to be used to set cut-off limits for impaired driving. It would have been interesting to collect more blood samples during the test days that would have provided more accurate 
pharmacokinetic data, but this was not possible due to the very tight schedule on the test days.

The buprenorphine concentrations in blood were very low, as described previously. The methods used to analyze the blood samples are sensitive. Still, we have seen that lower LOD and $L O Q$ are required for measuring buprenorphine in blood when such low doses of buprenorphine are administered.

The reliability of the laboratory tests was very good as all analysis were performed in an accredited forensic toxicological laboratory with validated methods.

\subsubsection{External and internal validity in the clinical study}

A good external validity of a study means that the results can be applied to a general population. In our clinical study the participants were not randomly chosen and a similar study in another study population might not provide the same results. The participants were healthy volunteers and do not represent pain patients. Furthermore, patients with chronic opioid use will develop tolerance to at least some of the effects of opioids. However, the study population is representative for persons who use opioids sporadically either as pain medication or recreationally.

Internal validity describes how well an experiment is done and how well it can rule out alternative explanations (confounders) to the findings. We performed a randomized clinical trial, which is considered the "gold standard" of experimental research. Our participants were selected by several criteria, including good health and significant driving experience. This could cause a selection bias. The frequent side effects, and consequently many missing data, could have biased the results as poor performance was not included in the data analysis, thereby underestimating the impairing effects of the drugs. 


\section{Conclusions}

The literature review revealed that recent epidemiological studies have found an increased risk of road traffic crash involvement in male patients treated with methadone and an increased odds ratio for being responsible for the crash in injured drivers exposed to either methadone or buprenorphine. However, the studies included few cases, so firm conclusions should not be drawn.

Furthermore, the literature review found that previous experimental studies on OMT patients showed impairment in some subjects, but also some improvement. However, methodological shortcomings make it difficult to compare the results between the different studies and draw conclusions. Patients treated with buprenorphine performed to a moderate extent better than methadone treated patients but the explanation for this might be reasons other than drug effects.

Finally, the literature review showed that previous experimental studies revealed at least some traffic relevant impairment in drug-naïve subjects after single doses of methadone and buprenorphine. However, few such studies have been conducted and none on actual onroad driving.

Our clinical study is the first study where methadone and buprenorphine have been administered to opioid-naïve subjects and an actual on-road driving test was performed in addition to several neurocognitive tests, and where blood samples were collected throughout the test day for analysis of drug concentrations. Our study showed that buprenorphine $0.4 \mathrm{mg}$ significantly impaired SDLP in the driving test, whereas equianalgesic doses of methadone did not. Even though mild effects on driving and driving related skills were observed it is worth noting that large individual variations were measured: Four out of 22 subjects prematurely terminated the driving test due to sleepiness after both drugs. The impairing effects of methadone and buprenorphine on driving relevant tasks found in the clinical study are in line with previous studies that indicate that both methadone and buprenorphine have an impairing potential in opioid-naïve subjects. 
Furthermore, we found dose-dependent effects on neurocognitive tests relevant to driving after administration of methadone and buprenorphine. However, few drug concentrationeffect correlations were found: some for buprenorphine but not for methadone.

Buprenorphine significantly impaired the SDLP of the driving test, however, the effects did not reach clinical relevance, i.e. effects comparable to a BAC of $0.05 \%$. Reaching clinical relevance would imply that the relative risk of causing a road traffic crash is significantly increased. On the other hand, both methadone and buprenorphine impaired tests of tracking and attention and calculation of effect size showed that the effects were comparable to BAC of $0.05 \%$ for some of the conditions.

Large inter-individual variations were observed in pharmacokinetics for both methadone and buprenorphine in both blood and oral fluid. Drug concentrations in blood were in general very low for buprenorphine as only one third of the results were above the limit of qualification. Large ranges of concentrations in blood were observed for both drugs especially after the high doses. It was not possible to calculate reliable concentrations in blood based on the drug concentrations in oral fluid. 


\section{Implications and future perspectives}

Methadone and buprenorphine should be included in future epidemiological studies on risk of road traffic crash as well as culpability studies in drivers exposed to these drugs. It would also be important to differentiate between OMT use, use in pain treatment and illicit use among drivers.

More studies on patients in OMT are needed, including standardized tests with baseline measures, categorization according dose-levels, information on past and present drug use and measuring drug concentrations in blood.

There seems to be sufficient evidence from our clinical study that both drugs have an impairing potential relevant to driving performance. The clinical relevance of our findings is, however, ambiguous as there were large individual variations. Nonetheless, our findings can be used to make recommendations with regards to driving for persons who receive opioids short-term, e.g. pain relief after surgical procedures, and for patients when opioid treatment is initiated or doses increased. The results should be known by doctors prescribing opioids to inform and warn the patients with regards to safe driving or workplace situations.

Furthermore, knowledge on driving impairment after opioid use can be important for health authorities when establishing guidelines for pain treatment and for health requirements for driving license.

Knowledge on reduced alertness, sleepiness and poor balance following opioid intake is useful to those performing a CTI or field sobriety test in order to detect impairment following opioid intake.

Future studies where higher doses of these drugs are administered would add valuable information, but ethical considerations could prevent approval of such studies.

Few concentration-effect relationships were found, but the question remains whether there are any predisposing factors that could tell us which patients/persons are at particular risk of being impaired. Predictive factors to identify persons who are more sensitive to the impairing effects of opioids, as well as side effects, will be important not only with regards to driving impairment but also to customize drug treatment. Knowledge on receptors and 
transport across the blood-brain barrier, combined with (pharmaco)genetic analyses, will enable adjustment of dosage and choice of $\operatorname{drug}(\mathrm{s})$ according to the characteristics of the individual patient.

Finally, our results show that improved methods to analyze low concentrations of buprenorphine in blood are required for future studies on low doses of buprenorphine. 


\section{Curriculum Vitae}

Maren Cecilie Strand received her M.D. from the VU University Amsterdam (Amsterdam, the Netherlands) in 2006 and became a specialist in clinical pharmacology in Norway in 2014.

Strand is working as a chief attending physician at the Department of Forensic Sciences at Oslo University Hospital (Oslo, Norway), and has previously worked as head of unit at the Center for Psychopharmacology, Diakonhjemmet Hospital, Oslo, and as a medical doctor at the Dept. of Addiction, Vestre Viken Hostpital Trust.

2012-2020 PhD candidate Oslo University / Maastricht University

$2019 \rightarrow \quad$ Member of the Norwegian Board of Forensic Medicine, toxicological group

$2017 \rightarrow \quad$ Member of the Regional Committees for Medical and Health Research Ethics

2014-2015 Secretary, Reference group for impairment based legislative limits for driving under the influence of non-alcohol drugs in Norway

2011-2015 President of the Norwegian Association of Clinical Pharmacology

2011-2012 Pompidou group, European Council, Member of Ad Hoc Expert group:

Substitution treatment and safe driving

2008-2011 The European Integrated Project DRUID (Driving under the Influence of Drugs, Alcohol and Medicines): Psychomotor performance after administration of opioids, narcoanalgetics and hallucinogens

$2008 \rightarrow \quad$ Expert witness Forensic toxicology 


\section{References}

1. SWOV Institute for Road Safety Research. Fact sheet: The use of drugs and medicines behind the wheel 2015 [Cited 2020 Jan 16]. Available from:

https://www.swov.nl/en/facts-figures/factsheet/use-drugs-and-medicines-behindwheel

2. Compton RP, Berning A. Drug and alcohol crash risk. Journal of Drug Addiction, Education, Eradication 2015;11(1):29.

3. Gjerde H, Strand MC, Mørland J. Driving under the influence of non-alcohol drugs - an update. Part I: epidemiological studies. Forensic Science Review 2015;27(2):89-113.

4. Strand MC, Gjerde H, Morland J. Driving under the influence of non-alcohol drugs An update. Part II: Experimental studies. Forensic Science Review 2016;28(2):79-101.

5. Drummer OH, Gerostamoulos J, Batziris H, Chu M, Caplehorn J, Robertson MD, et al. The involvement of drugs in drivers of motor vehicles killed in Australian road traffic crashes. Accident Analysis and Prevention 2004;36(2):239-48.

6. Longo MC, Hunter CE, Lokan RJ, White JM, White MA. The prevalence of alcohol, cannabinoids, benzodiazepines and stimulants amongst injured drivers and their role in driver culpability: part ii: the relationship between drug prevalence and drug concentration, and driver culpability. Accident Analysis and Prevention 2000;32(5):623-32.

7. Movig KL, Mathijssen MP, Nagel PH, van Egmond T, de Gier JJ, Leufkens HG, et al. Psychoactive substance use and the risk of motor vehicle accidents. Accident Analysis and Prevention 2004;36(4):631-6.

8. Ogden EJ, Moskowitz H. Effects of alcohol and other drugs on driver performance. Traffic Injury Prevention 2004;5(3):185-98.

9. Borkenstein RF, Crowther R, Shumate R. The role of the drinking driver in traffic accidents (The Grand Rapids Study). Blutalkohol 1974;11(Suppl.):1-131.

10. Blomberg RD, Peck RC, Moskowitz H, Burns M, Fiorentino D. The long beach/fort lauderdale relative risk study. Journal of Safety Research 2009;40(4):285-92.

11. Romano E, Torres-Saavedra PA, Calderon Cartagena HI, Voas RB, Ramirez A. AlcoholRelated Risk of Driver Fatalities in Motor Vehicle Crashes: Comparing Data From 2007 and 2013-2014. Journal of Studies on Alcohol and Drugs 2018;79(4):547-52. 
12. Zador PL, Krawchuk SA, Voas RB. Alcohol-related relative risk of driver fatalities and driver involvement in fatal crashes in relation to driver age and gender: an update using 1996 data. Journal of Studies on Alcohol 2000;61(3):387-95.

13. Bernhoft IM, Hels T, Lyckegaard A, Houwing S, Verstraete AG. Prevalence and risk of injury in Europe by driving with alcohol, illicit drugs and medicines. Procedia, Social and Behavioral Sciences 2012;48:2907-16.

14. Jongen S, Vuurman EF, Ramaekers JG, Vermeeren A. The sensitivity of laboratory tests assessing driving related skills to dose-related impairment of alcohol: $A$ literature review. Accident Analysis and Prevention 2016;89:31-48.

15. Ramaekers JG. Drugs and Driving Research in Medicinal Drug Development. Trends in Pharmacological Sciences 2017;38(4):319-21.

16. Louwerens J, Gloerich A, de Vries G, Brookhuis KA, O'Hanlon J, editors. The relationship between drivers' blood alcohol concentration (BAC) and actual driving performance during high speed travel. In: Noordzij PC, Roszbach, editors. Alcohol, drugs and traffic safety -Proceedings of the 10th International Conference on Alcohol, Drugs and Traffic Safety, T86. Amsterdam, The Netherlands: Excerpta Medica; 1986. p. 183-186. [Cited 2020 Jan 16]. Available from: http://www.icadtsinternational.com/files/documents/1986 017.pdf

17. Moskowitz H, Fiorentino D. A review of the literature on the effects of low doses of alcohol on driving-related skills (DOT HS 809 028). Washington DC: National Highway Traffic Safety Administration; 2000. [Cited 2020 Jan 16]. Available from: https://rosap.ntl.bts.gov/view/dot/1677/dot 1677 DS1.pdf

18. Moskowitz H, Zador P, Smiley A, Fiorentino D, Burns M. Driver characteristics and impairment at various BACs. Washington, DC: National Highway Traffic Safety Administration; 2000. [Cited 2020 Jan 16]. Available from:

https://www.nhtsa.gov/people/injury/research/pub/impaired driving/BAC/impairm ent.pdf

19. Engeland A, Skurtveit S, Morland J. Risk of road traffic accidents associated with the prescription of drugs: a registry-based cohort study. Annals of Epidemiology 2007;17(8):597-602.

20. Kelly E, Darke S, Ross J. A review of drug use and driving: epidemiology, impairment, risk factors and risk perceptions. Drug and Alcohol Review 2004;23(3):319-44.

21. Robert F. Borkenstein courses. Effects of Drugs on Human Performance and Behavior. Bloomington, IN: Indiana University; 2019 [Cited 2020 Jan 16]. Available from: https://bcahs.indiana.edu/drugcourse/index.html 
22. Walsh JM, de Gier JJ, Christopherson AS, Verstraete AG. Drugs and driving. Traffic Injury Prevention 2004;5(3):241-53.

23. Mørland J. Driving under the influence of non-alcohol drugs. Forensic Science Review 2000;12:79-105.

24. Bramness JG, Skurtveit S, Morland J, Engeland A. An increased risk of motor vehicle accidents after prescription of methadone. Addiction 2012;107(5):967-72.

25. Orriols L. Health-related factors and road safety: Influence of medicine use (The CESIR-A study). PhD Thesis no. 1723. Bordeaux, France: Université Bordeaux-II ; 2000. [Cited 2020 Jan 16]. Available from: https://www.theses.fr/2010BOR21723/abes

26. Corsenac P, Lagarde E, Gadegbeku B, Delorme B, Tricotel A, Castot A, et al. Road traffic crashes and prescribed methadone and buprenorphine: a French registrybased case-control study. Drug and Alcohol Dependence 2012;123(1-3):91-7.

27. Chihuri S, Li G. Use of prescription opioids and motor vehicle crashes: A meta analysis. Accident Analysis and Prevention 2017;109:123-31.

28. Strand MC, Fjeld B, Arnestad M, Mørland J. Psychomotor relevant performance: 1. After single dose administration of opioids, narcoanalgesics and hallucinogens to drug naïve subjects 2 . In patients treated chronically with morphine or methadone / buprenorphine. DRUID Deliverable D1.1.2C. Oslo, Norway: Norwegian Institute of Public Health; 2011. [Cited 2020 Jan 16]. Available from: https://www.bast.de/Druid/EN/deliveraleslist/downloads/Deliverable 1 1 1_2 2 C.pdf? blob=publicationFile\&v=1

29. Schneider U, Bevilacqua C, Jacobs R, Karst M, Dietrich DE, Becker $H$, et al. Effects of fentanyl and low doses of alcohol on neuropsychological performance in healthy subjects. Neuropsychobiology 1999;39(1):38-43.

30. Zacny JP, Gutierrez S. Characterizing the subjective, psychomotor, and physiological effects of oral oxycodone in non-drug-abusing volunteers. Psychopharmacology (Berl) 2003;170(3):242-54.

31. Verster JC, Veldhuijzen DS, Volkerts ER. Effects of an opioid (oxycodone/paracetamol) and an NSAID (bromfenac) on driving ability, memory functioning, psychomotor performance, pupil size, and mood. Clinical Journal of Pain 2006;22(5):499-504.

32. Zacny JP, Gutierrez S. Subjective, psychomotor, and physiological effects of oxycodone alone and in combination with ethanol in healthy volunteers. Psychopharmacology (Berl) 2011;218(3):471-81. 
33. Amato JN, Marie S, Lelong-Boulouard V, Paillet-Loilier M, Berthelon C, Coquerel A, et al. Effects of three therapeutic doses of codeine/paracetamol on driving performance, a psychomotor vigilance test, and subjective feelings.

Psychopharmacology (Berl) 2013;228(2):309-20.

34. Verstraete AG, Legrand S-A, Vandam L, Hughes B, Griffiths P. Drug use, impaired driving and traffic accidents, second edition (European Monitoring Centre for drugs and Drug Addiction): Office for Official Publications of the European Communities; 2014. [Cited 2020 Jan 16]. Available from:

http://www.emcdda.europa.eu/publications/insights/2014/drugs-and-driving

35. Stout PR, Farrell LJ. Opioids - Effects on Human Performance and Behavior. Forensic Science Review 2003 15(1):29-59.

36. Vindenes V, Jordbru D, Knapskog AB, Kvan E, Mathisrud G, Slordal L, et al. Impairment based legislative limits for driving under the influence of non-alcohol drugs in Norway. Forensic Science International 2012;219(1-3):1-11.

37. Houwing S, Hagenzieker M, Mathijssen R, Bernhoft IM, Hels T, Janstrup $K$, et al. Prevalence of alcohol and other psychoactive substance in drivers in general traffic. Part I: General results. DRUID Deliverable D 2.2.3. Leidschendam: SWOV Institute for Road Safety Research; 2011. [Cited 2020 Jan 16]. Available from:

https://orbit.dtu.dk/files/6341069/prod11323338158679.Deliverable 223 Part1\% 5B1\%5D.pdf

38. Furuhaugen $\mathrm{H}$, Jamt RE, Nilsson $\mathrm{G}$, Vindenes V, Gjerde $\mathrm{H}$. Roadside survey of alcohol and drug use among Norwegian drivers in 2016-2017: A follow-up of the 2008-2009 survey. Traffic Injury Prevention 2018;19(6):555-62.

39. Oslo University Hospital. Rusmiddelstatistikk. Funn i blodprøver hos bilførere mistenkt for påvirket kjøring 2018. Oslo, Norway: Oslo University Hospital; 2019. [Cited 2020 Jan 16]. Available from: https://oslouniversitetssykehus.no/seksjon/avdeling-for-rettsmedisinskefag/Documents/Rusmiddelstatistikk\%20-\%202018.pdf

40. Valen A, Bogstrand ST, Vindenes V, Gjerde H. Toxicological findings in suspected drugimpaired drivers in Norway - Trends during 1990-2015. Forensic Science International 2017;280:15-24.

41. Bernard JP, Morland J, Krogh M, Khiabani HZ. Methadone and impairment in apprehended drivers. Addiction 2009;104(3):457-64. 
42. Isalberti C, Van der Linden T, Legrand S-A, Verstraete A, Bernhoft IM, Hels T, et al. Prevalence of alcohol and other psychoactive substances in injured and killed drivers. DRUID Deliverable 2.2.5. Ghent, Belgium: Ghent University; 2011. [Cited 2020 Jan 16]. Available from:

https://orbit.dtu.dk/files/6341109/prod11323338975691.Deliverable 22 5.pdf

43. World Health Organization. Global status report on road safety 2018. Geneva, Switzerland: World Health Organization; 2018. [Cited 2020 Jan 16]. Available from: https://www.who.int/violence injury prevention/road safety status/2018/en/

44. Hedlund J. Drug-Impaired Driving: Marijuana and Opioids Raise Critical Issues for States. Washington, DC: Governor's Highway Safety Organization; 2018. [Cited 2020 Jan 16]. Available from: https://www.ghsa.org/resources/DUID18

45. Norwegian Ministry of Transport and Communications. Driving under the influence of non-alcohol drugs - legal limits implemented in Norway. Report No.: N-0554 E. Oslo, Norway: Norwegian Ministry of Transport and Communications; 2014. [Cited 2020 Jan 16]. Available from: https://www.regjeringen.no/no/dokumenter/Driving-underthe-influence-of-non-alcohol-drugs--legal-limits-implemented-in-Norway/id2351035/

46. Statistics Norway. Road traffic accidents involving personal injury, 2017. [Cited 2020 Jan 16]. Available from: https://www.ssb.no/en/transport-ogreiseliv/statistikker/vtu/aar

47. Valen A, Bogstrand ST, Vindenes V, Frost J, Larsson M, Holtan A, et al. Fatally injured drivers in Norway 2005-2015-Trends in substance use and crash characteristics. Traffic Injury Prevention 2019:1-7.

48. Statens Vegvesen. Dybdeanalyser av dødsulykker i vegtrafikken 2017. Oslo, Norway: Norwegian Public Roads Administration; 2018. [Cited 2020 Jan 16]. Available from: https://www.vegvesen.no/ attachment/2346577/binary/1267249

49. Bogstrand ST, Larsson M, Holtan A, Staff T, Vindenes V, Gjerde H. Associations between driving under the influence of alcohol or drugs, speeding and seatbelt use among fatally injured car drivers in Norway. Accident Analysis and Prevention 2015;78:14-9.

50. European Transport Safety Council (ETSC). Blood Alcohol Content (BAC) Drink Driving Limits across Europe. Brussels, Belgium: European Transport Safety Council; 2019. [Cited 2020 Jan 16]. Available from: https://etsc.eu/blood-alcohol-content-bac-drinkdriving-limits-across-europe/

51. Fell JC, Voas RB. The effectiveness of a 0.05 blood alcohol concentration (BAC) limit for driving in the United States. Addiction 2014;109(6):869-74. 
52. Hauge R, Snortum JR. Den skandinaviske myte-en realitet? Alkoholpolitik 1986;3(4):185-90.

53. UK Secretary of State. The Drug Driving Specified Limits Regulations 2014 (England and Wales). London, UK: Secretary of State; 2014. [Cited 2020 Jan 16]. Available from: http://www.legislation.gov.uk/id/uksi/2014/2868

54. Steentoft A, Simonsen KW, Linnet K. The frequency of drugs among Danish drivers before and after the introduction of fixed concentration limits. Traffic Injury Prevention 2010;11(4):329-33.

55. Government of the Netherlands. Besluit van 14 december 2016, houdende regels over de voorlopige onderzoeken en de vervolgonderzoeken die ter vaststelling van het gebruik van alcohol, drugs en geneesmiddelen in het verkeer. Staatsblad van het Koninkrijk der Nederlanden 2016;529:1-38. [Cited 2020 Jan 16]. Available from: https://zoek.officielebekendmakingen.nl/stb-2016-529.pdf

56. European Monitoring Centre for Drugs and Drug Addiction (EMCDDA). Legal approaches to drugs and driving. Lisbon, Portugal: European Monitoring Centre for Drugs and Drug Addiction. [Cited 2020 Jan 16]. Available from:

http://www.emcdda.europa.eu/publications/topic-overviews/legal-approaches-todrugs-and-driving/html en

57. Vindenes V, Boix F, Koksaeter P, Strand MC, Bachs L, Morland J, et al. Drugged driving arrests in Norway before and after the implementation of per se law. Forensic Science International 2014;245C:171-7.

58. Nagpal A, Xu R, Pangarkar S, Dworkin I, Singh JR. Driving under the influence of opioids. PM \& R: the Journal of Injury, Function, and Rehabilitation 2016;8(7):698705.

59. Michon JA. Explanatory pitfalls and rule-based driver models. Accident Analysis and Prevention 1989;21(4):341-53.

60. Gjerde H, Ramaekers JG, Mørland JG. Methodologies for establishing the relationship between alcohol/drug use and driving impairment - Differences between epidemiological, experimental, and real-case studies. Forensic Science Review. 2019;31(2):141-60.

61. Berning A, Compton RP, Wochinger K. Results of the 2013-2014 national roadside survey of alcohol and drug use by drivers (DOT HS 812 118). Washington DC: National Highway Traffic Safety Administration; 2015. [Cited 2020 Jan 16]. Available from: http://www.nhtsa.gov/staticfiles/nti/pdf/812118-Roadside Survey 2014.pdf 
62. Ramaekers JG, Berghaus G, van Laar $\mathrm{M}$, Drummer $\mathrm{OH}$. Dose related risk of motor vehicle crashes after cannabis use. Drug and Alcohol Dependence 2004;73(2):109-19.

63. Ramaekers JG, Berghaus G, van Laar MW, Drummer OH. Dose related risk of motor vehicle crashes after cannabis use: an update. In: Verster JC, Pandi-Perumal SR, Ramaekers JG, de Gier JJ, editors. Drugs, driving and traffic safety. Basel, Switzerland: Birkhäuser; 2009. p. 477-99.

64. Longo MC, Lokan RJ, White JM. The relationship between benzodiazepine concentration and vehicle crash culpability. Journal of Traffic Medicine 2001;29:3643.

65. Robertson MD, Drummer OH. Responsibility analysis: a methodology to study the effects of drugs in driving. Accident Analysis and Prevention 1994;26(2):243-7.

66. Walsh JM, Verstraete AG, Huestis MA, Morland J. Guidelines for research on drugged driving. Addiction 2008;103(8):1258-68.

67. Kay GG, Logan BK. Drugged driving expert panel report: A consensus protocol for assessing the potential of drugs to impair driving (DOT HS 811 438). Washington, DC: National Highway Traffic Safety Administration; 2011. [Cited 2020 Jan 16]. Available from: http://www.nhtsa.gov/staticfiles/nti/pdf/811438.pdf

68. Tanida K, Poppel E. A hierarchical model of operational anticipation windows in driving an automobile. Cognitive Processing 2006;7(4):275-87.

69. Krüger H-P, Kohnen R, Diehl M, Hüppe A. Auswirkungen geringer Alkoholmengen auf Fahrverhalten und Verkehrssicherheit (Problemstudie). Abschlußbericht zum FP 8707 für die Bundesanstalt für Straßenwesen. Forschungsberichte Band 213. Bergisch Gladbach, Germany: Bundesanstalt für Straßenwesen; 1990.

70. Ranney TA. Models of driving behavior: a review of their evolution. Accident Analysis and Prevention 1994;26(6):733-50.

71. Verster JC, Roth T. Drivers can poorly predict their own driving impairment: a comparison between measurements of subjective and objective driving quality. Psychopharmacology (Berl) 2012;219(3):775-81.

72. Strand MC, Arnestad M, Fjeld B, Morland J. Acute impairing effects of morphine related to driving: A systematic review of experimental studies to define blood morphine concentrations related to impairment in opioid naive subjects. Traffic Injury Prevention 2017;18(8):788-794 
73. Freedman D, Manly J. Use of normative data and measures of performance validity and symptom validity in assessment of cognitive function; 2015. [Cited 2020 Jan 16]. Available from: http://nationalacademies.org/hmd/ /media/Files/CommissionedPaper/FreedmanManlyCommissioned\%20paper.pdf

74. Palta P, Snitz B, Carlson MC. Neuropsychologic assessment. In: Handbook of Clinical Neurology, Vol . 138. Oxford, UK: Elsevier; 2016. p. 107-119. doi: 10.1016/B978-0-12802973-2.00007-0

75. Steckler A, McLeroy KR. The importance of external validity. American Journal of Public Health 2008;98(1):9-10.

76. Helland A. Driving Simulator Validation for Drug Impairment Research. Doctoral Thesis at NTNU, 2016:304. Trondheim, Norway: Norwegian University of Science and Technology; 2016. [Cited 2020 Jan 16]. Available from: https://ntnuopen.ntnu.no/ntnu-xmlui/handle/11250/2421901

77. Verster JC, Roth T. Standard operation procedures for conducting the on-the-road driving test, and measurement of the standard deviation of lateral position (SDLP). International Journal of General Medicine 2011;4:359-71.

78. Verster JC, Pandi-Perumal S, Ramaekers JG, de Gier JJ. Drugs, driving and traffic safety. Basel, Switzerland: Birkhüser; 2009.

79. Kaptein NA, Theeuwes J, Van Der Horst R. Driving simulator validity: Some considerations. Transport Research Record 1996;1550(1):30-6.

80. O'Hanlon JF. Driving performance under the influence of drugs: rationale for, and application of, a new test. British Journal of Clinical Pharmacology 1984;18 Suppl 1:121S-9S.

81. Jongen $S$, Vermeeren A, van der Sluiszen NN, Schumacher MB, Theunissen EL, Kuypers KP, et al. A pooled analysis of on-the-road highway driving studies in actual traffic measuring standard deviation of lateral position (i.e., "weaving") while driving at a blood alcohol concentration of $0.5 \mathrm{~g} / \mathrm{L}$. Psychopharmacology (Berl) 2017;234(5):837-844.

82. Veldstra JL, Bosker WM, de Waard D, Ramaekers JG, Brookhuis KA. Comparing treatment effects of oral THC on simulated and on-the-road driving performance: testing the validity of driving simulator drug research. Psychopharmacology (Berl) 2015;232(16):2911-9.

83. Jongen S, Vuurman E, Ramaekers JG, Vermeeren A. Comparing the effects of oxazepam and diazepam in actual highway driving and neurocognitive test performance: a validation study. Psychopharmacology (Berl) 2018;235(4):1283-94. 
84. Kuypers KP, Samyn N, Ramaekers JG. MDMA and alcohol effects, combined and alone, on objective and subjective measures of actual driving performance and psychomotor function. Psychopharmacology (Berl) 2006;187(4):467-75.

85. Ramaekers JG, Kuypers KP, Samyn N. Stimulant effects of 3,4methylenedioxymethamphetamine (MDMA) $75 \mathrm{mg}$ and methylphenidate $20 \mathrm{mg}$ on actual driving during intoxication and withdrawal. Addiction 2006;101(11):1614-21.

86. Ramaekers JG, O'Hanlon JF. Acrivastine, terfenadine and diphenhydramine effects on driving performance as a function of dose and time after dosing. European Journal of Clinical Pharmacology 1994;47(3):261-6.

87. O'Hanlon JF, Ramaekers JG. Antihistamine effects on actual driving performance in a standard test: a summary of Dutch experience, 1989-94. Allergy 1995;50(3):234-42.

88. Schumacher MB, Jongen $S$, Knoche A, Petzke F, Vuurman EF, Vollrath $M$, et al. Effect of chronic opioid therapy on actual driving performance in non-cancer pain patients. Psychopharmacology (Berl) 2017;234(6):989-99.

89. Owens K, Ramaekers JG. Drugs, driving, and models to measure driving impairment. . In: Verster JC, Pandi-Perumal SR, Ramaekers JG, de Gier JJ, editors. Drugs, driving and traffic safety. Basel, Switzerland: Birkhäuser Verlag; 2009. p. 43-58.

90. Helland A, Jenssen GD, Lervag LE, Moen T, Engen T, Lydersen S, et al. Evaluation of measures of impairment in real and simulated driving: Results from a randomized, placebo-controlled study. Traffic Injury Prevention 2016;17(3):245-50.

91. Helland A, Jenssen GD, Lervag LE, Westin AA, Moen T, Sakshaug K, et al. Comparison of driving simulator performance with real driving after alcohol intake: a randomised, single blind, placebo-controlled, cross-over trial. Accident Analysis and Prevention 2013;53:9-16.

92. Jongen S, Vuurman E, Ramaekers J, Vermeeren A. Alcohol calibration of tests measuring skills related to car driving. Psychopharmacology (Berl) 2014;231(12):2435-47.

93. Jongen S, Perrier J, Vuurman EF, Ramaekers JG, Vermeeren A. Sensitivity and validity of psychometric tests for assessing driving impairment: effects of sleep deprivation. PloS One 2015;10(2):e0117045.

94. Rang HP, Dale MM, Ritter JM, Flower RJ, Henderson G. Rang and Dale's Pharmacology, seventh edition. 7 ed. Edinburgh, UK: Elsevier Churchill Livingstone; 2012. 
95. Darcq E, Kieffer BL. Opioid receptors: drivers to addiction? Nature Reviews Neuroscience 2018;19(8):499-514.

96. Barar J, Rafi MA, Pourseif MM, Omidi Y. Blood-brain barrier transport machineries and targeted therapy of brain diseases. Bioimpacts 2016;6(4):225.

97. Chaves C, Remião F, Cisternino S, Declèves X. Opioids and the blood-brain barrier: A dynamic interaction with consequences on drug disposition in brain. Current Neuropharmacology 2017;15(8):1156-73.

98. Smith HS. Opioid metabolism. Mayo Clinic Proceedings 2009;84(7):613-24.

99. Wigen Skjerdal J, Andrew E, Gjertsen FJCt. Deaths by poisoning in Norway 20032012. Clinical Toxicology (Philadelphia, PA) 2016;54(6):495-500.

100. National Institute on Drug Abuse. Overdose death rates 2018. Rockville, MD: National Institute on Drug Abuse; 2018. [Cited 2018 Aug]. Available from:

https://www.drugabuse.gov/related-topics/trends-statistics/overdose-death-rates

101. Hedegaard H, Bastian BA, Trinidad JP, Spencer M, Warner M. Drugs most frequently involved in drug overdose deaths: United States, 2011-2016. National Vital Statistics Reports 2018; 67(9):1-14.

102. European Monitoring Centre for Drugs and Drug Addiction (EMCDDA). Preventing overdose deaths in Europe 2018. Lisbon, Portugal: European Monitoring Centre for Drugs and Drug Addiction; 2018. [Cited 2020 Jan 16]. Available from: http://www.emcdda.europa.eu/publications/pods/preventing-overdose-deaths en

103. Kriikku P, Häkkinen M, Ojanperä IJFsi. High buprenorphine-related mortality is persistent in Finland. Forensic Science International 2018;291:76-82.

104. Tjagvad C, Skurtveit S, Linnet K, Andersen LV, Christoffersen DJ, Clausen T. Methadone-related overdose deaths in a liberal opioid maintenance treatment programme. European Addiction Research 2016;22(5):249-58.

105. Helander A, Bäckberg M, Beck O. Intoxications involving the fentanyl analogs acetylfentanyl, 4-methoxybutyrfentanyl and furanylfentanyl: results from the Swedish STRIDA project. Clinical Toxicology (Philadelphia, PA) 2016;54(4):324-32.

106. Edlow JA, Rabinstein A, Traub SJ, Wijdicks EF. Diagnosis of reversible causes of coma. The Lancet 2014;384(9959):2064-76.

107. Waal H, Bussesund K, Clausen T, Lillevold PH, Skeie I. LAR 20 år - Status, vurderinger og perspektiver. Oslo, Norway: Norwegian Centre for Addiction Research (SERAF); 2018. 
108. Sieroslawski J, Deugnier D, Giamoustaris T, Strand MC. Guiding principles on Road traffic safety and substitution treatment. Strasbourg, France: Pompidou Group, Council of Europe; 2012. [Cited 2020 Jan 16]. Available from: https://rm.coe.int/2012-pg-rtd-5-road-traffic-subsitution-eng/16807865f9

109. Drummer OH. Epidemiology and traffic safety: culpability studies. In: Verster JC, Pandi-Perumal SR, Ramaekers JG, de Gier JJ, editors. Drugs, driving and traffic safety. Basel, Switzerland: Birkhäuser Verlag; 2009. p. 93-106.

110. Bukten A, Herskedal A, Skurtveit S, Bramness JG, Clausen TJA. Driving under the influence (DUI) among patients in opioid maintenance treatment (OMT): a registrybased national cohort study. Addiction 2013;108(11):1954-61.

111. Bernard JP, Opdal MS, Karinen R, Morland J, Khiabani HZ. Relationship between methadone and EDDP (2-ethylidene-1,5-dimethyl-3,3-diphenylpyrrolidine) in urine samples from Norwegian prisons. European Journal of Clinical Pharmacology 2007;63(8):777-82.

112. Baselt RC. Disposition of Toxic Drugs and Chemicals in Man, Eleventh edition. Foster City, CA: Biomedical Publications; 2017.

113. Eap CB, Buclin T, Baumann P. Interindividual variability of the clinical pharmacokinetics of methadone: implications for the treatment of opioid dependence. Clinical Pharmacokinetics 2002;41(14):1153-93.

114. Dale O, Hoffer C, Sheffels P, Kharasch ED. Disposition of nasal, intravenous, and oral methadone in healthy volunteers. Clinical Pharmacology and Therapeutics 2002;72(5):536-45.

115. Chow RM, Issa M. Methadone. In: Yong RJ, Nguyen M, Nelson E, Urman RD, editors. Pain Medicine: Cham, Switzerland: Springer; 2017. p. 157-8.

116. Gerber JG, Rhodes RJ, Gal J. Stereoselective metabolism of methadone Ndemethylation by cytochrome P4502B6 and 2C19. Chirality 2004;16(1):36-44.

117. Kharasch ED, Regina KJ, Blood J, Friedel C. Methadone pharmacogenetics: CYP2B6 polymorphisms determine plasma concentrations, clearance, and metabolism. Survey of Anesthesiology 2016;60(3):125.

118. Crettol S, Deglon JJ, Besson J, Croquette-Krokar M, Hammig R, Gothuey I, et al. ABCB1 and cytochrome $\mathrm{P} 450$ genotypes and phenotypes: influence on methadone plasma levels and response to treatment. Clinical Pharmacology and Therapeutics 2006;80(6):668-81. 
119. Kringen MK, Chalabianloo F, Bernard JP, Bramness JG, Molden E, Hoiseth G. Combined Effect of CYP2B6 Genotype and Other Candidate Genes on a Steady-State Serum Concentration of Methadone in Opioid Maintenance Treatment. Therapeutic Drug Monitoring 2017;39(5):550-5.

120. Andersen HT, Ekgren JS. Hjertearytmi og plutselig d $\varnothing$ d under metadonbehandling [Heart arrhythmia and sudden death during methadone therapy]. Tidsskr Nor Laegeforen 2007;127(1):63.

121. Krüger M. Forlenget korrigert QT-tid hos metadonbrukere. En gjennomgang av foreliggende forskning og drøfting av forskningens implikasjoner for eksisterende retningslinjer. Oslo, Norway: University of Oslo; 2014. [Cited 2020 Jan 16]. Available from: https://www.duo.uio.no/bitstream/handle/10852/41108/Forlenget-korrigertQT-tid-hos-metadonbrukere.pdf? sequence $=1$ \&isAllowed $=\mathrm{y}$

122. Collins GB, McAllister MS. Buprenorphine maintenance: a new treatment for opioid dependence. Cleveland Clinical Journal of Medicine 2007;74(7):514-20.

123. Statens Legemiddelverk. Preparatomtale (SPC) Buprenorfin. Oslo, Norway: Statens Legemiddelverk, 2017.

124. Welsh C, Valadez-Meltzer A. Buprenorphine: A (relatively) new treatment for opioid dependence. Psychiatry (Edgmont) 2005;2(12):29.

125. Elkader A, Sproule B. Buprenorphine. Clinical Pharmacokinetics 2005;44(7):661-80.

126. Walsh SL, Preston KL, Stitzer ML, Cone EJ, Bigelow GE. Clinical pharmacology of buprenorphine: ceiling effects at high doses. Clinical Pharmacology and Therapeutics 1994;55(5):569-80.

127. Everhart ET, Cheung P, Shwonek P, Zabel K, Tisdale EC, Jacob P, 3rd, et al. Subnanogram-concentration measurement of buprenorphine in human plasma by electron-capture capillary gas chromatography: application to pharmacokinetics of sublingual buprenorphine. Clinical Chemistry 1997;43(12):2292-302.

128. Kuhlman JJ, Lalani S, Magluilo J, Levine B, Darwin WD, Johnson RE, et al. Human pharmacokinetics of intravenous, sublingual, and buccal buprenorphine. Journal of Analytical Toxicology 1996;20(6):369-78.

129. Harris DS, Mendelson JE, Lin ET, Upton RA, Jones RT. Pharmacokinetics and subjective effects of sublingual buprenorphine, alone or in combination with naloxone: lack of dose proportionality. Clinical Pharmacokinetics 2004;43(5):329-40. 
130. The European Integrated Project DRUID - Driving under the Influence of Drugs, Alcohol and Medicines; 2011. [Cited 2020 Jan 16]. Available from: https://www.bast.de/Druid/EN/Home/home_node.html

131. Rothenberg S, Schottenfeld S, Gross K, Selkoe D. Specific oculomotor deficit after acute methadone. I. Saccadic eye movements. Psychopharmacology (Berl) 1980;67(3):221-7.

132. Rothenberg S, Schottenfeld S, Selkoe D, Gross K. Specific oculomotor deficit after acute methadone. II. Smooth pursuit eye movements. Psychopharmacology (Berl) 1980;67(3):229-34.

133. Rothenberg S, Schottenfeld S, Meyer RE, Krauss B, Gross K. Performance differences between addicts and non-addicts. Psychopharmacology (Berl) 1977;52(3):299-306.

134. Saarialho-Kere U, Mattila MJ, Paloheimo M, Seppala T. Psychomotor, respiratory and neuroendocrinological effects of buprenorphine and amitriptyline in healthy volunteers. European Journal of Clinical Pharmacology 1987;33(2):139-46.

135. Fredheim OM, Kaasa S, Dale O, Klepstad P, Landro NI, Borchgrevink PC. Opioid switching from oral slow release morphine to oral methadone may improve pain control in chronic non-malignant pain: a nine-month follow-up study. Palliative Medicine 2006;20(1):35-41.

136. Temgesic 0,2 mg og 0,4 mg sublingualtablett: Felleskatalogen. Oslo, Norway: Felleskatalogen; 2015. [Cited 2020 Jan 16]. Available from: http://www.felleskatalogen.no/medisin/temgesic-rb-pharmaceuticals-Itd-564488

137. Zacny JP, James P. A review of the effects of opioids on psychomotor and cognitive functioning in humans. Experimental and Clinical Psychopharmacology 1995;3(4):432-66.

138. Jex HR, McDonnell JD, Phatak AV. A "critical" tracking task for man-machine research related to the operator's effective delay time. I. Theory and experiments with a firstorder divergent controlled element (NASA CR-616). NASA Contract Reports 1966:1105. Washington, DC: National Aeronautics and Space Administration; 1966.

139. Moskowitz H. Laboratory studies of the effects of alcohol on some variables related to driving. Journal of Safety Research 1973;5(3):185-99.

140. Loh S, Lamond N, Dorrian J, Roach G, Dawson D. The validity of psychomotor vigilance tasks of less than 10-minute duration. Behavior Research Methods, Instruments, and Computers 2004;36(2):339-46. 
141. McLeod DR, Griffiths RR, Bigelow GE, Yingling J. An automated version of the digit symbol substitution test (DSST). Behavior Research Methods and Instrumentation 1982;14(5):4.

142. Leufkens TR, Lund JS, Vermeeren A. Highway driving performance and cognitive functioning the morning after bedtime and middle-of-the-night use of gaboxadol, zopiclone and zolpidem. Journal of Sleep Research 2009;18(4):387-96.

143. Mets MA, Volkerts ER, Olivier B, Verster JC. Effect of hypnotic drugs on body balance and standing steadiness. Sleep Medicine Reviews 2010;14(4):259-67.

144. Mets MA, de Vries JM, de Senerpont Domis LM, Volkerts ER, Olivier B, Verster JC. Next-day effects of ramelteon $(8 \mathrm{mg})$, zopiclone $(7.5 \mathrm{mg})$, and placebo on highway driving performance, memory functioning, psychomotor performance, and mood in healthy adult subjects. Sleep 2011;34(10):1327-34.

145. Ball K, Owsley C. The useful field of view test: a new technique for evaluating agerelated declines in visual function. Journal of the American Optometric Association 1993;64(1):71-9.

146. Bramness JG, Skurtveit S, Morland J. Clinical impairment of benzodiazepines--relation between benzodiazepine concentrations and impairment in apprehended drivers. Drug and Alcohol Dependence 2002;68(2):131-41.

147. Hjelmeland K, Gustavsen I, Bernard JP, Morland J. Can a simple clinical test detect impairment of zopiclone and alcohol? - A randomized controlled trial. Forensic Science International 2015;248:129-33.

148. Kristoffersen L, Langodegard M, Gaare KI, Amundsen I, Terland MN, Strand DH. Determination of 12 commonly found compounds in DUID cases in whole blood using fully automated supported liquid extraction and UHPLC-MS/MS. Journal of Chromatography. B, Analytical Technologies in the Biomedical and Life Sciences 2018;1093-1094:8-23.

149. Valen A, Oiestad AML, Strand DH, Skari R, Berg T. Determination of 21 drugs in oral fluid using fully automated supported liquid extraction and UHPLC-MS/MS. Drug Testing and Analysis 2017;9(5):808-23.

150. Faul F, Erdfelder E, Lang AG, Buchner A. G*Power 3: a flexible statistical power analysis program for the social, behavioral, and biomedical sciences. Behavior Research Methods 2007;39(2):175-91.

151. Ramaekers JG. Drugs and driving research in medicinal drug development. Trends in Pharmacological Sciences 2017;38(4):319-21. 
152. Dunlap WP, Cortina JM, Vaslow JB, Burke M. Meta-analysis of experiments with matched groups or repeated measures designs. Journal of Psychological Methods 1996;1(2):170.

153. Falleti MG, Maruff P, Collie A, Darby DG, McStephen M. Qualitative similarities in cognitive impairment associated with $24 \mathrm{~h}$ of sustained wakefulness and a blood alcohol concentration of 0.05\%. Journal of Sleep Research 2003;12(4):265-74.

154. Blomberg RD, Preusser DF. Narcotic use and driving behavior. Accident Analysis and Prevention 1974;6(1):23-32.

155. Maddux JF, Williams TR, Ziegler JA. Driving records before and during methadone maintenance. American Journal of Drug and Alcohol Abuse 1977;4(1):91-100.

156. Babst DV, Newman S, Gordon NB, Warner A. Driving records of methadone maintenance patients in New York State. Journal of Drug Issues 1973;3:285-92.

157. Orriols L, Delorme B, Gadegbeku B, Tricotel A, Contrand B, Laumon B, et al. Prescription medicines and the risk of road traffic crashes: a French registry-based study. PLoS Medicine 2010;7(11):e1000366.

158. Fishbain DA, Cutler RB, Rosomoff HL, Rosomoff RS. Are opioid-dependent/tolerant patients impaired in driving-related skills? A structured evidence-based review. Journal of Pain and Symptom Management 2003;25(6):559-77.

159. Escher M, Daali Y, Chabert J, Hopfgartner G, Dayer P, Desmeules J. Pharmacokinetic and pharmacodynamic properties of buprenorphine after a single intravenous administration in healthy volunteers: A randomized, double-blind, placebocontrolled, crossover study. Clinical Therapeutics 2007;29(8):1620-31.

160. Zacny JP, Conley K, Galinkin J. Comparing the subjective, psychomotor and physiological effects of intravenous buprenorphine and morphine in healthy volunteers. Journal of Pharmacology and Experimental Therapeutics 1997;282(3):1187-97.

161. Yassen A, Olofsen E, Romberg R, Sarton E, Teppema L, Danhof M, et al. Mechanismbased PK/PD modeling of the respiratory depressant effect of buprenorphine and fentanyl in healthy volunteers. Clinical Pharmacology and Therapeutics 2007;81(1):50-8.

162. Kuhlman Jr JJ, Levine B, Johnson RE, Fudala PJ, Cone EJ. Relationship of plasma buprenorphine and norbuprenorphine to withdrawal symptoms during dose induction, maintenance and withdrawal from sublingual buprenorphine. Addiction 1998;93(4):549-59. 
163. Pleuvry BJ. Hysteresis in drug response. Anaesthesia and Intensive Care Medicine 2008;9(8):372-3.

164. Huang P, Kehner GB, Cowan A, Liu-Chen LY. Comparison of pharmacological activities of buprenorphine and norbuprenorphine: norbuprenorphine is a potent opioid agonist. Journal of Pharmacology and Experimental Therapeutics 2001;297(2):68895.

165. Barbarossa A, Rambaldi J, Giunti M, Zaghini A, Cunto M, Zambelli D, et al. Pharmacokinetics of buprenorphine following constant rate infusion for postoperative analgesia in dogs undergoing ovariectomy. Veterinary Anaesthesia and Analgesia 2017;44(3):435-43.

166. Bachs L, Hoiseth G, Skurtveit S, Morland J. Heroin-using drivers: importance of morphine and morphine-6-glucuronide on late clinical impairment. European Journal of Clinical Pharmacology 2006;62(11):905-12.

167. Bachs L, Skurtveit S, Morland J. Codeine and clinical impairment in samples in which morphine is not detected. European Journal of Clinical Pharmacology 2003;58(12):785-9.

168. Riley J, Ross JR, Rutter D, Wells AU, Goller K, Du Bois R, et al. No pain relief from morphine? Supportive Care in Cancer 2006;14(1):56-64.

169. Hauri-Bionda R, Bar W, Friedrich-Koch A. [Driving fitness/driving capacity of patients treated with methadone]. Schweizerische Medizinische Wochenschrift 1998;128(41):1538-47.

170. Davis PE, Liddiard H, McMillan TM. Neuropsychological deficits and opiate abuse. Drug and Alcohol Dependence 2002;67(1):105-8.

171. Darke S, Sims J, McDonald S, Wickes W. Cognitive impairment among methadone maintenance patients. Addiction 2000;95(5):687-95.

172. Ramaekers JG. Antidepressants and driver impairment: Empirical evidence from a standard on-the-road test. Journal of Clinical Psychiatry 2003;64(1):20-9.

173. Vuurman EF, Rikken GH, Muntjewerff ND, de Halleux F, Ramaekers JG. Effects of desloratadine, diphenhydramine, and placebo on driving performance and psychomotor performance measurements. European Journal of Clinical Pharmacology 2004;60(5):307-13.

174. Leufkens TRM, Vermeeren A. Highway Driving in the Elderly the Morning After Bedtime Use of Hypnotics A Comparison Between Temazepam 20 mg, Zopiclone 7.5 $\mathrm{mg}$, and Placebo. Journal of Clinical Psychopharmacology 2009;29(5):432-8. 
175. Vermeeren A, Riedel WJ, van Boxtel MPJ, Darwish M, Paty I, Patat A. Differential residual effects of zaleplon and zopiclone on actual driving: a comparison with a low dose of alcohol. Sleep 2002;25(2):224-31.

176. Jewett ME, Dijk DJ, Kronauer RE, Dinges DF. Dose-response relationship between sleep duration and human psychomotor vigilance and subjective alertness. Sleep 1999;22(2):171-9.

177. Williamson AM, Feyer AM, Mattick RP, Friswell R, Finlay-Brown S. Developing measures of fatigue using an alcohol comparison to validate the effects of fatigue on performance. Accident Analysis and Prevention 2001;33(3):313-26.

178. Bougard C, Lepelley MC, Davenne D. The influences of time-of-day and sleep deprivation on postural control. Experimental Brain Research 2011;209(1):109-15.

179. Robbe HW, O'Hanlon JF. Acute and subchronic effects of paroxetine 20 and $40 \mathrm{mg}$ on actual driving, psychomotor performance and subjective assessments in healthy volunteers. European neuropsychopharmacology : the journal of the European College of Neuropsychopharmacology 1995;5(1):35-42.

180. Schuhfried G. Manual Expert System Traffic (XPSV). Schuhfried GmbH, Mödling; 2005.

181. Brunnauer A, Laux G, David I, Fric M, Hermisson I, Moller HJ. The impact of reboxetine and mirtazapine on driving simulator performance and psychomotor function in depressed patients. Journal of Clinical Psychiatry 2008;69(12):1880-6.

182. Risser R, Chaloupka C, Grundler W, Sommer M, Hausler J, Kaufmann C. Using nonlinear methods to investigate the criterion validity of traffic-psychological test batteries. Accident Analysis and Prevention 2008;40(1):149-57.

183. Schnabel E, Hargutt V, Krüger H. Meta-analysis of empirical studies concerning the effects of alcohol on safe driving: Driving under the influence of drugs, alcohol, and medicines (DRUID) 6th framework programme. Wuerzburg, Germany: University of Wuerzburg; 2010. [Cited 2020 Jan 16]. https://www.bast.de/Druid/EN/deliveraleslist/downloads/Deliverable 11 2.html?nn=613800 


\section{Erratum}

- Paper II uses mg ml-1 as unit for blood alcohol concentration, i.e. concentration by volume. The correct unit should be concentration by mass in $\mathrm{g} / \mathrm{kg}$ or $\%$. 
18. Papers I-III 



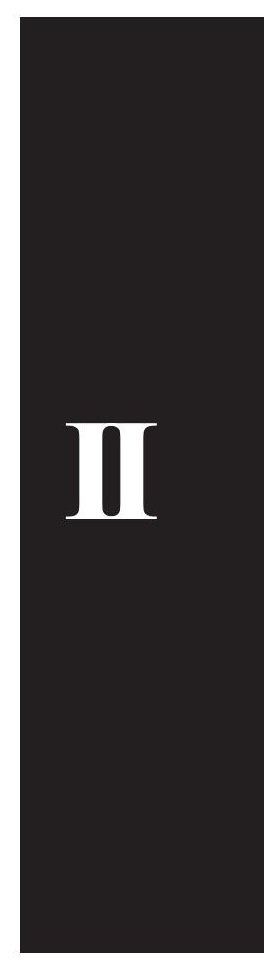





\title{
ORIGINAL ARTICLE
}

\section{A clinical trial on the acute effects of methadone and buprenorphine on actual driving and cognitive function of healthy volunteers}

Correspondence Maren Cecilie Strand, Oslo University Hospital, Department of Forensic Sciences, Oslo, Norway. Tel.: +47 915 02770; E-mail: marencstrand@hotmail.com

Received 4 July 2018; Revised 5 November 2018; Accepted 7 November 2018

\author{
Maren Cecilie Strand ${ }^{1,2,3, *} \mathbb{D}$, Vigdis Vindenes ${ }^{1,2}$, Hallvard Gjerde ${ }^{1}$, Jørg Gustav Mørland ${ }^{2,4}$ and \\ Johannes G. Ramaekers ${ }^{3, *}$ \\ ${ }^{1}$ Department of Forensic Sciences, Oslo University Hospital, Oslo, Norway, ${ }^{2}$ University of Oslo, Institute of Clinical Medicine, Oslo, Norway, \\ ${ }^{3}$ Department of Neuropsychology and Psychopharmacology, Faculty of Psychology and Neuroscience, University of Maastricht, Maastricht, \\ The Netherlands, and ${ }^{4}$ Division of Health Data and Digitalization, Norwegian Institute of Public Health, Oslo, Norway
}

*The authors confirm that the PIs for this paper are Maren Cecilie Strand, M.D. and specialist in clinical pharmacology, and prof.dr. Johannes Ramaekers, and that they had direct clinical responsibility for patients.

Keywords clinical trials, opioids, pharmacodynamics

AIMS

The present study assessed the acute effects of methadone and buprenorphine on actual on-road driving performance and neurocognitive function.

\section{METHODS}

Methadone ( 5 and $10 \mathrm{mg}$ per os) and buprenorphine ( 0.2 and $0.4 \mathrm{mg}$ sublingual) were administered to 22 healthy volunteers in a five-way, double-blind, randomized, placebo-controlled, double-dummy, cross-over study. Driving performance was assessed with an on-road driving test. The primary outcome measure was standard deviation of lateral position (SDLP), a measure of road tracking control. Laboratory tests were used to measure cognitive function (e.g. reaction time and attention) and questionnaires were used to assess subjective measures of mood and sedation.

\section{RESULTS}

There was no significant main effect of treatment on SDLP. Yet, analysis of individual drug-placebo contrast data revealed that buprenorphine $0.4 \mathrm{mg}$ significantly increased SDLP. Driving impairment was mild and below the impairment threshold of a blood alcohol concentration of $0.5 \mathrm{mg} \mathrm{ml}^{-1}$. Four participants stopped their driving test while under the influence of either opioid due to sleepiness. Both opioids produced impairments of cognitive task performance and increased sleepiness particularly at the highest dose.

\section{CONCLUSIONS}

Analgesic doses of buprenorphine produced mild impairing effects on driving and related cognitive skills, while methadone impaired cognitive task performance but not driving performance. Large individual variations were observed for both drugs. Patients should be informed about the possibility of driving impairment when initiating opioid treatment. 
WHAT IS ALREADY KNOWN ABOUT THIS SUBJECT

- Opioids have been associated with increased crash risk among drivers but it is unknown whether this association generalizes to all opioids or pertains to specific opioids in particular.

\section{WHAT THIS STUDY ADDS}

- An on-road driving test was used to assess the acute effects of analgesic doses of methadone and buprenorphine.

- Buprenorphine $0.4 \mathrm{mg}$ mildly impaired on-road driving.

- Buprenorphine and methadone produced some cognitive and clinical impairments and increased sleepiness, particularly after the high doses.

\section{Introduction}

Opioids are frequently prescribed for the treatment of pain. The global consumption of opioids was close to 12 billion of defined daily doses in 2016 [1]. Over the last 20 years, the global consumption has more than tripled and the share of synthetic opioids has increased to $39 \%$. In addition, non-medical use of prescription opioids has been rising excessively. The large numbers of overprescription, abuse and overdose death have subsequently generated an opioid crisis, particularly in North America. In 2016, more than 42000 persons died in the US as a result of an opioid overdose, including prescription opioids [2]. Between January 2016 and September 2017 there were close to 6000 opioidrelated deaths in Canada [3].

Besides the overdoses, mortality among opioid users has also been associated with accidents related to driving under the influence. Epidemiological studies have shown a statistically significant association between opioid use and road traffic crashes [4]. A European case-control study that was conducted as part of the research project DRUID concluded that the average odds ratio of getting seriously injured or killed in an accident increased by a factor of 2-10 when driving under the influence of medicinal opioids. The latter is comparable to the risk of driving under the influence of alcohol at blood alcohol concentrations (BAC) of $0.5-0.8 \mathrm{mg} \mathrm{ml}^{-1}$ [5].

Methadone and buprenorphine are opioids widely used as analgesics and in opioid maintenance treatment. In blood samples from drivers suspected of drugged driving in Norway in 2016, methadone was detected in $2 \%$ and buprenorphine in $3 \%$ of cases [6]. Approximately 26000 persons used buprenorphine or methadone on prescription in Norway in 2016, 18000 of which used buprenorphine as an analgesic patch [7]. Opioid prescription in Norway between 2014-2016 was 12 defined daily doses (DDD) per 1000 inhabitants per day [8].

Methadone is a synthetic, long-acting opioid. Methadone acts primarily on $\mu$-opioid receptors that are thought to be particularly important for analgesia, euphoria, respiratory depression, tolerance and dependence. A regular dose of methadone in pain treatment is $5-10 \mathrm{mg}$ per os $3-4$ times per day. Buprenorphine is a semi-synthetic partial opioid agonist/antagonist which binds to $\delta$-receptors, $\mu$-receptors and $\kappa$-receptors in the brain. Buprenorphine has a wide therapeutic range due to its agonist/antagonist effects, which limits its depressant effects especially on respiratory and cardiac functions. A regular dose of buprenorphine in pain treatment is $0.2-0.4 \mathrm{mg}$ sublingual up to $3-4$ times daily.
Although epidemiological studies indicate that opioid use increases crash risk among drivers, it is less clear whether driving impairment is caused by each and every opioid within this group. Traditionally, placebocontrolled studies have been employed to study differential effects of opioids on neurocognitive function and skills related to driving [9]. So far, experimental studies on the acute effects of methadone and buprenorphine on driving-related performance in opioid-naïve subjects have been inconclusive. Few studies on psychomotor and cognitive performance among healthy volunteers after administration of a single dose of methadone or buprenorphine have been performed [10-17]. Only some of these indicated that methadone $5 \mathrm{mg}$ per os and buprenorphine $0.3 \mathrm{mg}$ sublingual produced psychomotor impairment in opioid naïve individuals [13-16]. However, the clinical relevance of these findings is difficult to establish as these studies neither included a reference drug like ethanol, nor included standardized tests to assess impairment [18-20].

Dedicated driving studies to determine and qualify the clinical relevance of drug effects on driver safety have been conducted for over 30 years by researchers in the Netherlands [21]. These studies employed a standardized on-road driving test that is conducted on a primary highway in normal traffic. The primary outcome parameter is standard deviation of lateral position (SDLP), a measure of road tracking performance. This measure has been shown to significantly increase in drivers who are exposed to acute or repeated doses of sedating drugs [21] and to be sensitive to BAC as low as $0.35 \mathrm{mg} \mathrm{ml}^{-1}$ [22]. Alcohol produced an exponential rise in SDLP with increasing BACs. The mean increment in SDLP (i.e. $2.5 \mathrm{~cm}$ ) that was observed while driving with a BAC of $0.5 \mathrm{mg} \mathrm{ml}^{-1}$ has been defined as the minimal cut-off value to represent clinical relevance [23]. Recently, the on-road test was used to compare driving performance of chronic non-cancer pain patients who received chronic opioid therapy (e.g. hydromorphone, oxycodone and fentanyl) to that of matched controls. Driving performance of these patients did not significantly differ from that of controls indicating tolerance to certain opioid effects, although large interindividual variations were observed [24]. On-road studies assessing the acute effects of buprenorphine and methadone are still lacking.

The aims of this study were to assess and compare the effects of methadone and buprenorphine on actual driving and cognitive and psychomotor performance in healthy volunteers. 


\section{Methods}

\section{Subjects}

Twenty-two healthy volunteers (11 male, 11 female) aged 23-49 years (mean age 36 years) were included after screening of 29 volunteers in total. They were recruited via advertisements in local newspapers and poster advertisements in Maastricht University. None of the volunteers used opioid analgesics regularly at the time of testing.

Inclusion criteria were: healthy males or females based on a physical examination, medical history, vital signs, electrocardiogram, and the results of blood chemistry and haematology tests, and urine analysis; age between 23 and 50 years; body mass index (weight/length ${ }^{2}$ ) between 19 and $29 \mathrm{~kg} \mathrm{~m}^{-2}$; possession of a valid driving license for minimum 4 years; driving experience of minimum $5000 \mathrm{~km}$ per year on average; and good sleeper.

Exclusion criteria were: pregnancy or lactation, sleep disorders; drug or alcohol abuse; use of psychoactive medication or drug considered to influence the test drugs; excessive alcohol use ( $>21$ units per week); excessive caffeine use ( $\geq 5$ cups per day); smoking $>6$ cigarettes per day; intake of any opioid within 3 months before the study; significant disease; and poor metabolism of methadone due to CYP2B6 polymorphism.

Approval of the study was obtained from the independent Ethics Committee of Maastricht University and the Academic Hospital Maastricht in the Netherlands and from the Regional Committees for Medical and Health Research Ethics in Norway. This study was conducted according to the code of ethics on human experimentation established by the Declaration of Helsinki (1964) and amended in Fortaleza, Brazil (2013) and in accordance with the Medical Research Involving Human Subjects Act. Written informed consent was obtained from all volunteers.

\section{Design and treatments}

The study followed a five-way, double-blind, randomized, placebo-controlled, double-dummy, cross-over design to compare the acute effects of two single doses of methadone ( 5 and $10 \mathrm{mg}$ per os) and buprenorphine ( 0.2 and $0.4 \mathrm{mg}$ sublingual) with placebo. The minimum washout period between test days was 10 days.

Similar doses of methadone and buprenorphine have been administered to opioid naïve users in previous studies [13-16]. The dose regimen of methadone frequently used for pain relief is $5-10 \mathrm{mg}$ per os 3-4 times daily. Buprenorphine is used in pain treatment in doses of $0.2-0.4 \mathrm{mg}$ sublingual up to $3-4$ times daily. A single dose of buprenorphine $0.8 \mathrm{mg}$ sublingual is equivalent to morphine $60 \mathrm{mg}$ per os, while a single dose of methadone $20 \mathrm{mg}$ per os is equivalent to morphine $60 \mathrm{mg}$ per os [25].

Methadone (methadone capsules and placebo capsules) and buprenorphine (buprenorphine sublingual tablets and placebo sublingual tablets) were purchased, blinded and labelled by University Pharmacy (Nijmegen, the Netherlands) and Tiofarma (Oud-Beijerland, the Netherlands), respectively, according to the Good Manufacturing Practice guidelines.

\section{Procedure}

When participants arrived, urine samples were screened for drugs by using the SureStep ${ }^{\mathrm{TM}}$ Drug Screen Cup (Abbott, Abbott Park, IL, USA); a pregnancy test was performed using the Alere ${ }^{\mathrm{TM}}$ hCG Cassette (Abbott), and breath alcohol was analysed using Dräger Alcotest 5000 (Drägerwerk AG \& Co., Lübeck, Germany).

Participants were asked to refrain from consuming caffeine (coffee, tea and soft drinks) on test days from awakening until the end of testing as well as alcohol intake from $24 \mathrm{~h}$ prior to test days. Participants were instructed to have a normal night of sleep before test days. This was assessed with the Groningen Subjective Quality of Sleep Questionnaire [26]. Drug screens assessed for the presence of methamphetamine, cocaine, THC, morphine, benzodiazepines and amphetamine in urine. On each test day participants received two capsules containing methadone or placebo and two sublingual tablets containing buprenorphine or placebo, according to a double-dummy procedure. Figure 1 provides a schematic overview of a test day.

Blood was collected using 5-ml Vacutainer ${ }^{\circledR}$ tubes containing sodium fluoride $(20 \mathrm{mg})$ and sodium heparin (143 IU) (BD Diagnostics, Franklin Lakes, NJ, USA).

\section{Highway driving test}

The on-road driving test was performed on a $100 \mathrm{~km}$ primary highway segment in normal traffic [21,27]. Participants were instructed to drive with a steady lateral position within the right traffic lane at a constant speed of $95 \mathrm{~km} \mathrm{~h}^{-1}$ (60 mph). A licensed driving instructor accompanied the driver. A specially instrumented vehicle was used to measure standard deviation of lateral position (SDLP in $\mathrm{cm}$ ) or 'weaving', the primary outcome variable [28], see Figure 2. In addition to SDLP, the standard deviation of speed (SDSP) and mean lateral position (MLP) were measured.

\section{Cognitive and psychomotor tests}

The Psychomotor Vigilance Task (PVT) measured sustained attention by assessing the reaction time in response to a visual stimulus. The subject had to react to the onset of the counter as quickly as possible by pressing a response button [29]. Lapses were defined as a failure to react or any reaction exceeding $500 \mathrm{msec}$.

The Critical Tracking Task (CTT) measured the ability to control an unstable error signal in a first-order compensatory tracking task [30]. Subjects were instructed to keep an unstable bar in the middle of a horizontal plane by counteracting or reversing its movements with the aid of a joystick. The frequency of cursor deviations at which the subject lost control is the critical frequency.

The Divided Attention Test (DAT) measured the ability to divide attention between two simultaneously performed tasks [31]. In the primary task, the subject performed the same tracking task as described above (CTT), yet at a constant level of difficulty set at $50 \%$ of his or her maximum capacity. In the secondary task, the subject monitored 24 peripheral displays in which single digits changed asynchronously at $5 \mathrm{~s}$ intervals. Subjects were instructed to remove their foot from a pedal as rapidly as possible whenever the digit ' 2 ' appeared. 


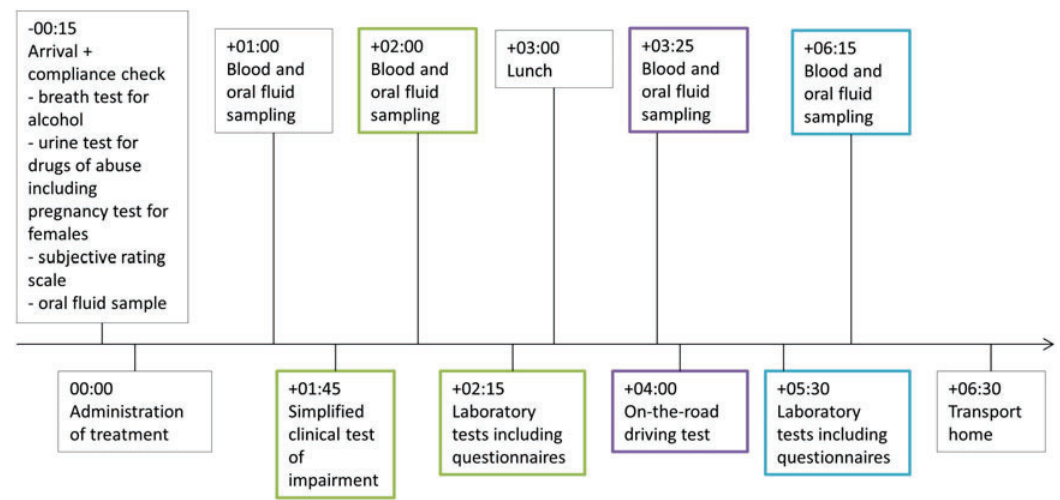

Figure 1

Schematic overview of a test day
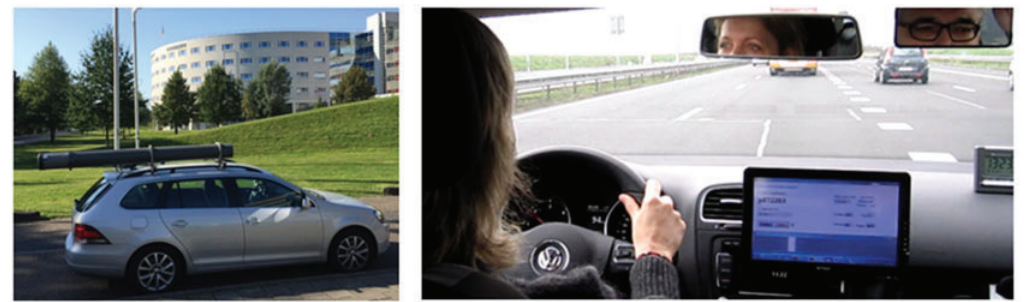

Standard Deviation of Lateral Position (SDLP)

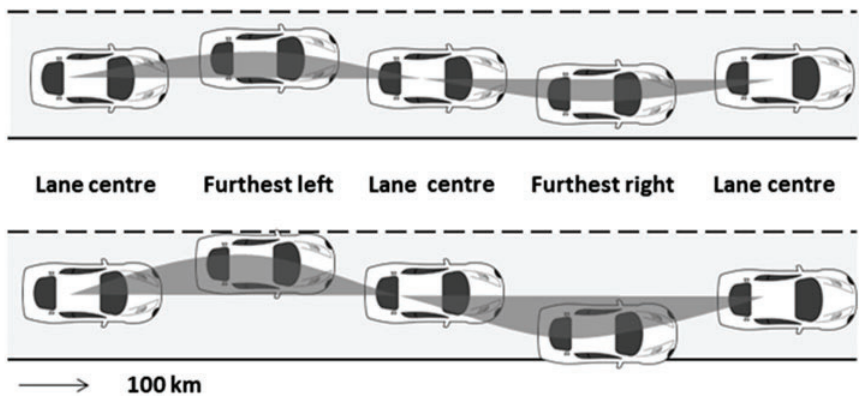

Placebo

(e.g. SDLP=16cm)

Sedating drug

(SDLP increases)

\section{Figure 2}

Standardized highway driving test. A specially instrumented car was used during the on-road driving test. Participants were instructed to drive with a steady lateral position between the delineated borders of the right lane with a constant speed of $95 \mathrm{~km} \mathrm{~h}^{-1}(60 \mathrm{mph})$. A licensed driving instructor was accompanying the participant in the car (upper panels). The standard deviation of lateral position (SDLP in cm) is an index of road tracking error or 'weaving' (lower panel)

The Useful Field of View Test (UFOV) included three increasingly difficult, visually presented subtests: stimulus identification, divided attention and selective attention [32]. The participants had to identify a target presented at a central fixation point on the screen, and the second and third subtest included peripheral simultaneous targets as visual distractors.

The Digit Symbol Substitution Test (DSST) measured executive attention and processing speed [33]. A computerized version was used [34]. The subject was required to match digits with a symbol from an encoding list as rapidly as possible by clicking the corresponding response button.
Postural Balance test (PBT) measured balance using the AMTI AccuSway System for Balance and Postural Sway Measurement (Advanced Mechanical Technology, Inc., Watertown, MA, USA) force platform [35, 36]. Postural sway was assessed in two trials (eyes open and eyes closed) by measuring the length of the path of the centre-of-pressure (COP), and the area of the $95 \%$ confidence ellipse enclosing the COP (A95).

Vienna Test System - Determination Test (DT/S1) measured resilience of attention and reaction speed under conditions of sensory stress. The task of the respondent was to identify various stimuli and to react to them by pressing the 
respective corresponding response buttons. This test presented the stimuli a little faster than would be optimal given the respondents' reaction speed, thus resulting in a condition of sensory stress.

A simplified clinical test of impairment was performed [37]. The clinical test of impairment, used in Norway by medical doctors working for the police with suspects driving under the influence of drugs, consists of 25 tests and observations related to common signs of drug impairment [38]. Five subtests from the Norwegian clinical test of impairment were selected: gait-on-line test, turn-on-line test, finger-to-finger test, finger-to-nose test, and Romberg's test (standing steady on one leg for at least $5 \mathrm{~s}$ with arms stretched out and eyes closed) [37]. For each of the five subtests, the performance was measured and scored as either 'habitual', 'somewhat deviant' or 'deviant'. An overall impression of the subject, termed the 'global impression', being the sixth subtest, was graded as either 'not impaired', 'slightly impaired', 'moderately impaired' or 'obviously impaired'.

\section{Subjective evaluations}

Subjective evaluations of mood and apparent sedation were assessed by using a series of visual analogue scales $(100 \mathrm{~mm})$ [39]. Subjects rated their subjective feelings on a 16-item mood scale which provided three factor analytically defined summary scores for 'alertness', 'contentedness' and 'calmness'.

The Karolinska sleepiness scale is a subjective rating scale with scores that range from 1, 'extremely alert,' to 9 , 'very sleepy, great effort to keep alert, fighting sleep' [40]. Reyner and Horne modified the original scale by adding verbal descriptions to intermediate steps, which do not have any descriptions in the original version [41].

\section{Safety assessment}

During test periods, side effects either observed by the investigator or spontaneously reported by the subject were recorded.

\section{Pharmacokinetics}

Concentrations of methadone and buprenorphine in samples of whole blood were determined using ultra-highperformance liquid chromatography-tandem mass spectrometry (UHPLC-MS/MS) after 96-well supported liquid extraction [42], which was slightly modified for the determination of methadone and buprenorphine by adding relevant calibration standards. The cut-off concentrations were $0.5 \mathrm{nM}$ for methadone and $0.2 \mathrm{nM}$ for buprenorphine.

\section{Statistics}

All measures were analysed using General Linear Model (GLM) univariate measures. The model included two fixed factors, i.e. Treatment (5 levels) and Time (2 levels), and a random factor for Subjects. Independent of the results of the main effect of treatment analysis, a drug-placebo contrast as well as low dose $v s$. high dose contrast for each opioid was performed. In addition, a non-inferiority analysis was conducted on SDLP data collected in the highway driving test to determine clinical relevance of drug-induced changes relative to placebo. For SDLP, non-inferiority between treatment and placebo was concluded if the upper limit of the 95\% CI of the mean difference between drug and placebo was $<2.5 \mathrm{~cm}$. The latter criterion represents a clinically relevant change in SDLP as observed after a BAC of $0.5 \mathrm{mg} \mathrm{ml}^{-1}$ [23]. A power analysis showed that in order to detect drug effects of medium size $(f=0.25)$ on the within subject variable (SDLP), a total of 20 participants would be adequate, using a two-sided $t$-test with $95 \%$ power at a significance level of $5 \%$. All statistical analyses were conducted using SPSS for Windows (version 25; SPSS Inc., Chicago, IL, USA).

\section{Nomenclature of targets and ligands}

Key protein targets and ligands in this article are hyperlinked to corresponding entries in http://www. guidetopharmacology.org, the common portal for data from the IUPHAR/BPS Guide to PHARMACOLOGY [43], and are permanently archived in the Concise Guide to PHARMACOLOGY 2017/18 [44].

\section{Results}

\section{Failure to complete driving test and missing data}

Driving tests had to be terminated prematurely on request of the participants six times (by four participants). In all cases, the participants told the driving instructor that they wanted to terminate the driving session because they felt too sleepy to continue driving. Driving tests were stopped twice during methadone $10 \mathrm{mg}$ and buprenorphine $0.4 \mathrm{mg}$ and once following buprenorphine 0.2 and placebo. Two subjects did not complete all treatment conditions. All data from the onroad driving test entered the analysis, except one prematurely terminated ride where driving data was collected for $6 \mathrm{~min}$ only (in the buprenorphine $0.2 \mathrm{mg}$ condition). Extreme outliers, defined as deviating more than $\pm 3 \mathrm{SD}$ from the mean were removed from the respective parameter. In the PBT, three values were excluded in the eyes open condition, and five values in the eyes closed condition.

On several test days subjects were not able to complete neurocognitive tests because of side effects. These data were registered as missing data and were not included in the analysis. The number (\%) of subjects that were unable to perform neurocognitive tasks were: PVT $n=3(14 \%)$; CTT $n=5(23 \%)$; DAT $n=7(32 \%) ;$ DSST $n=4(18 \%) ;$ DTS1 $n=7$ (32\%); UFOV $n=5(23 \%)$; and PBT $n=10(45 \%)$.

\section{Highway driving test}

Table 1 presents a summary of mean (SE) driving and cognitive test performances in all treatment conditions and their associated GLM statistics.

Analysis of variance showed no significant main effects of Treatment on SDLP or standard deviation of speed (SDSP), but a significant effect on mean lateral position (MLP). Drug-placebo contrasts revealed that buprenorphine $0.4 \mathrm{mg}$ significantly increased SDLP. Non-inferiority was shown for both methadone conditions as well as the low dose of buprenorphine. The high dose of buprenorphine 


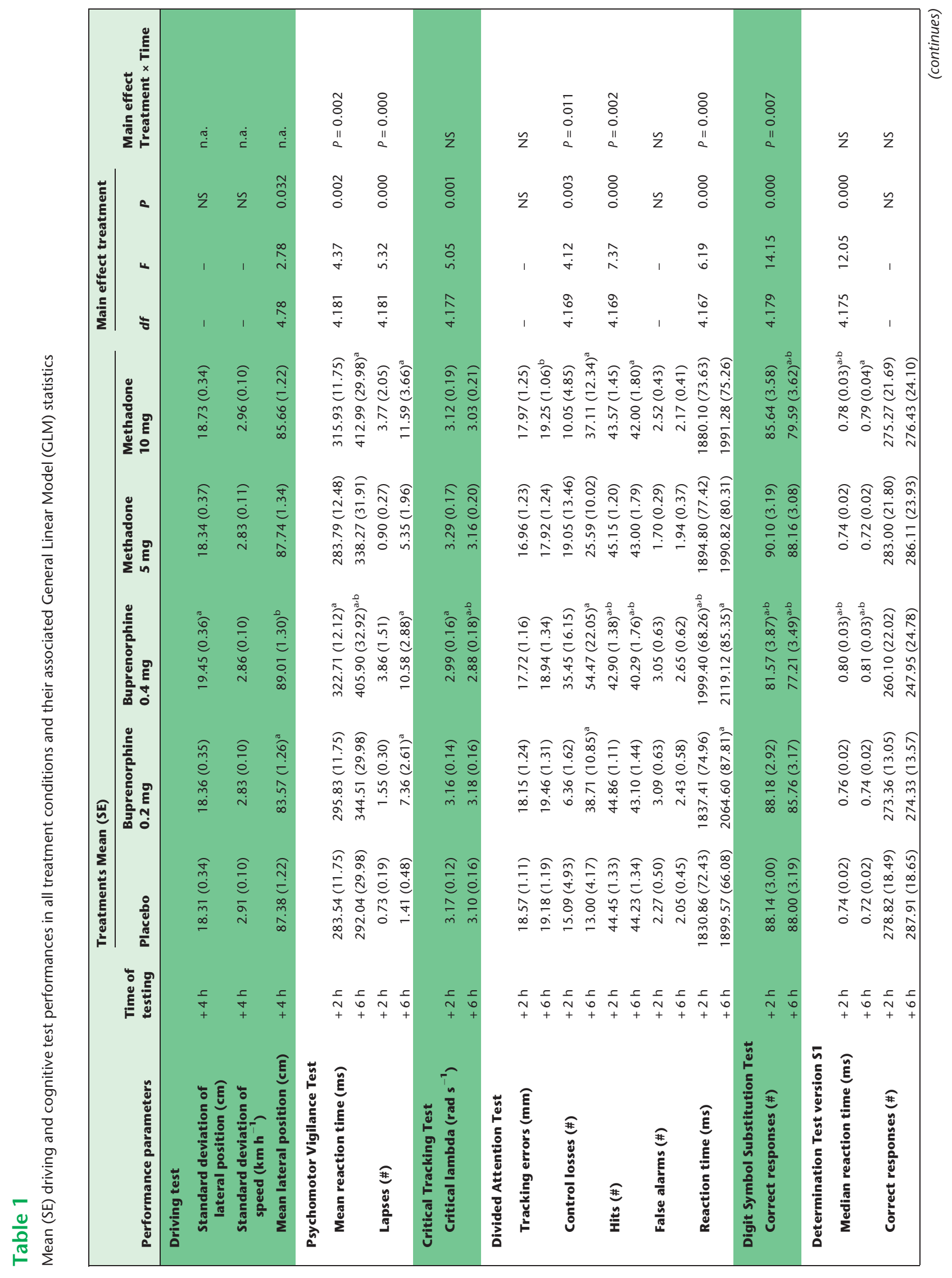

Br J Clin Pharmacol (2019) 85 442-453 447 


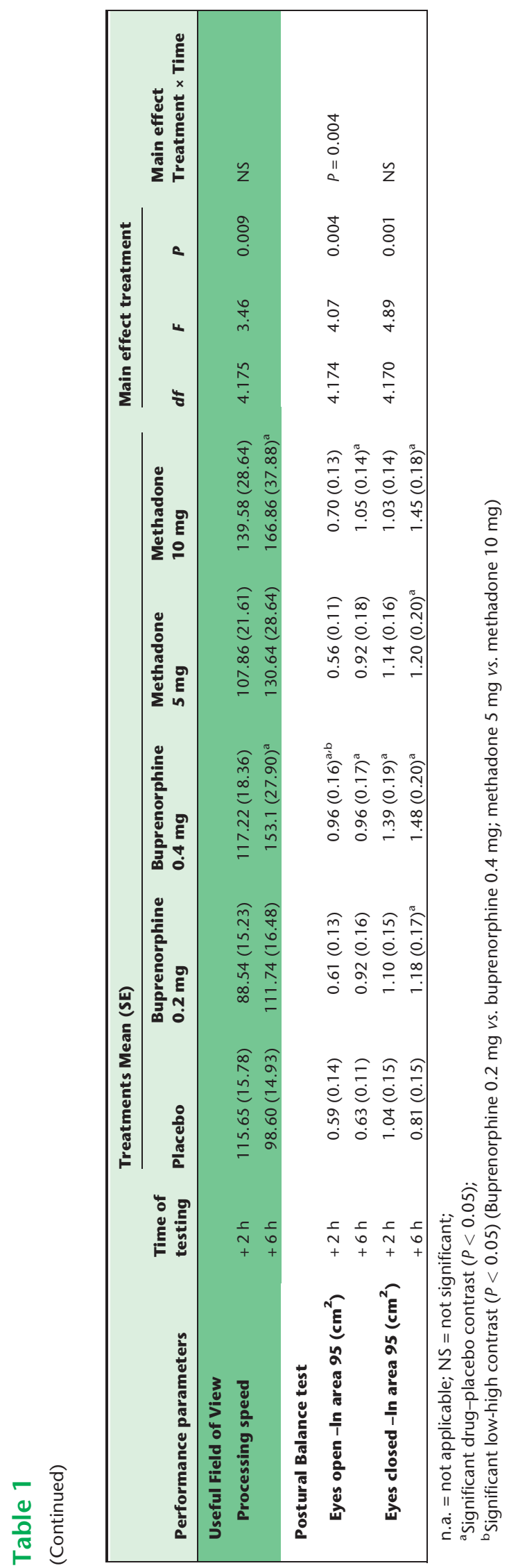

significantly increased SDLP relative to placebo, but the 95\% CI did not include the criterion for clinical relevance at a BAC of $0.5 \mathrm{mg} \mathrm{ml}^{-1}$. Mean changes in SDLP (95\% CI) in all drug conditions are shown in Figure 3.

\section{Cognitive tests}

Significant main effects of Treatment and Treatment $\times$ Time were observed in the PVT (reaction time and lapses), the DAT (control losses, hits and reaction time), Postural balance (eyes open) and the DSST (correct response). Main effects of Treatment were found for all tests.

Drug-placebo contrasts revealed that the low dose of methadone did not affect any of the cognitive parameters, except for an increase in postural balance in the eyes closed condition. The high dose of methadone significantly increased number of lapses (PVT), number of control losses (DAT), reaction time (PVT and DT) and decreased number of hits (DAT), correct responses (DSST), processing speed (UFOV) and postural balance. Drug-drug contrast revealed that impairments observed in reaction time (DT), tracking error (DAT) and correct responses (DSST) were significantly more pronounced during the high as compared to the low dose.

The low dose of buprenorphine significantly increased reaction time (DAT), number of lapses (PVT), number of control losses (DAT) and postural balance (eyes closed). The high dose of buprenorphine significantly increased reaction time (PVT, DAT and DT), number of lapses (PVT), tracking (CTT), number of control losses (DAT) and decreased number of hits (DAT), correct responses (DSST), processing speed (UFOV) and postural balance. Drug-drug contrast revealed that impairments observed in reaction time (PVT, DAT and DAT), tracking (CTT), hits (DAT), correct responding (DSST) and postural balance were significantly more pronounced during the high as compared to the low dose.

\section{Questionnaires and clinical test of impairment} Table 2 presents mean (SE) scores on questionnaires and the clinical test of impairment in every treatment condition and statistics for main effects, drug-placebo and low $v s$. high dose contrasts.

Main effects of treatment were observed for all parameters of the clinical test of impairment except the finger-to-nose test, the Karolinska sleepiness scale and the factors alertness and contentedness of the Bond and Lader scale. Main effects of Treatment $\times$ Time were only observed for ratings of sleepiness and alertness.

Drug-placebo contrasts showed that the low dose of methadone increased sleepiness, clinical impairment rating (on one parameter) and reduced alertness. The high dose also increased sleepiness, clinical ratings of impairment (on five parameters) and alertness. Levels of impairment did not significantly differ between both doses on any of these parameters.

The low dose of buprenorphine increased sleepiness, clinical ratings of impairment (on two parameters) and reduced alertness and contentedness. The high dose increased sleepiness, clinical ratings of impairment (on four parameters) and reduced alertness and contentedness. Sleepiness, loss of alertness and clinical ratings of impairment (on one 


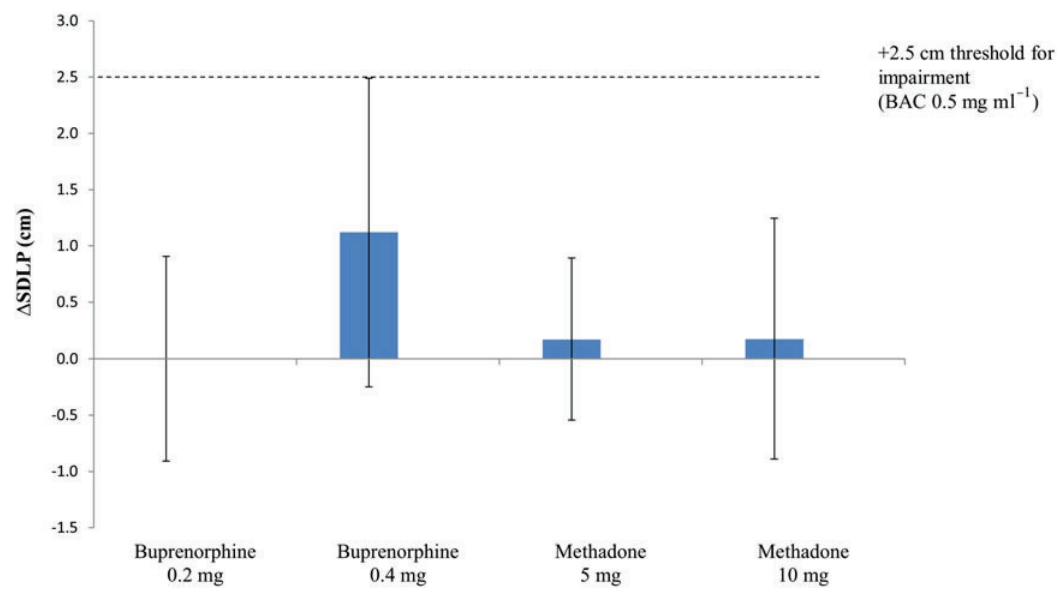

Figure 3

Mean $(95 \% \mathrm{Cl})$ changes in standard deviation of lateral position (SDLP) relative to placebo, in every drug condition

parameter) were more pronounced after the high dose as compared to the low dose.

\section{Side effects}

No serious adverse events were observed during the study. The most frequently reported side effects were nausea, vomiting, dizziness and tiredness/sleepiness. A summary of the most frequently reported side effects is given in Table 3.

\section{Pharmacokinetics}

Mean $( \pm \mathrm{SD})$ methadone and buprenorphine blood concentrations are presented in Table 4.

\section{Discussion}

In the current study the acute effects of methadone (5 $\mathrm{mg}$ and $10 \mathrm{mg})$ and buprenorphine $(0.2 \mathrm{mg}$ and $0.4 \mathrm{mg})$ on on-road driving, psychomotor and cognitive performance were assessed. A significant increase in SDLP (i.e. $1.12 \mathrm{~cm}$ ) during highway driving was found after $0.4 \mathrm{mg}$ of buprenorphine as compared to placebo. The low dose of buprenorphine as well as both doses of methadone did not affect on-road driving. The influence of both opioids on cognitive task performance was more prominent. Particularly the high doses produced performance impairments on several neurocognitive tests. In addition, both drugs increased levels of sleepiness, reduced alertness and increased ratings of clinical impairment.

On-road driving data indicated that overall, the influence of methadone and buprenorphine were mild or even absent. Non-inferiority was shown for both methadone doses as well as the low dose of buprenorphine, relative to placebo. The high dose of buprenorphine significantly increased SDLP relative to placebo, but the $95 \%$ CI did not exceed the BAC $\left(0.5 \mathrm{mg} \mathrm{ml}^{-1}\right)$ criterion for clinical relevance. Mean lateral position (LP) differed significantly across treatments, mainly because mean LP was lower after the low dose of buprenorphine, relative to placebo. During this treatment condition, subjects chose a lane position that was slightly left of the lane centre. Mean LP is a control measure to check if subjects adhered to the instruction of driving in the centre of the lane. The current data thus indicated that subjects did not entirely adhere to that instruction during the lower dose of buprenorphine but instead chose to drive closer to the midline of the road. One can only speculate that the choice to drive closer to the middle line reflects risk-taking behaviour, a strategy for road tracking or other motivations. Driving impairment was sometimes noticeable at the individual level across treatment conditions. Four participants (18\%) decided to prematurely finish their driving tests while under the influence of buprenorphine (on three occasions) and methadone (on two occasions) because of sleepiness while driving. This indicates large interindividual variations in driving performance of patients who receive opioid treatment, some of whom might be impaired whilst most are not. Individual differences in impairment levels might be associated to individual differences in drug concentrations, drug sensitivity and the presence of side effects that may affect driving.

In contrast to the sparse impairments observed in the driving tests, all of the cognitive and psychomotor tests showed dose-related impairment during opioid treatment conditions as compared to placebo. Seven cognitive tests were included to measure skills related to driving, such as psychomotor speed (CTT, PVT, DSST, DAT), divided attention (DAT, UFOV), sustained attention (PVT), reaction speed (DTS1) and postural balance (PBT). The high doses of buprenorphine and methadone impaired performance in almost every cognitive test. The low doses of buprenorphine and methadone, on the other hand, only affected some parameters in the PBT, DAT and PVT and in the PBT, respectively. These findings are in line with previous research showing that methadone and buprenorphine can impair reaction time and attention [18]. For several tasks, a significant Treatment $\times$ Time interaction was observed indicating that opioid effects were more pronounced at $6 \mathrm{~h}$ post administration as compared to $2 \mathrm{~h}$. This suggests that impairments levels may increase with increasing time on task due to tiredness. 


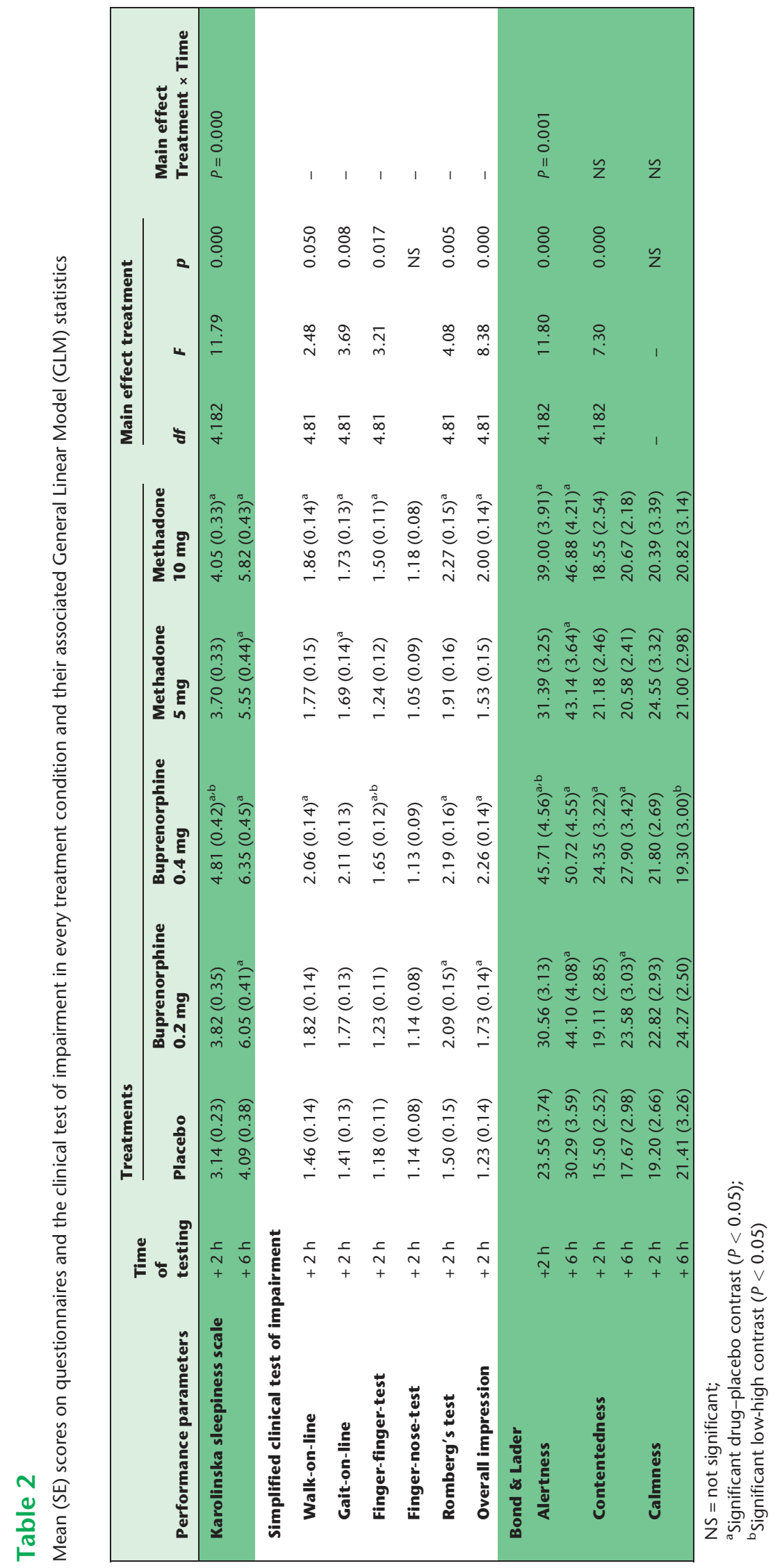


Table 3

Side effects occurring in $>2$ subjects

\begin{tabular}{|c|c|c|c|c|c|}
\hline Side effects & $\begin{array}{l}\text { Placebo } \\
(n=22) n(\%)\end{array}$ & $\begin{array}{l}\text { Buprenorphine } 0.2 \mathrm{mg} \\
(n=22) n(\%)\end{array}$ & $\begin{array}{l}\text { Buprenorphine } 0.4 \mathrm{mg} \\
(n=21) n(\%)\end{array}$ & $\begin{array}{l}\text { Methadone } 5 \mathrm{mg} \\
(n=20) n(\%)\end{array}$ & $\begin{array}{l}\text { Methadone } 10 \mathrm{mg} \\
(n=22) n(\%)\end{array}$ \\
\hline Nausea & $1(5)$ & $5(23)$ & $15(71)$ & $4(20)$ & $11(50)$ \\
\hline Vomiting & - & - & $9(43)$ & $1(5)$ & $4(18)$ \\
\hline Tiredness & $7(32)$ & $9(41)$ & $8(38)$ & $11(55)$ & $11(50)$ \\
\hline Sleepiness & $6(27)$ & $10(45)$ & $6(29)$ & $7(35)$ & $7(32)$ \\
\hline Headache & $2(9)$ & $2(9)$ & $2(10)$ & $4(20)$ & $1(5)$ \\
\hline Warm/sweaty & - & $1(5)$ & $5(24)$ & $1(5)$ & $4(18)$ \\
\hline Clammy & - & - & $3(14)$ & $1(5)$ & - \\
\hline Paleness & - & - & $3(14)$ & - & $4(18)$ \\
\hline Dizziness & - & $7(32)$ & $11(52)$ & $7(35)$ & $14(64)$ \\
\hline Itching & - & - & - & $1(5)$ & $3(14)$ \\
\hline $\begin{array}{l}\text { Concentration } \\
\text { problems }\end{array}$ & $2(9)$ & $2(9)$ & $1(5)$ & - & - \\
\hline Euphoria & - & - & - & $1(5)$ & $2(9)$ \\
\hline Drowsiness & - & $1(5)$ & $2(10)$ & - & $1(5)$ \\
\hline Dry mouth & $2(9)$ & $2(9)$ & $1(5)$ & - & $3(14)$ \\
\hline
\end{tabular}

Table 4

Drug concentrations in whole blood in all opioid condition as a function of the time after administration (mean \pm SD) ( $\mathrm{nM}$ )

\begin{tabular}{|c|c|c|c|c|c|c|c|c|}
\hline Time post drug (h) & Buprenorphine $0.2 \mathrm{mg}$ & $n$ & Buprenorphine $0.4 \mathrm{mg}$ & $n$ & Methadone 5 mg & $n$ & Methadone 10 mg & $n$ \\
\hline 1 & $0.16(0.08)$ & 20 & $0.30(0.13)$ & 21 & $14.44(11.82)$ & 19 & $19.18(16.33)$ & 20 \\
\hline 2 & $0.21(0.10)$ & 21 & $0.38(0.18)$ & 21 & $30.10(10.33)$ & 20 & $53.73(21.06)$ & 20 \\
\hline 3.5 & $0.15(0.09)$ & 22 & $0.28(0.12)$ & 21 & $36.28(9.35)$ & 20 & $65.13(15.30)$ & 20 \\
\hline 6.5 & $0.05(0.04)$ & 21 & $0.09(0.05)$ & 20 & $25.83(6.28)$ & 19 & $51.78(8.33)$ & 20 \\
\hline
\end{tabular}

Participants indeed felt less alert and more sleepy during the final part of the test schedule.

Buprenorphine and methadone furthermore increased sleepiness, ratings of clinical impairment and reduced alertness and contentedness. Well-known side effects of opioid use such as nausea and vomiting, sleepiness/tiredness and dizziness were frequently observed, and pronounced in some subjects. Concentration problems were reported by one subject only in the high dose buprenorphine condition. Two participants reported to experience euphoria, in the methadone condition. Frequently reported side effects such as sleepiness and reduced alertness might have contributed significantly to impairments of driving and neurocognitive function that were observed after both opioids.

Impairments observed during on-road driving and during neurocognitive testing in the present study are not necessarily inconsistent. Impairments of neurocognitive test performance and on-road driving were most prominent after the high dose of both opioids and virtually absent for the low dose. The impaired driving observed after the high dose of buprenorphine was less than that observed while driving with a BAC of $0.5 \mathrm{mg} \mathrm{ml}^{-1}$. Likewise, when compared to alcohol, neurocognitive impairment observed in the DSST and DAT (i.e. reaction time) in the present study were equivalent to impairments previously observed at BACs between 0.2 and $0.8 \mathrm{mg} \mathrm{ml}^{-1}$ [45]. It has been demonstrated that the presence or absence of impairments in neurocognitive tests are relatively poor predictors of drug effects in the on-road test [46, 47]. In part, the lack of correlation between drug-induced impairment during on-road and neurocognitive performance might be explained by a lack of overlap in their underlying cognitive domains [20]. The SDLP of the on-road driving test primarily measures sustained attention and road tracking performance. As such, it measures operational performance that is highly overlearned and automated and which does not require higher order cognitive control that one typically observes during complex task performance as assessed with neurocognitive tasks of executive function [20,48]. Alternatively, participants in the present study may have been able to compensate for their level of drowsiness to some degree 
when confronted with real-life risk situations such as driving in traffic. The need to compensate is less urgent when performing neurocognitive tests in a laboratory setting.

A number of limitations of the current study should be considered. The driving tests were performed at the time at which the maximum concentration of drug in blood $\left(T_{\max }\right)$ is observed during the methadone conditions but slightly after the expected $T_{\max }$ during buprenorphine. This could imply that driving impairment observed after buprenorphine might have been more pronounced when measured at $T_{\max }$. However, buprenorphine concentrations assessed prior to driving were very much in the range of the expected maximum concentration in blood $\left(C_{\max }\right)$, which indicates that the present buprenorphine data do represent impairment levels at maximal buprenorphine concentrations. In addition, many subjects suffered from adverse events that sometimes prevented data from being collected. Driving impairment in tests that were stopped prematurely might have progressively increased if the test had continued. Likewise, a number of cognitive tasks were never conducted because subjects were unable to perform the task. None of these 'missing' data contributed to performance measures that were established in this study. This could mean that the impairment levels observed in the present study might be an underestimation of impairment levels that can be expected in real life.

We conclude that overall, the influence of single analgesic doses of buprenorphine and methadone on actual driving performance were mild. Cognitive functions were somewhat more affected. At the group level, impairment was most evident following the high dose of buprenorphine but its magnitude was below the BAC $\left(0.5 \mathrm{mg} \mathrm{ml}^{-1}\right)$ criterion threshold of clinical relevance. For both drugs, more pronounced effects were found after the higher dose. At the individual level, however, four participants felt unsafe and discontinued their driving test while under the influence of buprenorphine or methadone. Based on these findings it is therefore impossible to state that use of buprenorphine and methadone will not impair driving in any patient. Consequently, patients should always be informed about the potential driving impairment that might be caused by buprenorphine and methadone.

\section{Competing Interests}

There are no competing interests to declare.

The authors would like to thank Nadia Hutten for her contribution to the data collection and Håvard Furuhaugen for performing the analysis of the blood samples. We would also like to thank all participants as well as Anita van Oers, Irma Brauers, Henk Brauers and Cees van Leeuwen. This study was sponsored by the Norwegian Ministry of Transport and Communications.

\section{References}

1 International Narcotics Control Board, Supply of opiate raw materials and demand for opiates for medical and scientific purposes. International Narcotics Control Board, 2018.
2 Centers for Disease Control and Prevention. Drug Overdose Death Data, 2018. Available at https://www.cdc.gov/drugoverdose/data/ statedeaths.html (last accessed 14 June 2018).

3 Government of Canada. Apparent opioid-related deaths, 2018. Available at https://www.canada.ca/en/health-canada/services/ substance-abuse/prescription-drug-abuse/opioids/apparent-opioid-related-deaths.html (last accessed 2 June 2018).

4 Gjerde H, Strand MC, Mørland J. Driving under the influence of non-alcohol drugs - an update. Part I: epidemiological studies. Forensic Sci Rev 2015; 27: 89-113.

5 Schulze H, Schumacher M, Urmeew R, Auerbach K. DRUIDDriving under the Influence of Drugs, Alcohol and Medicines. Final Report: Work performed, main results and recommendations. 6th Framework Programme Deliverable (0.1.8), 2012.

6 Rusmiddelstatistikk. Funn i blodprøver hos bilførere mistenkt for påvirket kjøring 2017. Oslo: Oslo University Hospital, 2018.

7 The Norwegian Institute of Public Health. The Norwegian Prescription Database (NorPD). Available at http://www.norpd. no/ (last accessed 2 February 2018).

8 International Narcotics Control Board, Narcotic Drugs: Estimated World Requirements for 2018 - Statistics for 2016. Vienna: INCB, 2018.

9 Strand MC, Gjerde H, Morland J. Driving under the influence of non-alcohol drugs - an update. Part II: Experimental studies. Forensic Sci Rev 2016; 28: 79-101.

10 Jensen ML, Sjogren P, Upton RN, Foster DJ, Bonde P, Graae C, et al. Pharmacokinetic-pharmacodynamic relationships of cognitive and psychomotor effects of intravenous buprenorphine infusion in human volunteers. Basic Clin Pharmacol Toxicol 2008; 103: 94-101.

11 MacDonald FC, Gough KJ, Nicoll RA, Dow RJ. Psychomotor effects of ketorolac in comparison with buprenorphine and diclofenac. BrJ Clin Pharmacol 1989; 27: 453-9.

12 Manner T, Kanto J, Salonen M. Simple devices in differentiating the effects of buprenorphine and fentanyl in healthy volunteers. EurJ Clin Pharmacol 1987; 31: 673-6.

13 Rothenberg S, Schottenfeld S, Gross K, Selkoe D. Specific oculomotor deficit after acute methadone. I Saccadic eye movements. Psychopharmacology (Berl) 1980; 67: 221-7.

14 Rothenberg S, Schottenfeld S, Meyer RE, Krauss B, Gross K. Performance differences between addicts and non-addicts. Psychopharmacology (Berl) 1977; 52: 299-306.

15 Rothenberg S, Schottenfeld S, Selkoe D, Gross K. Specific oculomotor deficit after acute methadone. II Smooth pursuit eye movements. Psychopharmacology (Berl) 1980; 67: 229-34.

16 Saarialho-Kere U, Mattila MJ, Paloheimo M, Seppala T. Psychomotor, respiratory and neuroendocrinological effects of buprenorphine and amitriptyline in healthy volunteers. Eur J Clin Pharmacol 1987; 33: 139-46.

17 Zacny JP, Conley K, Galinkin J. Comparing the subjective, psychomotor and physiological effects of intravenous buprenorphine and morphine in healthy volunteers. J Pharmacol Exp Ther 1997; 282: 1187-97.

18 Strand MC, Fjeld B, Arnestad M, Mørland J. Can patients receiving opioid maintenance therapy safely drive? A systematic review of epidemiological and experimental studies on driving ability with a focus on concomitant methadone or buprenorphine administration. Traffic Inj Prev 2013; 14: 26-38. 
19 Jongen S, Vuurman EF, Ramaekers JG, Vermeeren A. The sensitivity of laboratory tests assessing driving related skills to dose-related impairment of alcohol: a literature review. Accid Anal Prev 2016; 89: 31-48.

20 Walsh JM, Verstraete AG, Huestis MA, Morland J. Guidelines for research on drugged driving. Addiction 2008; 103: 1258-68.

21 Ramaekers JG. Drugs and driving research in medicinal drug development. Trends Pharmacol Sci 2017; 38: 319-21.

22 Vuurman EF, Muntjewerff ND, Uiterwijk MM, van Veggel LM, Crevoisier C, Haglund L, et al. Effects of mefloquine alone and with alcohol on psychomotor and driving performance. Eur J Clin Pharmacol 1996; 50: 475-82.

23 Jongen S, Vermeeren A, van der Sluiszen NN, Schumacher MB, Theunissen EL, Kuypers KP, et al. A pooled analysis of on-the-road highway driving studies in actual traffic measuring standard deviation of lateral position (i.e., 'weaving') while driving at a blood alcohol concentration of $0.5 \mathrm{~g} / \mathrm{L}$. Psychopharmacology (Berl) 2017; 234: 837-44.

24 Schumacher MB, Jongen S, Knoche A, Petzke F, Vuurman EF, Vollrath $\mathrm{M}$, et al. Effect of chronic opioid therapy on actual driving performance in non-cancer pain patients. Psychopharmacology (Berl) 2017; 234: 989-99.

25 Zacny JP, James P. A review of the effects of opioids on psychomotor and cognitive functioning in humans. Exp Clin Psychopharmacol 1995; 3: 432-66.

26 van der Mulder-Hajonides Meulen WREH, Van den Hoofdakker $\mathrm{RH}$, eds. The Groningen Sleep Quality Scale. The 14th CINP Congress, 1984; Florence.

27 O'Hanlon JF, Haak TW, Blaauw GJ, Riemersma JB. Diazepam impairs lateral position control in highway driving. Science 1982; 217: 79-81.

28 O'Hanlon JF. Driving performance under the influence of drugs: rationale for, and application of, a new test. Br J Clin Pharmacol 1984; 18 (Suppl. 1): 121S-9S.

29 Loh S, Lamond N, Dorrian J, Roach G, Dawson D. The validity of psychomotor vigilance tasks of less than 10-minute duration. Behav Res Methods Instrum Comput 2004; 36: 339-46.

30 Jex HR, McDonnell JD, Phatak AV. A 'critical' tracking task for man-machine research related to the operator's effective delay time. I. Theory and experiments with a first-order divergent controlled element. NASA CR-616. NASA Contract Rep NASA CR 1966; 1-105.

31 Moskowitz H. Laboratory studies of the effects of alcohol on some variables related to driving. J Safety Res 1973; 5: 185-99.

32 Ball K, Owsley C. The useful field of view test: a new technique for evaluating age-related declines in visual function. J Am Optom Assoc 1993; 64: 71-9.

33 McLeod DR, Griffiths RR, Bigelow GE, Yingling J. An automated version of the digit symbol substitution test (DSST). Behav Res Methods Instrum 1982; 14: 463-6.

34 Leufkens TR, Lund JS, Vermeeren A. Highway driving performance and cognitive functioning the morning after bedtime and middle-of-the-night use of gaboxadol, zopiclone and zolpidem. J Sleep Res 2009; 18: 387-96.

35 Mets MA, Volkerts ER, Olivier B, Verster JC. Effect of hypnotic drugs on body balance and standing steadiness. Sleep Med Rev 2010; 14: 259-67.

36 Mets MA, de Vries JM, de Senerpont Domis LM, Volkerts ER, Olivier B, Verster JC. Next-day effects of ramelteon $(8 \mathrm{mg})$, zopiclone $(7.5 \mathrm{mg})$, and placebo on highway driving performance, memory functioning, psychomotor performance, and mood in healthy adult subjects. Sleep 2011; 34: 1327-34.

37 Hjelmeland K, Gustavsen I, Bernard JP, Morland J. Can a simple clinical test detect impairment of zopiclone and alcohol? A randomized controlled trial. Forensic Sci Int 2015; 248: 129-33.

38 Bramness JG, Skurtveit S, Morland J. Clinical impairment of benzodiazepines - relation between benzodiazepine concentrations and impairment in apprehended drivers. Drug Alcohol Depend 2002; 68: 131-41.

39 Bond A, Lader $\mathrm{M}$. The use of analogue scales in rating subjective feelings. Br J Med Psychol 1974; 47: 211-8.

40 Akerstedt T, Gillberg M. Subjective and objective sleepiness in the active individual. Int J Neurosci 1990; 52: 29-37.

41 Reyner LA, Horne JA. Falling asleep whilst driving: are drivers aware of prior sleepiness? Int J Leg Med 1998; 111: 120-3.

42 Kristoffersen L, Langødegård M, Gaare KI, Amundsen I, Nilsen M, Strand DH. Determination of 12 commonly found compounds in DUID cases in whole blood using fully automated supported liquid extraction and UHPLC-MS/MS. J Chromatogr B 2018; 1093-1094: 8-23.

43 Harding SD, Sharman JL, Faccenda E, Southan C, Pawson AJ, Ireland S, et al. The IUPHAR/BPS Guide to PHARMACOLOGY in 2018: updates and expansion to encompass the new guide to IMMUNOPHARMACOLOGY. Nucl Acids Res 2017; 46: D1091-106.

44 Alexander SP, Christopoulos A, Davenport AP, Kelly E, Marrion NV, Peters JA, et al. The Concise Guide to PHARMACOLOGY 2017/18: G protein-coupled receptors. Br J Pharmacol 2017; 174: S17-29.

45 Jongen S, Vuurman E, Ramaekers J, Vermeeren A. Alcohol calibration of tests measuring skills related to car driving. Psychopharmacology (Berl) 2014; 231: 2435-47.

46 Ramaekers JG. Antidepressants and driver impairment: Empirical evidence from a standard on-the-road test. J Clin Psychiatry 2003; 64: 20-9.

47 Verster JC, Roth T. Predicting psychopharmacological drug effects on actual driving performance (SDLP) from psychometric tests measuring driving-related skills. Psychopharmacology (Berl) 2012; 220: 293-301.

48 Michon JA. A critical view of driver behavior models: what do we know, what should we do? In: Human Behavior and Traffic Safety, eds Evans L, Schwing RC. Springer, Boston, MA: Springer, 1985; 485-524. 


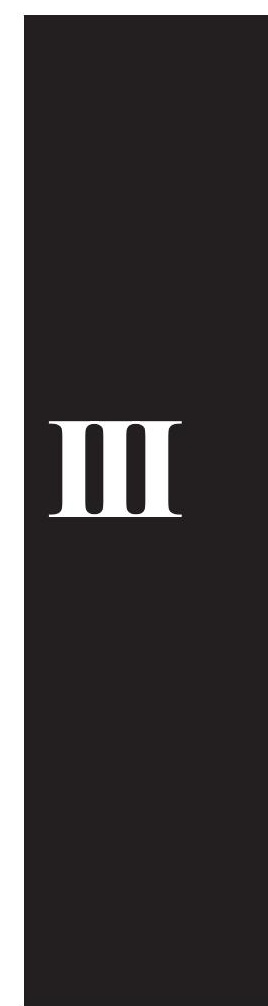



Pharmacokinetics of single doses of methadone and buprenorphine in blood and oral fluid, and correlation with effects on psychomotor and cognitive functions

Maren Cecilie Strand, MD ${ }^{1,2,3}$; Johannes G Ramaekers, Professor ${ }^{3}$; Hallvard Gjerde, MSc PhD ${ }^{1}$; Jørg Mørland, Professor ${ }^{2,4}$; Vigdis Vindenes, MD PhD ${ }^{1,2}$

${ }^{1}$ Oslo University Hospital, Department of Forensic Sciences, Oslo, Norway

${ }^{2}$ University of Oslo, Institute of Clinical Medicine, Oslo, Norway

${ }^{3}$ University of Maastricht, Department of Neuropsychology and Psychopharmacology, Faculty of Psychology and Neuroscience, Maastricht, The Netherlands

${ }^{4}$ Norwegian Institute of Public Health, Division of Health Data and Digitalization, Oslo, Norway

Corresponding author: Maren Cecilie Strand, macest@ous-hf.no

Oslo University Hospital, Department of Forensic Sciences, P.O. Box 4950 Nydalen, 0424 Oslo, Norway

Tel: +4791502770

\section{CONFLICT OF INTEREST}

The authors declared no conflict of interest.

\section{FUNDING}

This study was funded by the Norwegian Ministry of Transport and Communications, the Norwegian Institute of Public Health and Oslo University hospital, Department of forensic sciences.

\section{RUNNING TITLE}

Methadone and buprenorphine 


\section{ABSTRACT \\ Background}

Few studies have investigated neurocognitive effects of methadone and buprenorphine while measuring drug concentrations in blood. We studied the pharmacokinetics of methadone and buprenorphine in blood and oral fluid after single dose administration as well as the correlation between effects on neurocognitive functions in relation to concentrations in blood.

Methods

A five-way, double-blind, randomized, placebo-controlled, double-dummy, cross-over study was performed to study the pharmacokinetics and neurocognitive effects of methadone (5 and $10 \mathrm{mg}$ per oral) and buprenorphine (0.2 and $0.4 \mathrm{mg}$ sublingual) in 22 healthy volunteers. Blood and oral fluid were collected throughout the test days and drug concentrations in both matrixes were analysed using UHPLC-MS/MS. On-road driving testing, neurocognitive computerized tests and subjective questionnaires were performed.

Results

Large individual variations in concentrations of methadone and buprenorphine in blood and oral fluid, and accordingly oral fluid/blood drug concentration ratios, were observed. E.g. the mean ratio 6.5 hours after drug administration was 2.0 (range 0.49 - 7.39) for methadone after both doses. Buprenorphine was not detected above the limit of quantification in blood after 6.5 hours. Correlations between buprenorphine concentrations in blood were found for standard deviation of lateral position (SDLP) of the driving test $(\mathrm{r}=.477, p=0.002)$, and measures of reaction time, divided attention and balance test, as well as alertness, contentedness and sleepiness. No significant correlations were found for methadone.

\section{Conclusions}

Concentrations of methadone and buprenorphine in blood and oral fluid showed large interindividual variations. Concentration-effect correlations were found for some tests after administration of buprenorphine, but not for methadone.

Key words: Oral fluid, blood, methadone, buprenorphine, neurocognitive 


\section{INTRODUCTION}

Opioids, like methadone and buprenorphine, are widely used as analgesics, mainly to relieve moderate to severe pain for short time periods, but also for long-term treatment of patients with chronic pain and cancer and for maintenance treatment of patients with opioid use disorder.

Previous studies on the acute effects of a single dose of methadone on psychomotor or cognitive functions in healthy volunteers did not measure drug concentrations in blood (1-3). Only one study measured buprenorphine concentrations in plasma while testing psychomotor and cognitive effects (4) whereas other studies on performance did not include pharmacokinetic measurements of buprenorphine (5-8). Drug measurements in blood are essential when establishing concentration-effect relationships.

The use of oral fluid for detection and quantification of drugs of abuse has increased during the last decade. The relationship between drug concentrations in blood and oral fluid has been studied for several opioids and low correlations between oral fluid and blood concentrations were observed and their ratios varied widely (9-11). The latter indicates that opioid concentrations in oral fluid cannot be used to reliably estimate opioid concentrations in blood. Few studies have measured buprenorphine in oral fluid (12), while previous studies of methadone have indicated oral fluid/blood concentration ratios and oral fluid/plasma ratios ranging from 0.5 to $7.2(10,11)$. No studies have measured concentrations of buprenorphine in oral fluid after single dose administration.

Both methadone and buprenorphine can impair cognitive function and may affect a patient's ability to drive safely $(13,14)$.With regards to opioids and traffic safety in general, most epidemiological studies have found significant associations between opioid use and road traffic crashes (15) while experimental studies have found that opioids can have some moderate effects on neurocognitive performance without a clear dose relationship (16).

A recent study on the effects of analgesic doses of methadone (5 and $10 \mathrm{mg}$ ) and buprenorphine ( 0.2 and $0.4 \mathrm{mg}$ ) on driving and related skills showed that both drugs caused impairment in opioid-naïve subjects (17). Buprenorphine produced mild impairment of driving, while more pronounced and dose dependent impairment of cognitive skills related to driving were found for both opioids, in line with previous studies $(2,8)$. 
Positive correlations between drug concentrations in blood and impairment of neurocognitive function have previously been reported for some drugs, although less clear for opioids than for other drug classes; for references see (18). This indicates some uncertainty for methadone and buprenorphine with respect to the association between blood drug concentrations and their impairing effects. Establishment of concentration-effect relations for both drugs are of relevance for assigning per se limits for driving under the influence of these compounds. For example, Norway implemented legal limits for methadone and buprenorphine in 2012 in the Road Traffic Act. The law was updated in 2016. Eventually, three levels of limits were established, comparable to traffic relevant impairment seen at blood alcohol concentrations (BAC) of $0.02,0.05$ and $0.12 \%$ (18). The thresholds for methadone and buprenorphine corresponding to $0.02 \%$ BAC limits were set at $80 \mathrm{nM}$ and $0.8 \mathrm{nM}$, respectively.

The current paper is a follow-up publication of our previous study (17), which suggested a relation between drug dose and neurocognitive impairment, which has, to our knowledge, not been studied previously (19). In the present study we investigated the association between methadone and buprenorphine concentrations in blood and psychomotor and cognitive performance.

This study aimed to answer whether drug concentrations in oral fluid, would reflect drug concentrations in blood. Furthermore, we wanted to study whether concentrations of methadone and buprenorphine in blood are correlated to the level of impairment that these compounds produce on actual driving and neurocognitive function.

\section{MATERIALS AND METHODS}

The methods used have been described in detail by Strand et al. (17).

Subjects

Twenty-two healthy volunteers (11 males, 11 females) aged 23-49 years (mean age 36 years) with a mean body mass index (weight/lenght ${ }^{2}$ ) of $24.2 \mathrm{~kg} / \mathrm{m}^{2}$ (range 19.6-29.1) were included. They were recruited via advertisements in local newspapers and poster advertisements at Maastricht University. 
Inclusion criteria were: males or females with good health based on a physical examination and the results of blood chemistry and haematology tests; age between 23 and 50 years; body mass index between 19 and $29 \mathrm{~kg} / \mathrm{m}^{2}$; and experienced drivers.

Exclusion criteria were: pregnancy or lactation, sleep disorders; drug or alcohol abuse; use of psychoactive medication; excessive alcohol and/or caffeine use; smoking $>6$ cigarettes per day; intake of any opioid within 3 months before the study; and significant disease.

Ethical approval for the study was obtained from the independent Ethics Committee of Maastricht University and the Academic Hospital Maastricht in The Netherlands and from the Regional Committees for Medical and Health Research Ethics in Norway. This study was conducted according to the code of ethics on human experimentation established by the declaration of Helsinki (1964) and amended in Fortaleza, Brazil (2013) and in accordance with the Medical Research Involving Human Subjects Act. Written informed consent was obtained from all volunteers.

Design and treatments

The acute effects of two single doses of buprenorphine ( 0.2 and $0.4 \mathrm{mg}$ sublingual) and methadone (5 and $10 \mathrm{mg}$ per oral) were studied in a five-way, double-blind, randomized, placebo-controlled, double-dummy, cross-over study. The minimum wash-out period between the test days was 10 days. Similar doses of methadone and buprenorphine have been administered to opioid naïve volunteers in previous studies $(1-3,7)$.

Methadone (methadone capsules and placebo capsules) and buprenorphine (buprenorphine sublingual tablets and placebo sublingual tablets) were purchased, blinded and labelled by Tiofarma (Oud-Beijerland, the Netherlands) and the University Pharmacy of Nijmegen (the Netherlands), respectively, according to the Good Manufacturing Practice guidelines.

\section{Procedure}

On the test days, urine samples were screened for drugs by using the SureStep ${ }^{\mathrm{TM}}$ Drug Screen Cup (Abbott, Abbott Park, IL, USA); a pregnancy test was performed using the Alere ${ }^{\mathrm{TM}}$ hCG Cassette (Abbott), and breath alcohol was analysed using Dräger Alcotest 5000 (Drägerwerk AG \& Co., Lübeck, Germany). Blood samples were collected 1, 2, 3.5 and 6.5 hours after drug administration, while the highway driving test was performed after 4 hours and the 
neurocognitive tests and subjective evaluations after 2 and 6 hours (morning and afternoon condition).

Pharmacokinetic assessments and drug analysis

The analytical results in blood and oral fluid samples for two subjects were excluded from the data analysis due to incorrect labelling of the samples.

Blood was collected using $5 \mathrm{ml}$ Vacutainer® tubes containing Sodium Fluoride (20 mg) and Sodium Heparin (143 IU) (BD Diagnostics, Franklin Lakes, NJ, USA). Drug concentrations in whole blood samples were determined using UHPLC-MS/MS (20); the method was slightly modified for the determination of methadone and buprenorphine by adding relevant calibration standards. The limits of quantification (LOQ) in blood were $0.5 \mathrm{nM}$ for methadone and $0.2 \mathrm{nM}$ for buprenorphine, while the limits of detection (LOD) were $0.15 \mathrm{nM}$ for methadone and $0.02 \mathrm{nM}$ for buprenorphine.

Oral fluid was collected using QuantisalTM Oral Fluid Collection Device (Abbot, Lake Bluff, IL, USA). Concentrations of methadone and buprenorphine in oral fluid were determined using ultra-high performance liquid chromatography - tandem mass spectrometry (UHPLCMS/MS) after 96-well supported liquid extraction (21). The LOQ in oral fluid was $1 \mathrm{nM}$ for both methadone and buprenorphine, while the LOD was $0.15 \mathrm{nM}$ for both drugs. The oral fluid samples were diluted with $3 \mathrm{ml}$ preservative buffer that was present in the Quantisal device. Therefore, the samples were weighed to determine the amount of oral fluid collected in order to calculate concentrations in neat oral fluid, which were calculated by multiplying the concentration of drug in oral fluid by with the oral fluid weight (in $\mathrm{g}$ ) $+3 \mathrm{~g}$, and divide this by the oral fluid weight.

All data was included in the calculation of median values for blood and oral fluid concentrations shown in Figure 1. An outlier was defined as any value exceeding the third quartile plus the interquartile range $\times 1.5$ or being less than the first quartile minus the interquartile range $\times 1.5$.

Highway driving test

The on-road driving test was performed on a $100 \mathrm{~km}$ primary highway segment in normal traffic with duration of approximately one hour $(22,23)$. Participants were instructed to drive with a steady lateral position within the right traffic lane at a constant speed of $95 \mathrm{~km} / \mathrm{h}(60$ 
mph) and a specially instrumented vehicle was used to measure standard deviation of lateral position (SDLP) in centimetres, also named "weaving" (24).

Cognitive and psychomotor tests

A detailed description of the tests used are given in Strand et al. (17). The Psychomotor Vigilance Task (PVT) measured sustained attention by assessing the reaction time in response to a visual stimulus (25). The Critical Tracking Task (CTT) measured the ability to control an unstable error signal in a compensatory tracking task (26). The Divided Attention Test (DAT) measured the ability to divide attention between two simultaneously performed tasks (27). The Useful Field of View Test (UFOV) measured stimulus identification, divided attention, and selective attention (28). The Digit Symbol Substitution Test (DSST) measured executive attention and processing speed (29). Postural Balance test (PBT) measured balance in two trials (eyes open and eyes closed) (30, 31). The Determination Test (DT/S1) of the Vienna Test System measured resilience of attention and reaction speed under conditions of sensory stress (32).

A clinical test of impairment was performed 2 hours after drug administration, consisting of the following subtests: gait-on-line, turn-on-line, finger-to-finger, finger-to-nose, and Romberg's test (standing steady on one leg for at least 5 seconds with arms stretched out and eyes closed) (33). An overall impression of the subject, termed the "global impression", being the "sixth subtest", was graded as either "not impaired", "slightly impaired", "moderately impaired" or "obviously impaired".

Subjective evaluations

Subjective evaluations of mood and apparent sedation were assessed by using a series of visual analogue scales (100 mm) (Bond and Lader) (34). Subjects rated their subjective feelings and summary scores were found for "alertness", "contentedness", and "calmness".

The Karolinska sleepiness scale, modified by Reyner and Horne, has scores that range from 1 (“extremely alert,") to 9 (“very sleepy, great effort to keep alert, fighting sleep") $(35,36)$.

\section{Statistics}

Bivariate correlations were used to evaluate associations between opioid concentrations in blood and opioid induced changes in driving and neurocognitive performance (concentration in blood $\mathrm{x}$ test). The concentrations measured 3.5 hours after administration were used to 
calculate correlation with the driving test, while the concentrations measured after 2 and 6.5 hours were used to calculate correlation with the neurocognitive tests and subjective evaluations performed in the morning and afternoon, respectively. Correlations were calculated for the morning and afternoon separately due to the risk of acute tolerance to the drug effects. To calculate drug induced change, performance scores during placebo were subtracted from performance scores during treatment with methadone and buprenorphine. The statistical analyses were conducted using SPSS® Statistics version 25 (IBM Corporation, Armonk, NY, USA).

\section{RESULTS}

Pharmacokinetics

\section{Blood}

Mean concentrations of methadone and buprenorphine in whole blood are shown in Figure 1.

After administration of methadone, concentrations were above the LOQ of $0.5 \mathrm{nM}$ in all samples, except from one subject, who did not have methadone concentrations above the LOD 1 hour after both doses. The high dose of methadone caused mean concentrations that were almost twice as high as concentrations seen after the low dose, see Figure 1. Maximum concentrations were observed 3.5 hours after drug administration for both doses.

For buprenorphine, only $36 \%$ of the blood samples had concentrations above the LOQ of 0.2 nM. Only one subject had a concentration of buprenorphine in blood above the LOQ 6.5 hours after administration of $0.4 \mathrm{mg}$ buprenorphine. Nine subjects did not have concentrations of buprenorphine in blood above the LOQ at any sampling time after administration of the low dose. After the high dose all subjects had buprenorphine concentrations in blood above the LOQ in two or more samples. In general, the high dose $(0.4 \mathrm{mg})$ caused mean concentrations approximately twice as high as those after the lower dose at all time points of blood sampling, see Figure 1. Estimated concentrations below the LOQ, and above the LOD, are included in Figure 1. The mean maximum concentration $\left(\mathrm{C}_{\max }\right)$ was observed 2 hours after drug administration for both the low and the high dose.

\section{Oral fluid}


Mean concentrations of methadone and buprenorphine in neat oral fluid are shown in Figure 1. The curve profiles for drug concentration versus time were completely different for oral fluid as compared to blood for both drugs.

Methadone was detected in low concentrations in oral fluid in four subjects up to 16 days after intake of the drug, as measured in oral fluid samples on later test days when methadone was not administered. The concentrations ranged from 0.1 to $0.28 \mathrm{nM}$. This occurred after intake of both 5 and $10 \mathrm{mg}$ of methadone, and all subjects were female.

Buprenorphine was only detected in oral fluid from collected on the day of drug administration. The mean buprenorphine concentrations in oral fluid decreased to a very low level after 6.5 hours, see Figure 1.

\section{Concentration ratios in oral fluid/blood}

A box-plot of all oral fluid/blood concentration ratios at the different times of sampling is shown in Figure 2. Only concentrations exceeding the LOQ were used to calculate oral fluid/blood ratios. There was a substantial difference between methadone and buprenorphine ratios.

Highway driving test

The results of the correlation analysis between opioid concentrations in blood and changes in driving performance are shown in Table 1.

There was a significant correlation between the concentrations of buprenorphine in blood and changes in $\operatorname{SDLP}(r=.477, \mathrm{p}=0.002)$ and $\operatorname{MLP}(\mathrm{r}=.323, \mathrm{p}=0.039)$. For methadone, no significant correlation between concentrations and driving performance was observed. Scatter plots of change in SDLP as a function of opioid concentrations in blood are shown in Figure 3.

Cognitive and psychomotor tests

The results of the correlation analyses between opioid concentrations in blood and changes in neurocognitive functions in the morning are shown in Table 1.

There was a significant correlation between concentrations of buprenorphine in blood and the following measures in the morning: PVT reaction time $(\mathrm{r}=.369, \mathrm{p}=0.016)$, PVT lapses $(\mathrm{r}=.327, \mathrm{p}=0.035)$, DAT reaction time $(\mathrm{r}=.335, \mathrm{p}=0.032)$, DSST $(\mathrm{r}=-.342, \mathrm{p}=0.027)$, PBT eyes 
open $(\mathrm{r}=.428, \mathrm{p}=0.005)$ and PBT eyes closed $(\mathrm{r}=.383, \mathrm{p}=0.013)$. During the afternoon a significant correlation was found for buprenorphine in DAT hits $(r=-.335, p=0.040)$. Methadone concentration significantly correlated with change in DSST $(r=-.371, p=0.022)$ in the afternoon.

Subjective evaluations and clinical test of impairment

Significant correlations between concentrations of buprenorphine in blood and measured alertness $(r=.573, p=0.000)$, contentedness $(r=.417, p=0.006)$ and sleepiness $(r=.408, p=0.007)$ were found in the morning. In the afternoon, changes in alertness $(r=.358, p=0.022)$ were significantly correlated to buprenorphine concentrations in blood.

\section{DISCUSSION}

Our study found large individual variations in blood and oral fluid concentrations for both drugs. Mean concentrations of methadone in blood were lower than previously reported concentrations after similar doses in healthy volunteers (37). Concentrations of methadone in plasma showed large individual differences after intake of methadone $20 \mathrm{mg}$ per oral in opiate dependent subjects during detoxification, ranging from concentrations similar to those found in our study, up to $200 \mathrm{nM}$ (38). Previous studies where buprenorphine has been administered to healthy volunteers have in most cases given higher doses than those in the current study, i.e. doses of 4 and $8 \mathrm{mg}$ sublingual (39-41). If using their data to estimate the expected drug concentrations in blood after administration of 0.2 and $0.4 \mathrm{mg}$ doses, the extrapolated concentrations of buprenorphine would be higher than those found in our study. This could indicate some type of saturation pharmacokinetics for buprenorphine when higher doses are administered.

$\mathrm{C}_{\max }$ of methadone in blood was measured 3.5 hours after administration, which is within the range previously established as time to maximum concentration after oral intake.

Buprenorphine was administered sublingual, which is likely the reason for the rapid absorption observed as compared to methadone with a $\mathrm{C}_{\max }$ of buprenorphine after two hours (42).

Our findings indicate that the doses given caused detectable concentrations of buprenorphine in oral fluid up to approximately 6.5 hours after administration. A previous study reported that 
after acute sublingual administration of buprenorphine saliva and plasma levels were substantially elevated during the first twelve hours (12). The oral fluid/blood ratios for buprenorphine were more than 1,000 times higher than those of methadone. This is most likely due to presence of residual buprenorphine in the oral cavity after sublingual administration. This also caused the oral fluid/blood concentration ratios for buprenorphine to be extremely large during the first hours. Buprenorphine concentrations in blood were below the LOQ after 6.5 hours, at a time where one could expect a steady state between blood and oral fluid, thus a reliable oral fluid/blood concentration could not be calculated at equilibrium.

The curve for methadone in oral fluid shows a "dip" at +3.5 hours after drug administration. It might be due to the intake of lunch, even though not all participants had lunch due to side effects like nausea. This effect has previously also been described after intake of zopiclone (43), and it has been suggested that the intake of a meal will increase saliva secretion and thereby dilute the oral fluid sample. This effect was however not observed for buprenorphine.

Significant correlations were found for buprenorphine concentrations in blood and its effect on driving (SDLP) and neurocognitive performance. No correlation was found between methadone concentrations in blood and performance, except for the DSST.

Most of the significant correlations were found for buprenorphine in the morning. This coincides with the time of maximum concentration of buprenorphine in blood. In a previous study, Zacny et al. (8) found a dose dependant reduction in DSST performance, as did we (17). In the present study we observed a blood buprenorphine concentration relationship to the outcome of the DSST. However, the tests that showed dose-dependent effects were not always coinciding with those where a concentration-dependent effect was found, even though the higher doses of methadone and buprenorphine caused higher mean concentrations in blood as compared to the lower doses. Dose-dependent effects were found only in about half of the tests showing correlation with the drug concentrations. E.g. in the morning condition concentration-correlations were found for the SDLP, MLP, PVT, DAT, DSST and PBT (eyes open and closed), while dose-effect was seen for the DAT, DSST, DT/S1 and PBT (eyes open), after buprenorphine administration (17). The main explanation for this discrepancy between dose-effects and drug concentration-effects is probably that the degree of impairment also depends on factors other than drug concentrations in blood, i.e. drug transport across the blood-brain barrier $(44,45)$ and the activation of opioid-receptors (46). Future studies are required to add knowledge to this subject. 
Significant correlations were found between buprenorphine concentrations in blood and alertness and contentedness in the morning condition, as well as alertness in the afternoon condition, indicating that subjects felt less alert and less content depending on the buprenorphine concentration in blood. Furthermore, a significant correlation was found for KSS in the morning condition, showing that the volunteers felt more sleepy a few hours after buprenorphine administration depending on the blood buprenorphine concentration.

No correlation was found between methadone concentrations in blood and neurocognitive performance. Methadone is a full agonist, whereas buprenorphine is a partial agonist, to the opioid receptors. For this reason, one would expect to see more effects after methadone administration as compared to buprenorphine than what we observed in our study. However, both the doses administered and the concentration levels measured in blood were relatively low. It is possible that the drug concentrations in blood were too low to detect concentrationeffect correlations at a larger scale. A previous review on the effects of morphine on neurocognitive performance in healthy volunteers showed that there was a concentrationeffect relationship (47) and concentration-related effects on cognition and motor control have been reported after morphine administration (48). Single doses of buprenorphine $0.8 \mathrm{mg}$ sublingual and methadone $20 \mathrm{mg}$ per oral are considered equianalgesic to a single dose of morphine $60 \mathrm{mg}$ per oral (49). Our findings show, however, that $0.4 \mathrm{mg}$ of buprenorphine produced more significant effects on driving and neurocognitive tests than $10 \mathrm{mg}$ of methadone. As buprenorphine $0.4 \mathrm{mg}$ did not seem to be equipotent to methadone $10 \mathrm{mg}$ with respect to those effects, this might be the reason for the lack of concentration-effect relationship for methadone.

In 2012/2016, Norway implemented legislative limits for non-alcohol drugs in the Road Traffic Act, aiming to have a more similar handling of cases of driving under the influence of alcohol and psychoactive drugs. In our study, only four subjects had a maximum concentration of methadone in blood higher than the legislative limit of $80 \mathrm{nM}$ (comparable to a BAC of $0.02 \%$ ) implemented in the Norwegian Road Traffic Act. None of the measured concentrations of buprenorphine in blood in our study exceeded the Norwegian legislative limit of $0.8 \mathrm{nM}$ for buprenorphine. From the on-road driving test we found that only the high dose of buprenorphine caused significant impairment as compared to placebo (17). The mean concentration of buprenorphine in blood at the time of the driving test was $0.28 \mathrm{nM}$ (range $0.08-0.48)$. It seems that the legislative limit for buprenorphine at $0.8 \mathrm{nM}$ is rather liberal and could be adjusted downwards. None of the doses of methadone caused a significant change in 
driving performance compared to placebo, this in accordance with the mean concentrations observed in blood that were below the legislative limit comparable to a BAC of $0.02 \%$. Furthermore, these findings could indicate that low concentrations of opioids in blood might not be the best indicator to determine whether a patient can drive safely. An individual evaluation of the degree of impairment and fitness to drive is probably a more reliable tool for assessing possible driving impairment among patients in opioid treatment.

The large inter-individual variations in blood and oral fluid concentrations for also caused wide ranges of the oral fluid/blood concentration ratios. A mean oral fluid/blood concentration ratio for methadone of 0.7 has previously been reported (10) and oral fluid/plasma concentration ratios between 0.5 and 7.2 (11). The ratios for methadone 6.5 hours after drug administration, at a point where steady state between oral fluid and blood was probably achieved, were similar to these ratios.

We conclude that large inter-individual variations were observed in both blood and oral fluid concentrations after single dose administration of methadone and buprenorphine.

Furthermore, correlations were found between buprenorphine concentrations in blood and effects on driving performance, subjective ratings and neurocognitive function, but no such correlations were found after methadone administration.

\section{Acknowledgements}

The authors would like to thank Håvard Furuhaugen for performing the analysis of the blood and oral fluid samples. 


\section{REFERENCES}

1. Rothenberg S, Schottenfeld S, Gross K, Selkoe D. Specific oculomotor deficit after acute methadone. I. Saccadic eye movements. Psychopharmacology (Berl). 1980;67(3):221-7. 2. Rothenberg S, Schottenfeld S, Meyer RE, Krauss B, Gross K. Performance differences between addicts and non-addicts. Psychopharmacology (Berl). 1977;52(3):299-306.

3. Rothenberg S, Schottenfeld S, Selkoe D, Gross K. Specific oculomotor deficit after acute methadone. II. Smooth pursuit eye movements. Psychopharmacology (Berl). 1980;67(3):229-34.

4. Jensen ML, Sjogren P, Upton RN, Foster DJ, Bonde P, Graae C, et al. Pharmacokinetic-pharmacodynamic relationships of cognitive and psychomotor effects of intravenous buprenorphine infusion in human volunteers. Basic Clin PharmacolToxicol. 2008;103(1):94-101.

5. MacDonald FC, Gough KJ, Nicoll RA, Dow RJ. Psychomotor effects of ketorolac in comparison with buprenorphine and diclofenac. BrJ Clin Pharmacol. 1989;27(4):453-9. 6. Manner T, Kanto J, Salonen M. Simple devices in differentiating the effects of buprenorphine and fentanyl in healthy volunteers. EurJ Clin Pharmacol. 1987;31(6):673-6. 7. Saarialho-Kere U, Mattila MJ, Paloheimo M, Seppala T. Psychomotor, respiratory and neuroendocrinological effects of buprenorphine and amitriptyline in healthy volunteers. EurJ Clin Pharmacol. 1987;33(2):139-46.

8. Zacny JP, Conley K, Galinkin J. Comparing the subjective, psychomotor and physiological effects of intravenous buprenorphine and morphine in healthy volunteers. Journal of Pharmacology and Experimental Therapeutics 1997;282(3):1187-97.

9. Langel K, Gjerde H, Favretto D, Lillsunde P, Øiestad EL, Ferrara SD, et al. Comparison of drug concentrations between whole blood and oral fluid. Drug Test Anal. 2014;6(5):461-71.

10. Gjerde H, Mordal J, Christophersen AS, Bramness JG, Morland J. Comparison of drug concentrations in blood and oral fluid collected with the Intercept ${ }^{\circledR}$ sampling device. $\mathbf{J}$ Anal Toxicol. 2010;34(4):204-9.

11. Wille SMR, Raes E, Lillsunde P, Gunnar T, Laloup M, Samyn N, et al. Relationship between oral fluid and blood concentrations of drugs of abuse in drivers suspected of DUID. Ther Drug Monit. 2009;31(4):511-9. 
12. Cone EJ, Dickerson S, Darwin W, Fudala P, Johnson RE. Elevated drug saliva levels suggest a "depot-like" effect in subjects treated with sublingual buprenorphine. NIDA Res Monogr. 1990;105:569.

13. SPC buprenorphine sublingual tablet 2017 [Available from:

https://www.medicines.org.uk/emc/product/4158/smpc.

14. SPC methadone tablet 2017 [Available from:

https://www.medicines.org.uk/emc/product/3568/smpc.

15. Gjerde H, Strand MC, Mørland J. Driving under the influence of non-alcohol drugs an update. Part I: epidemiological studies. Forensic Sci Rev. 2015;27(2):89-113.

16. Strand MC, Gjerde H, Morland J. Driving under the influence of non-alcohol drugs An update. Part II: Experimental studies. Forensic Sci Rev. 2016;28(2):79-101.

17. Strand MC, Vindenes V, Gjerde H, Mørland JG, Ramaekers JG. A clinical trial on the acute effects of methadone and buprenorphine on actual driving and cognitive function of healthy volunteers. Br J Clin Pharmacol. 2018;85(2):442-53.

18. Strand MC, Morland J, Slordal L, Riedel B, Innerdal C, Aamo T, et al. Conversion factors for assessment of driving impairment after exposure to multiple benzodiazepines/zhypnotics or opioids. Forensic Sci Int. 2017;281:29-36.

19. Strand MC, Fjeld B, Arnestad M, Mørland JG. Can Patients Receiving Opioid Maintenance Therapy Safely Drive? A Systematic Review of Epidemiological and Experimental Studies on Driving Ability With a Focus on Concomitant Methadone or Buprenorphine Administration. Traffic Injury Prevention. 2013;14(1):26-38.

20. Kristoffersen L, Langødegård M, Gaare K, Amundsen I, Nilsen M, Strand D. Determination of 12 commonly found compounds in DUID cases in whole blood using fully automated supported liquid extraction and UHPLC-MS/MS. Journal of Chromatography B. 2018;1093-1094:8-23.

21. Valen A, Leere Oiestad AM, Strand DH, Skari R, Berg T. Determination of 21 drugs in oral fluid using fully automated supported liquid extraction and UHPLC-MS/MS. Drug Test Anal. 2017;9(5):808-23.

22. O'Hanlon JF, Haak TW, Blaauw GJ, Riemersma JB. Diazepam impairs lateral position control in highway driving. Science. 1982;217(4554):79-81.

23. Ramaekers JG. Drugs and Driving Research in Medicinal Drug Development. Trends Pharmacol Sci. 2017;38(4):319-21.

24. O'Hanlon JF. Driving performance under the influence of drugs: rationale for, and application of, a new test. Br J Clin Pharmacol. 1984;18 Suppl 1:121S-9S. 
25. Loh S, Lamond N, Dorrian J, Roach G, Dawson D. The validity of psychomotor vigilance tasks of less than 10-minute duration. Behav Res Methods Instrum Comput. 2004;36(2):339-46.

26. Jex HR, McDonnell JD, Phatak AV. A "critical" tracking task for man-machine research related to the operator's effective delay time. I. Theory and experiments with a firstorder divergent controlled element. NASA CR-6161966 Nov. 1-105 p.

27. Moskowitz H. Laboratory studies of the effects of alcohol on some variables related to driving. Journal of safety research. 1973;5(3):185-99.

28. Ball K, Owsley $\mathrm{C}$. The useful field of view test: a new technique for evaluating agerelated declines in visual function. J Am Optom Assoc. 1993;64(1):71-9.

29. McLeod DR, Griffiths RR, Bigelow GE, Yingling J. An automated version of the digit symbol substitution test (DSST). Behavior Research Methods \& Instrumentation. 1982;14(5):4.

30. Mets MA, Volkerts ER, Olivier B, Verster JC. Effect of hypnotic drugs on body balance and standing steadiness. Sleep Med Rev. 2010;14(4):259-67.

31. Mets MA, de Vries JM, de Senerpont Domis LM, Volkerts ER, Olivier B, Verster JC. Next-day effects of ramelteon $(8 \mathrm{mg})$, zopiclone $(7.5 \mathrm{mg}$ ), and placebo on highway driving performance, memory functioning, psychomotor performance, and mood in healthy adult subjects. Sleep. 2011;34(10):1327-34.

32. Schuhfried G. Manual Expert System Traffic (XPSV). Schuhfried GmbH, Mödling; 2005.

33. Hjelmeland K, Gustavsen I, Bernard JP, Morland J. Can a simple clinical test detect impairment of zopiclone and alcohol? - A randomized controlled trial. Forensic Sci Int. 2015;248:129-33.

34. Bond A, Lader M. The use of analogue scales in rating subjective feelings. British Journal of Medical Psychology. 1974;47(3):8.

35. Akerstedt T, Gillberg M. Subjective and objective sleepiness in the active individual. Int J Neurosci. 1990;52(1-2):29-37.

36. Reyner LA, Horne JA. Falling asleep whilst driving: are drivers aware of prior sleepiness? Int J Legal Med. 1998;111(3):120-3.

37. Dale O, Hoffer C, Sheffels P, Kharasch ED. Disposition of nasal, intravenous, and oral methadone in healthy volunteers. Clinical Pharmacology \& Therapeutics. 2002;72(5):536-45. 
38. Meresaar U, Nilsson MI, Holmstrand J, Anggard E. Single dose pharmacokinetics and bioavailability of methadone in man studied with a stable isotope method. Eur J Clin Pharmacol. 1981;20(6):473-8.

39. Kuhlman JJ, Lalani S, Magluilo J, Levine B, Darwin WD, Johnson RE, et al. Human pharmacokinetics of intravenous, sublingual, and buccal buprenorphine. Journal of analytical toxicology. 1996;20(6):369-78.

40. Harris DS, Mendelson JE, Lin ET, Upton RA, Jones RT. Pharmacokinetics and subjective effects of sublingual buprenorphine, alone or in combination with naloxone: lack of dose proportionality. Clin Pharmacokinet. 2004;43(5):329-40.

41. Nath RP, Upton RA, Everhart ET, Cheung P, Shwonek P, Jones RT, et al. Buprenorphine pharmacokinetics: relative bioavailability of sublingual tablet and liquid formulations. Journal of clinical pharmacology. 1999;39(6):619-23.

42. Weinberg DS, Inturrisi CE, Reidenberg B, Moulin DE, Nip TJ, Wallenstein S, et al. Sublingual absorption of selected opioid analgesics. Clinical Pharmacology \& Therapeutics. 1988;44(3):335-42.

43. Hjelmeland K, Gustavsen I, Oiestad EL, Oiestad AML, Hoiseth G, Morland J. Zopiclone concentrations in oral fluid and blood after, administration of therapeutic doses of zopiclone. Forensic Sci Int. 2017;278:177-83.

44. Chaves C, Remião F, Cisternino S, Declèves X. Opioids and the Blood-Brain Barrier: A Dynamic Interaction with Consequences on Drug Disposition in Brain. Current neuropharmacology. 2017;15(8):1156-73.

45. Linnet K, Ejsing TB. A review on the impact of P-glycoprotein on the penetration of drugs into the brain. Focus on psychotropic drugs. European Neuropsychopharmacology. 2008;18(3):157-69.

46. Darcq E, Kieffer BL. Opioid receptors: drivers to addiction? Nat Rev Neurosci. 2018;19(8):499-514.

47. Strand MC, Arnestad M, Fjeld B, Morland J. Acute Impairing Effects of Morphine Related to Driving: A Systematic Review of Experimental Studies to Define Blood Morphine Concentrations Related to Impairment in Opioid Naive Subjects. Traffic Inj Prev. 2017:0. 48. Kerr B, Hill H, Coda B, Calogero M, Chapman CR, Hunt E, et al. Concentrationrelated effects of morphine on cognition and motor control in human subjects. Neuropsychopharmacol. 1991;5(3):157-66.

49. Zacny JP, James P. A review of the effects of opioids on psychomotor and cognitive functioning in humans. Experimental and Clinical Psychopharmacology 1995;3(4):432-66. 
Figure 1 Mean (SD) concentrations of methadone and buprenorphine in oral fluid and whole blood (nM) after administration of 5 and $10 \mathrm{mg}$ methadone per oral (po) and 0.2 and $0.4 \mathrm{mg}$ buprenorphine sublingual (sl).

\section{Oral fluid}

\section{- - - - - Blood}
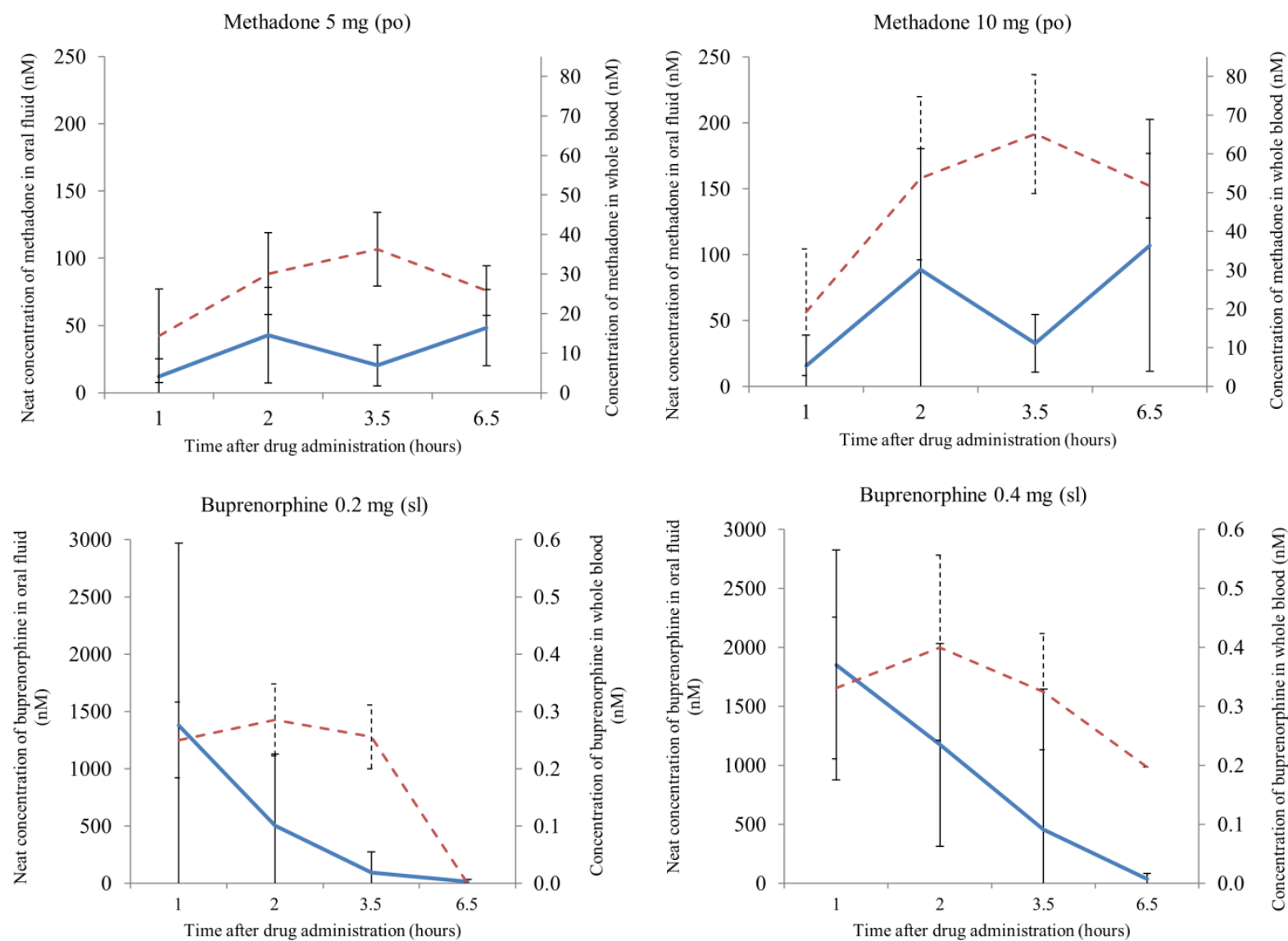
Figure 2 Boxplots showing rations between concentrations of methadone in oral fluid compared to whole blood.

$x=$ maximum outliers

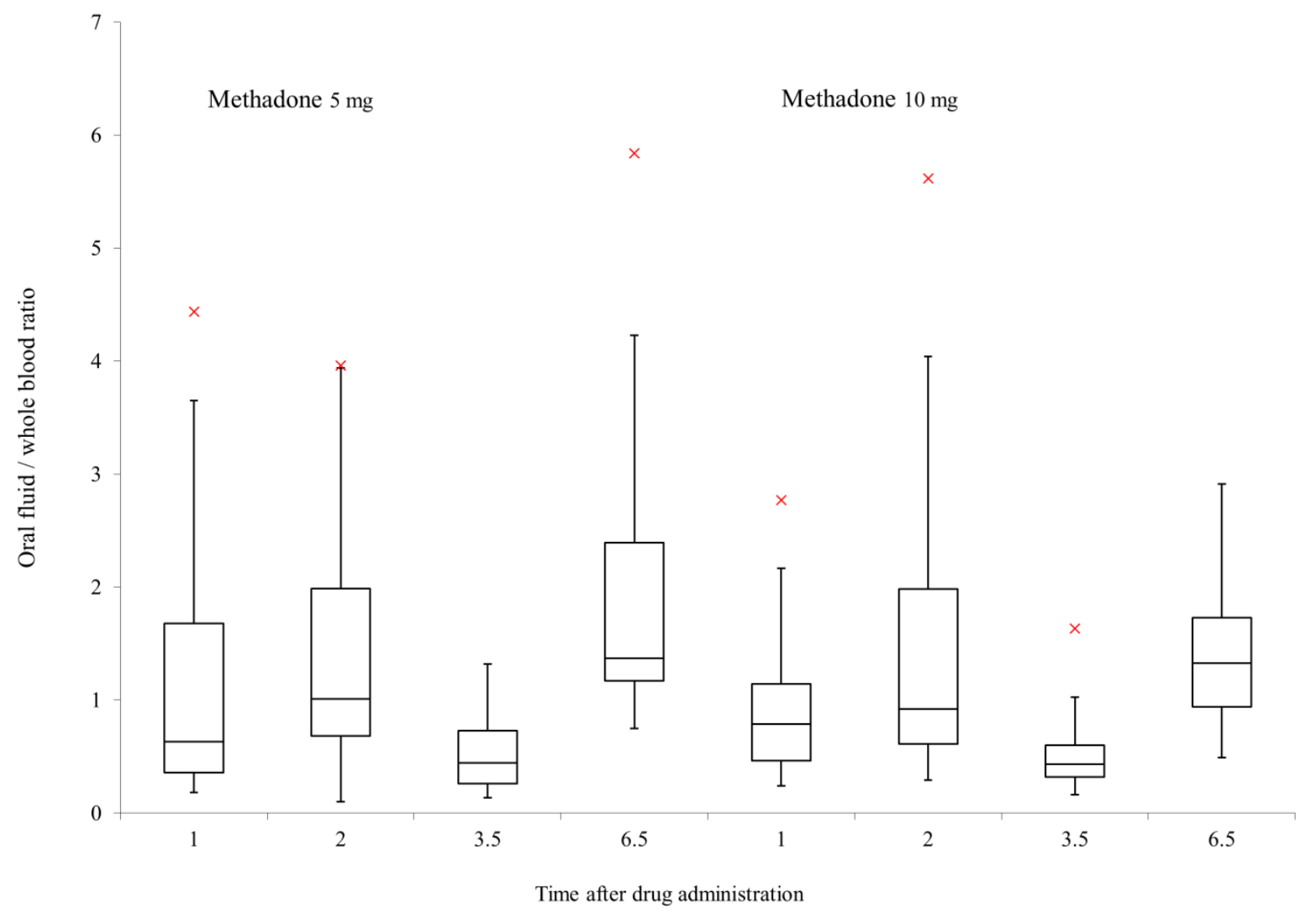


Table 1 Correlation between concentrations of buprenorphine and methadone in blood and significant effects on highway driving test, cognitive and psychomotor tests and subjective evaluations. All correlations given in the table are from data collected in the morning condition ( 2 hours after drug administration for the neurocognitive tests and 3.5 hours for the driving test).

$\mathrm{ns}=$ not significant

\begin{tabular}{|c|c|c|}
\hline \multirow[t]{2}{*}{ Performance parameters } & \multicolumn{2}{|c|}{ Correlation blood concentration x Performance } \\
\hline & Buprenorphine & Methadone \\
\hline $\begin{array}{l}\text { Highway driving test } \\
\text { Standard deviation of lateral position }(\mathrm{cm})\end{array}$ & $\mathrm{r}=.477(p=0.002)$ & $\mathrm{ns}$ \\
\hline Standard deviation of speed $(\mathrm{km} / \mathrm{h})$ & $\mathrm{ns}$ & ns \\
\hline Mean lateral position $(\mathrm{cm})$ & $\mathrm{r}=.323(p=0.039)$ & ns \\
\hline $\begin{array}{l}\text { Psychomotor Vigilance Test } \\
\text { Mean reaction time }(\mathrm{ms})\end{array}$ & $\mathrm{r}=.369(p=0.016)$ & ns \\
\hline Lapses (\#) & $\mathrm{r}=.327(p=0.035)$ & ns \\
\hline $\begin{array}{l}\text { Critical Tracking Test } \\
\text { Critical lambda }\left(\mathrm{rad} \mathrm{s}^{-1}\right)\end{array}$ & ns & ns \\
\hline $\begin{array}{l}\text { Divided Attention Test } \\
\text { Tracking errors (mm) }\end{array}$ & ns & ns \\
\hline Control losses (\#) & ns & ns \\
\hline Hits (\#) & ns & ns \\
\hline False alarms (\#) & ns & ns \\
\hline Reaction time (ms) & $\mathrm{r}=.335(p=0.032)$ & ns \\
\hline $\begin{array}{l}\text { Digit Symbol Substitution Test } \\
\text { Correct responses (\#) }\end{array}$ & $\mathrm{r}=-.342(p=0.027)$ & ns \\
\hline $\begin{array}{l}\text { Determination Test version S1 } \\
\text { Median reaction time }(\mathrm{ms})\end{array}$ & ns & ns \\
\hline Correct responses (\#) & ns & ns \\
\hline $\begin{array}{l}\text { Useful Field of View } \\
\text { Processing speed }\end{array}$ & ns & ns \\
\hline $\begin{array}{l}\text { Postural Balance test } \\
\text { Eyes open }-\ln \text { area } 95\left(\mathrm{~cm}^{2}\right)\end{array}$ & $\mathrm{r}=.428(p=0.005)$ & ns \\
\hline Eyes closed $-\ln$ area $95\left(\mathrm{~cm}^{2}\right)$ & $\mathrm{r}=.383(p=0.013)$ & ns \\
\hline Karolinska sleepiness scale & $\mathrm{r}=.408(p=0.007)$ & $\mathrm{ns}$ \\
\hline $\begin{array}{l}\text { Simplified clinical test of impairment } \\
\text { Walk-on-line }\end{array}$ & 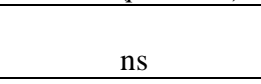 & ns \\
\hline Gait-on-line & ns & ns \\
\hline Finger-finger-test & ns & ns \\
\hline Finger-nose-test & ns & ns \\
\hline Romberg's test & ns & ns \\
\hline Overall impression & ns & ns \\
\hline $\begin{array}{l}\text { Bond\&Lader } \\
\text { Alertness }\end{array}$ & $\mathrm{r}=.573(p=0.000)$ & ns \\
\hline Contentedness & $\mathrm{r}=.417(p=0.006)$ & ns \\
\hline Calmness & $\mathrm{ns}$ & ns \\
\hline
\end{tabular}


Figure 3 Scatter plot showing the relationship between differences in standard deviation of lateral position (SDLP) from placebo and concentrations of buprenorphine and methadone in whole blood. A significant correlation was found between concentration of buprenorphine in blood and change in SDLP as compared to the placebo condition.
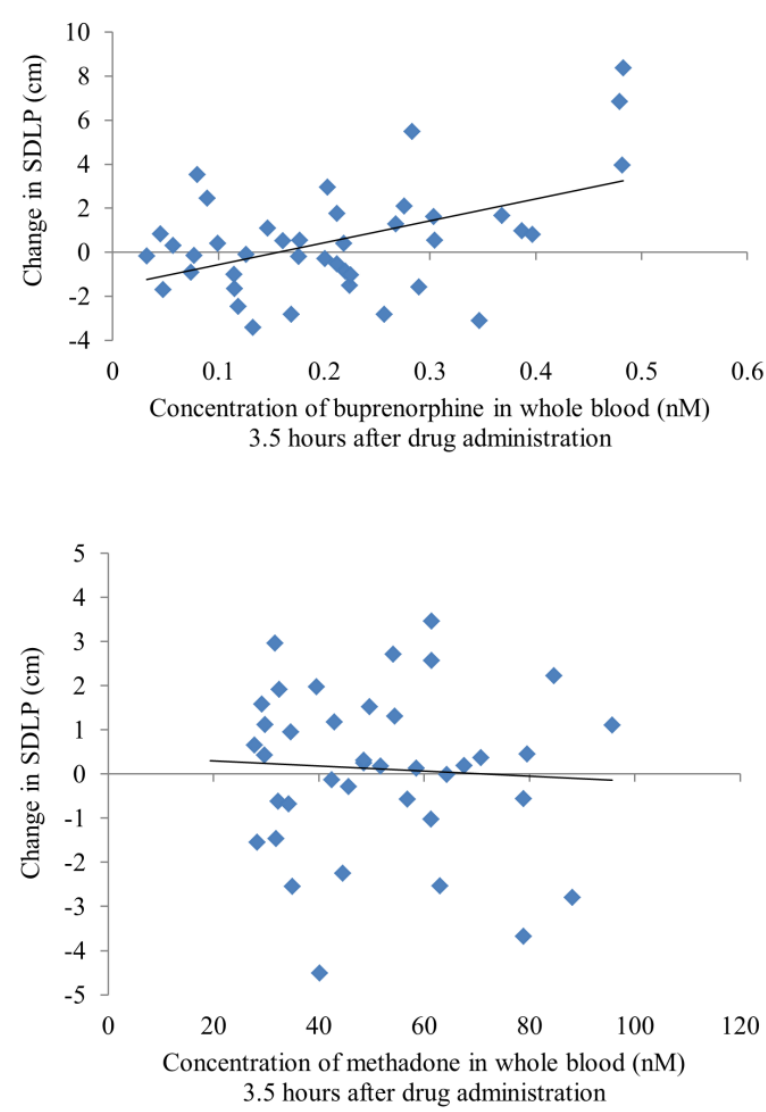